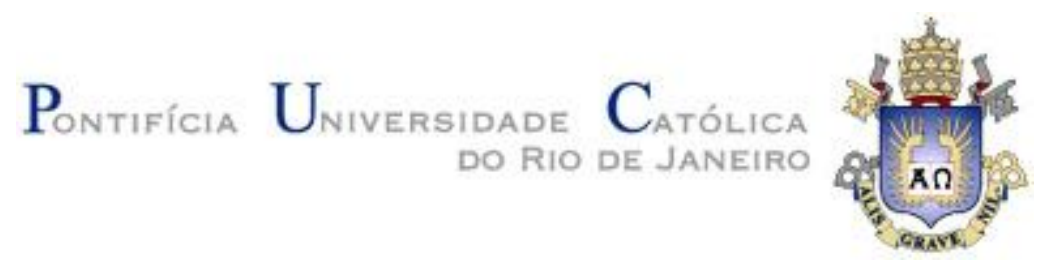

Diego Moah Lobato Tavares

\title{
Abordagens Exatas e Heurísticas para Variantes do Problema de Roteirização com Estoque
}

Dissertação de Mestrado

Dissertação apresentada como requisito parcial para obtenção do grau de Mestre pelo Programa de Pós-Graduação em Engenharia de Produção do Departamento de Engenharia Industrial da PUC-Rio.

Orientador: Prof. Rafael Martinelli Pinto

Rio de Janeiro

Setembro de 2018 


$$
\text { Pontifícia } \text { Universidade }_{\text {do Rio de Janeiro }}
$$

Diego Moah Lobato Tavares

\section{Abordagens Exatas e Heurísticas para Variantes do Problema de Roteirização com Estoque}

Dissertação apresentada como requisito parcial para obtenção do grau de Mestre pelo Programa de Pós-Graduação em Engenharia de Produção da PUC-Rio. Aprovada pela Comissão Examinadora abaixo assinada.

Prof. Rafael Martinelli Pinto

Orientador

Departamento de Engenharia Industrial - PUC-Rio

Prof. Jose Eugenio Leal Departamento de Engenharia Industrial - PUC-Rio

Prof. Orivalde Soares da Silva Júnior Departamento de Engenharia Industrial - PUC-Rio

Prof. Márcio da Silveira Carvalho Coordenador Setorial do Centro Técnico Científico - PUC-Rio

Rio de Janeiro, 21 de setembro de 2018 
Todos os direitos reservados. É proibida a reprodução total ou parcial do trabalho sem autorização do autor, do orientador e da universidade.

\section{Diego Moah Lobato Tavares}

Graduou-se em Engenharia de Produção pela Universidade do Estado do Pará (UEPA) em 2015. Atuou como aluno pesquisador no grupo de pesquisa Gestão de Sistemas Logísticos e de Sistemas Produtivos para o Desenvolvimento Regional. Aluno de mestrado da PUC-Rio desde março de 2016.

Ficha Catalográfica

Tavares, Diego Moah Lobato

Abordagens Exatas e Heurísticas para Variantes do Problema de Roteirização com Estoque / Diego Moah Lobato Tavares; orientador: Rafael Martinelli Pinto. Rio de Janeiro: PUC, Departamento de Engenharia Industrial - 2018.

96 f.: il. (color.); $30 \mathrm{~cm}$

Dissertação (mestrado) - Pontifícia Universidade Católica do Rio de Janeiro, Departamento de Engenharia Industrial, 2018.

Inclui Referências bibliografias

1. Engenharia Industrial - Teses. 2. Roteirização com estoques. 3. Gestão de estoques pelo fornecedor. 4. Roteirização de veículos. 5. Meta-heurística. 6. Programação linear inteira mista. I. Pinto, Rafael Martinelli. II. Pontifícia Universidade Católica do Rio de Janeiro. Departamento de Engenharia Industrial. III. Título. 


\section{Agradecimentos}

Agradeço aos meus pais Moacir Tavares e Ana Lobato por toda ajuda e esforço para me criar e educar. Agradeço também por sempre estarem presentes nos meus momentos mais difíceis.

Agradeço meus irmãos por toda ajuda, companheirismo e cumplicidade em minha vida. Vocês dois Diogo e Moana são minhas razões de viver.

Agradeço a um outro irmão que Deus colocou na minha vida Joelson Silva, sem você amigo não sei como teria sido minha vida no Rio e não tenho palavras para te agradecer.

Agradeço ao professor Rafael Martinelli meu orientador que soube entender minhas falhas e com sabedoria soube como ensinar-me a preencher minhas lacunas para realização desta pesquisa.

Agradeço aos outros professores da PUC-Rio que contribuíram para meu desenvolvimento como pesquisador tais como Eugênio Leal, Orivalde, Silvio Hamacher, Márcio Thomé, Felipe Scavarda e Thuener Silva.

Agradeço aos amigos estiveram presentes nessa etapa da minha vida e que contribuíram para o meu desenvolvimento como pessoa e profissional. Vocês foram fundamentais nessa caminhada Leonardo, Iuri, Lucas, Pyerri, Tamires, Ana Paula, Kamila, Andrew e Simone.

Agradeço aos amigos que mesmo a distância foram muito importantes Igor, Daniel, Deyvisson, Fábio, Yasmim, Pamela, Manuel Felipe, Plácido, Rodrigo, Fabyola, Leury, Pedro, Ney, Alberto, Antônio Batista, Lauro e André Melo.

Por fim, agradeço a todos os brasileiros que pagam impostos que possibilitou ao CNPq e à PUC-Rio concederem auxílios, sem os quais o desenvolvimento desse trabalho não seria possível. 


\section{Resumo}

Tavares, Diego Moah Lobato; Pinto, Rafael Martinelli (orientador). Abordagens Exatas e Heurísticas para Variantes do Problema de Roteirização com Estoque. Rio de Janeiro, 2018. 96p. Dissertação de Mestrado - Departamento de Engenharia Industrial, Pontifícia Universidade Católica do Rio de Janeiro.

Esta pesquisa trata de duas variantes do conhecido Problema de Roteirização de Veículos com Estoque (do inglês Inventory Routing Problem - IRP). O problema nasce num contexto de um sistema de Vendor Managed Inventory (VMI) no qual o fornecedor é responsável pela gestão de estoques do cliente. Tal problema é a junção dos problemas de transporte e gestão de estoques, que correspondem aos maiores custos em uma operação logística. Destarte este trabalho apresenta um modelo matemático para uma variante do IRP que considera que o fornecedor tem clientes dentro e fora do sistema de VMI. Este caso surge quando para alguns clientes não é interessante a realização do controle de seus estoques dentro do sistema de VMI, somente o atendimento de suas demandas. Além disto, o modelo contempla três diferentes tipos de políticas de gestão de estoques e é capaz de lidar com casos contendo vários períodos e vários veículos. Após sua elaboração, o modelo foi validado em instâncias do IRP, do Problema de Roteamento de Veículos (do inglês Capacitated Vehicle Routing Problem - CVRP) e instâncias próprias para a variante. Foram realizados também estudos sobre os impactos das diferentes políticas de gestão de estoques. Além do modelo matemático, foi desenvolvida uma meta-heurística híbrida que resolve uma variante do IRP considerando vários períodos e vários veículos. Cada movimento considerado durante a meta-heurística é divido em duas etapas, a primeira sendo a modificação da posição de um ou mais clientes nos veículos e períodos e uma segunda etapa que resolve de forma exata um Problema de Fluxo Máximo a Custo Mínimo para a atribuição ótima do volume de carga transportada para cada cliente por cada veículo em cada período. Esta abordagem é então testada em instâncias clássicas para esta variante do IRP, obtendo resultados que comprovam a eficiência do algoritmo.

\section{Palavras-chaves}

Roteirização com estoques; gestão de estoques pelo fornecedor; roteirização de veículos; meta-heurística; programação linear inteira mista. 


\begin{abstract}
Tavares, Diego Moah Lobato; Pinto, Rafael Martinelli (Advisor). Exact and Heuristic Approaches for Inventory Routing Problem Variants. Rio de Janeiro, 2018. 96p. Dissertação de Mestrado - Departamento de Engenharia Industrial, Pontifícia Universidade Católica do Rio de Janeiro.
\end{abstract}

This research deals with two variants of the Inventory Routing Problem (IRP). This problem comes from the context of a Vendor Managed Inventory (VMI) system in which the vendor is responsible for managing the customer's inventory. It is the combination of transportation and inventory management problems, which correspond to the higher costs in a logistics operation. Hence, this paper presents a mathematical model for an IRP variant, in which the vendor has customers inside and outside the VMI system. This situation is presented when it is not interesting to manage the inventories of some clients within the VMI system, resulting only in meeting their demands. In addition, the model considers three different types of stock management policies and it can comprehend multiple periods and multiple vehicles. After its modelling, the model was validated using IRP instaces, the Vehicle Routing Problem (CVRP) and specific instances for this variant. The impacts of different inventory management policies were also analyzed. In addition to the mathematical model, a hybrid meta-heuristic was developed, which solves an IRP variant considering several periods and several vehicles. Each iteration of the metaheuristic is divided into two stages: the first is modifying the position of one or more customers attended by the vehicles and periods, and a second step that solves a Maximum Flow at Minimum Cost problem, to optimally assign the load volumes transported to each customer in each vehicle in each period. Then, this approach is tested in classical instances for this IRP variant, obtaining results that prove the efficiency of the algorithm.

\title{
Keywords
}

Inventory Routing Problem; vendor managed inventory; vehicle routing problem; meta-heuristics; mixed-integer linear programming. 


\section{Sumário}

1 Introdução 11

1.1 Considerações iniciais 11

1.2 Justificativa e Motivação 12

1.3 Objetivos 15

1.3.1 Objetivo Geral 15

1.3.2 Objetivo específicos 15

1.4 Hipótese 16

$\begin{array}{ll}\text { 1.5 Metodologia de pesquisa } & 16\end{array}$

1.5.1 Caracterização e delineamento da pesquisa 16

1.5.2 Etapas de Concepção da Pesquisa 17

1.6 Estrutura da Pesquisa 17

2 Referencial Teórico 19

2.1 Gestão da Cadeia de Suprimentos $\quad 19$

2.2 Logística Empresarial 20

2.3 Distribuição Física 22

2.4 Vendor Managed Inventory 23

2.5 O Problema de Roteirização de Veículos 24

2.6 Inventory Routing Problem 27

2.6.1 Políticas do Inventory Routing Problem 36

2.7 Extensões do Inventory Routing Problem 37

2.7.1 The Production-Routing Problem 40

2.7.2 Inventory Routing Problem With Transshipment 42

2.7.3 The Consistent Inventory Routing Problem 44

2.7.4 Stochastic Inventory Routing Problem 45

2.7.5 Dynamic e Stochastic Inventory-Routing Problem 46

2.7.6 Metaheuristicas para o IRP 47

3 Formulação para o Problema de Roteirização MultiVeículos com a Opção de Estoques

3.1 Caracterização do Problema e Formulação do Modelo 50

3.2 Validação do Modelo 
4 Uma Heurística Iterated Local Search para o Problema de Roteirização MultiVeículos com Estoques

4.1 Vizinhanças 56

4.2 Fluxo Máximo a Custo Mínimo 60

4.3 Descida em Vizinhança Variável Aleatória 62

4.4 Iterated Local Search

5Experimentos computacionais 66

5.1 Sumário dos Resultados 66

5.2 Resultados 69

6 Considerações finais

7 Referências bibliográficas

ANEXO A 


\section{Lista de Figuras}

Figura 1 - Comparação entres Brasil, US, China e Canadá em relação ao indicador Logistic Performance Index.

Figura 2 - Mapa-Múndi em relação ao índice Logistic Performance Index. 13

Figura 3 - Representatividade dos custos logísticos em relação ao PIB. $\quad 14$

Figura 4 - Estrutura da cadeia de suprimentos integrada. 20

Figura 5 - Triângulo de tomada de decisão logísticas. 21

Figura 6 - Atividades logísticas na cadeia de suprimentos imediata da empresa. 22

Figura 7 - Rotas da frota. $\quad 25$

Figura 8 - Percurso de seleção de atigos. 28

Figura 9 - Ilutração do IRP. $\quad 30$

Figura 10 - Exemplo da estrutura de vizinhança Insert. $\quad 57$

Figura 11 - Exemplo da estrutura de vizinhança Remove. 58

Figura 12 - Exemplo da estrutura de vizinhança Shift. 58

Figura 13 - Exemplo da estrutura de vizinhança Swap. 59

Figura 14 - Exemplo da estrutura de vizinhança Relocate. 59

Figura 15 - Exemplo da estrutura de vizinhança 2opt. 60

Figura 16 - Ilutração do Fluxo Máximo a custo mínimo parao IRP. 61

Figura 17 - Ilutsração do ILS. 


\section{Lista de Tabelas}

Tabela 1 - Sumário de variantes do IRP e suas características. 39

Tabela 2 - Sumário de trabalhos sobre PRP e suas características. $\quad 41$

Tabela 3 - Conjuntos e índices do Modelo. $\quad 51$

Tabela 4 - Parâmetros do Modelo. $\quad 51$

Tabela 5 - Variáveis do Modelo. $\quad 51$

Tabela 6 - Instâncias de MIRP abs1n5. $\quad 54$

Tabela 7 - Instâncias de MIRP abs2n5. $\quad 54$

Tabela 8 - Instâncias de MVRP dois veículos. 54

Tabela 9 - Instâncias de MVRP três veículos.

Tabela 10 - Instâncias do Modelo proposto 10 clientes. . 55

Tabela 11 - Instâncias do Modelo proposto 14 clientes. 55

$\begin{array}{ll}\text { Tabela } 12 \text { - Indices das estruturas de vizinhança. } & 57\end{array}$

Tabela 13 - Algoritmo RVND. 63

Tabela 14 - Algoritmo ILS. $\quad 64$

Tabela 15 - Algoritmo ILS. $\quad 64$

Tabela 16 - Comparação entre Algoritmos ILS e RVND. 65

Tabela 17 - Resumo do resultado de todas as instâncias. 68

Tabela 18 - Resumo do resultado acima dos encontrados na literatura. $\quad 68$

Tabela 19 - Resumo do resultado das instâncias para 2 veículos. 68

Tabela 20 - Resumo do resultado das instâncias para 3 veículos. 68

Tabela 21 - Resumo do resultado das instâncias para 4 veículos. 69

Tabela 22 - Resumo do resultado das instâncias para 5 veículos. 69

Tabela 23 - Resultados do AP x Literatura K = 5 e H = 6 HighCost. 70

Tabela 24 - Resultados do AP x Literatura $\mathrm{K}=5$ e H = 6 LowCost. 71

Tabela 25 - Resultados do AP x Literatura $\mathrm{K}=2$ e H=3. 84

Tabela 26 - Resultados do AP x Literatura $\mathrm{K}=2$ e $\mathrm{H}=6$.

Tabela 27 - Resultados do AP x Literatura $\mathrm{K}=3$ e H $=3$. 87

Tabela 28 - Resultados do AP x Literatura K = 3 e H=6. 90

Tabela 29 - Resultados do AP x Literatura $\mathrm{K}=4$ e $\mathrm{H}=3$. 91

Tabela 30 - Resultados do AP x Literatura $\mathrm{K}=4$ e $\mathrm{H}=6$.

Tabela 31 - Resultados do AP x Literatura K = 5 e H = 3.. 94 


\section{Introdução}

O presente Capítulo tem o propósito de expor as considerações iniciais descrevendo e contextualizando o problema estudado, justificativa e motivação, os objetivos a serem atendidos da pesquisa, a hipótese da pesquisa, metodologia e a estrutura da pesquisa.

\section{1}

\section{Considerações iniciais}

Esta pesquisa apresenta uma nova meta-heuristica e uma variante do Problema de Roteirização com estoques (Inventory Routing Problem - IRP) com Frota Homogênea com diferentes políticas de reposição. O IRP é a junção do Problema de Roteirização de Veículos (Vehicle routing problem - VRP) e o Problema de Gestão de Estoques (Inventory Management- IM), tais problemas são comuns na maioria dos sistemas logísticos especialmente no Vendor Managed Inventory (VMI). O VMI é um sistema logístico de gestão integrada da cadeia de suprimento, no qual o fornecedor faz a gestão de estoque dos clientes, tomando para si parte dos custos de estoques. O VMI agrega algumas vantagens entre elas destacam-se que os fornecedores economizam nos custos de produção e distribuição, portanto podem coordenar carregamentos para diversos clientes, já os clientes, ganham por não utilizarem recursos para controlar e gerir estoque, criando uma relação em que todos ganham (Coelho et al., 2012a).

O IRP vem sendo estudado constantemente na última década em busca de soluções satisfatórias para o problema por se tratar de um problema NP-difícil as maiores instâncias do problema ainda estão em aberto na literatura. As variações do IRP também vêm sendo extremamente abordadas, de modo que o problema exposto neste estudo surge em um contexto no qual existem clientes que fazem parte de um sistema de VMI e outros os quais não é interessante a inclusão no sistema, necessitando assim apenas atender suas demandas arcando somente com os custos de transportes. Destarte, o modelo é uma variação do IRP que considera 
os clientes dentro e fora do sistema de VMI, sendo um modelo híbrido atendo ao mesmo tempo os problemas de IRP e VRP. O algoritmo proposto também é híbrido sendo o subproblema de roteirização resolvido por heurísticas e o subproblema de estoques com algoritmo de método exato através do problema de Fluxo Máximo de Custo Mínimo.

\section{2 \\ Justificativa e Motivação}

Em busca de maior competitividade, as empresas buscam reduzir custos. Nesse contexto, para as organizações, os custos logísticos podem variar entre $4 \%$ e $30 \%$ do valor total das vendas (Ballou, 2006). Mesmo sendo os custos logísticos relevantes, a ênfase dos interesses não está unicamente focada na diminuição dos custos, mas na capacidade logística para desenvolver estratégias e criar vantagens competitivas (Bowersox et. al, 2013).

O Brasil em relação à infraestrutura logística deixa a desejar quando comparado com outros países (Salgado, 2013). Desse modo, propor estratégias eficazes tem sido um desafio (ou diferencial), uma vez que, para isso torna-se importante identificar claramente informações sobre necessidades e especificidades de modais de transportes mais adequados, segmentos de mercado, clientes, fornecedores ou operações.

O Banco Mundial divulgou índice Logistic Performance Index (LPI), faz anualmente um ranking internacional de desempenho do setor logística com base em um levantamento realizado em 160 países com objetivo de aferir quão eficiente é cada país, permitindo assim uma comparação do desempenho logístico dos países. O Brasil ficou na posição 55 em 2016 a Figura 1 contém uma comparação do Brasil com os Estados Unidos, Canadá e China, países com dimensões continentais igual ao Brasil.

O LPI é formado por 6 indicadores: Desembaraço Aduaneiro; Infraestrutura nacional; Embarque Internacional; Serviços Logísticos Internos; Monitoramento e Rastreamento; Pontualidade das Operações. Esses indicadores são avaliados considerando a eficiência, qualidade e outros. $\mathrm{O}$ índice tem uma escala de zero a cinco. A Figura 2 contém o Mapa-Múndi e as faixas de desempenho de cada país em sua escala. 


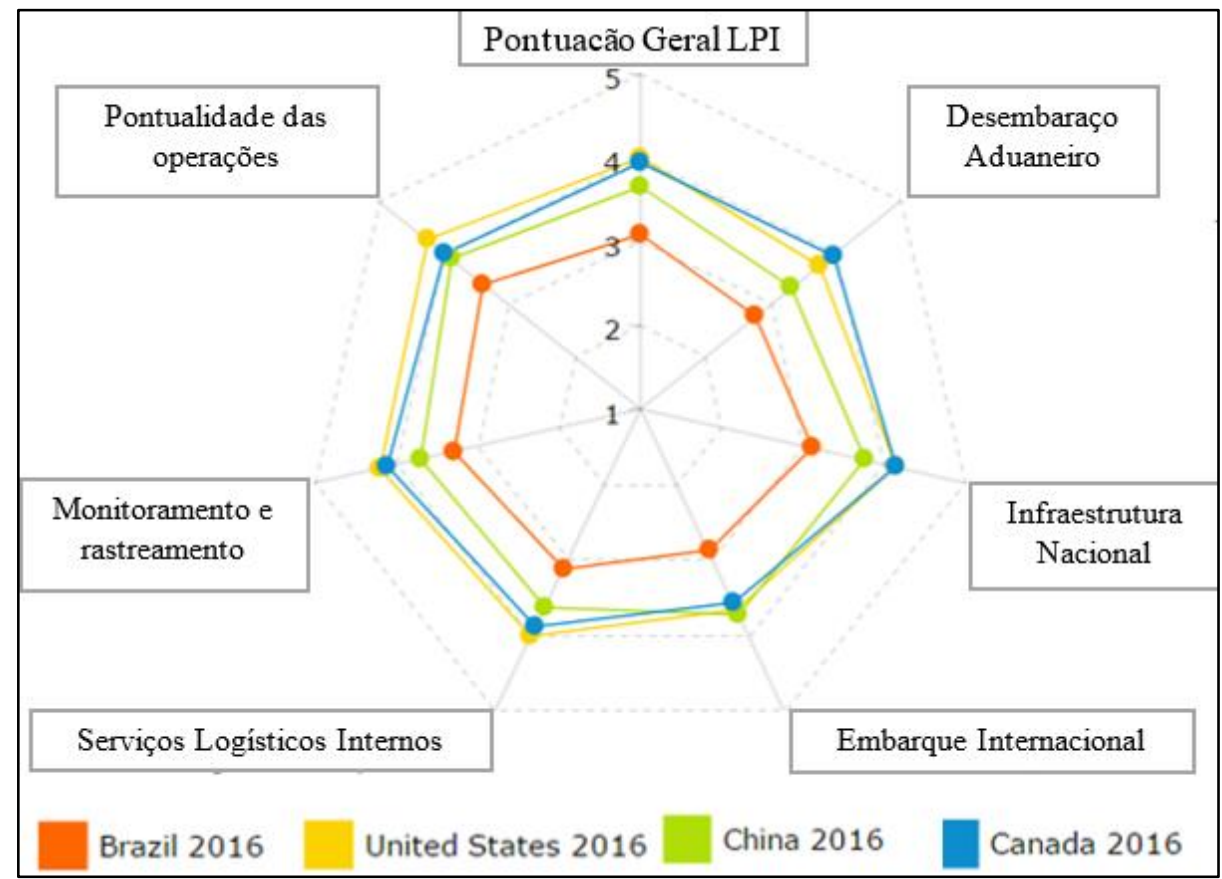

Figura 1 - Comparação entres Brasil, US, China e Canadá em relação ao indicador Logistic Performance Index. Fonte: Banco Mundial (2017).

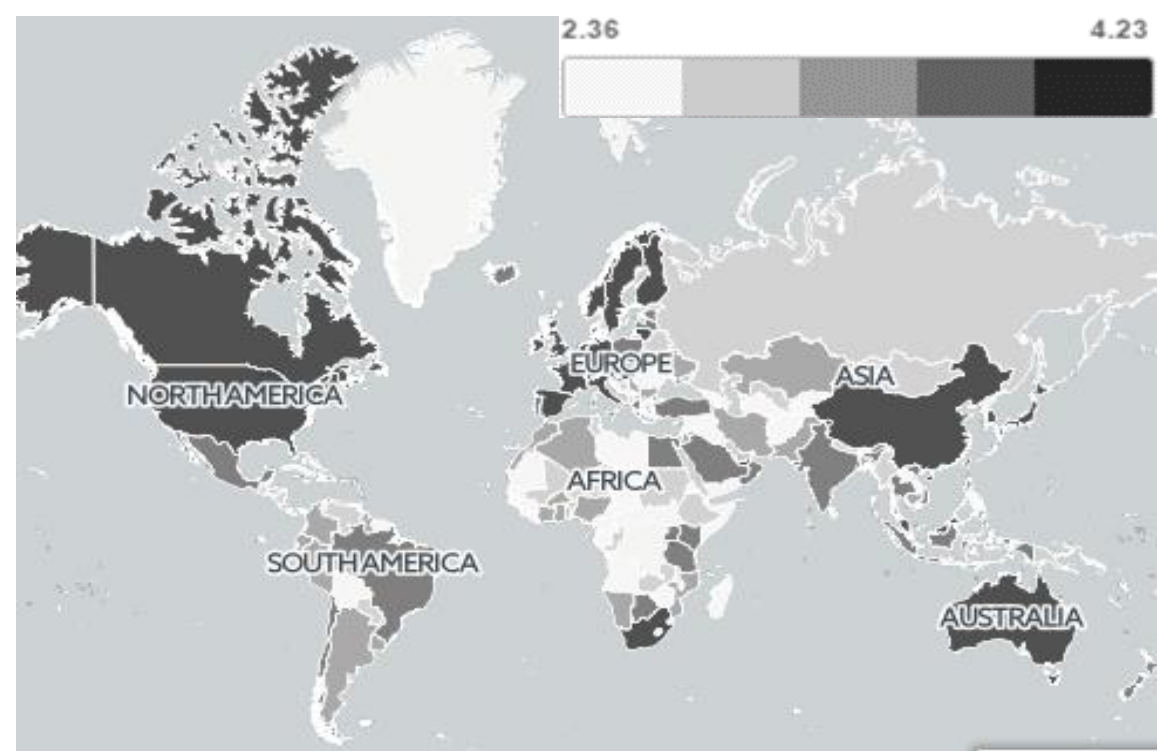

Figura 2 - Mapa-Múndi em relação ao índice Logistic Performance Index. Fonte: Banco Mundial (2017).

Como mostrado nas Figuras 1 e 2 o Brasil ainda tem uma infraestrutura e desempenho logístico deficitário quando comparado a outros países, o que faz com que nas empresas percam competitividade logística. Isto mostra a importância de desenvolver estratégias e estudos na área.

O Instituto de Logística e Supply Chain (ILOS) realizou uma pesquisa que indicou que desde 2012 os custos logísticos no Brasil vêm crescendo, chegando a 2015 com um total de 12,3\% do seu Produto Interno Bruto (PIB), enquanto que 
países desenvolvidos como os Estado Unidos gastaram 8,8\% do PIB no mesmo ano. Na Figura 3, apresenta-se a divisão dos custos logísticos ao longo dos anos.

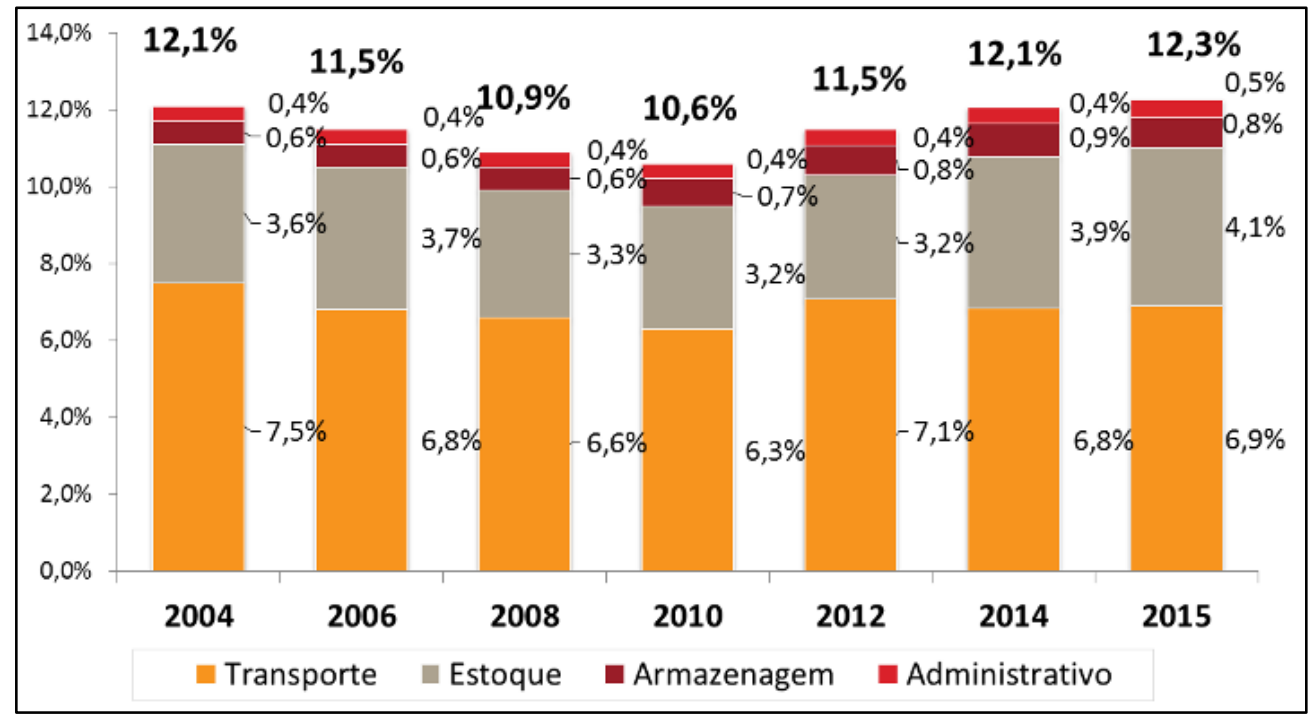

Figura 3 - Representatividade dos custos logísticos em relação ao PIB. Fonte: ILOS (2017).

A presente dissertação propõe um novo modelo matemático para o IRP que visa atuar diretamente nos custos de transporte e estoques, apontados pela Figura 3 como os mais representativos dos custos logísticos.

O IRP tem o objetivo de minimizar os custos de distribuição e de estoque, sendo que simultaneamente as restrições sejam satisfeitas, como as restrições de capacidade de veículo e de armazenagem das instalações, etc. (Guemri et al., 2016).

Para a resolução do IRP faz-se necessária a proposição de um algoritmo de aproximação (heurísticas e meta-heurística) pois o IRP pertence a classe de problemas NP-Difícil, desse modo propor e desenvolver métodos para alcaçar soluções de qualidade em um tempo satisfatório se faz necessário e ao mesmo tempo é um desafio.

Apesar do crescente número de publicações sobre o tema, não se observa na literatura um modelo de IRP que contemple os clientes dentro e fora do sistema de VMI. Dessa forma, o presente trabalho vem preencher essa lacuna, propondo um modelo que satisfaça o atendimento todos os clientes de forma integrada.

A inspiração para este estudo foi de um caso prático observado pelo o autor em algumas empresas que realizam os roteiros de entregas não integrados para clientes dos sistemas de VMI e de fora do sistema. Casos similares acontecem também em franquias no qual para as grandes lojas, lojas importantes ou lojas 
estratégicas é interessante aplicar o sistema de VMI e outras lojas o mesmo não se faz interessante, mas sua demanda dever ser atendida.

A motivação para a realização desta pesquisa é a contribuir ao acrescentar à literatura uma nova abordagem heurística visando maior eficiência na resolução do IRP, e um novo modelo considerando os clientes fora do sistema de VMI tornando assim o transporte e a roteirização de veículos mais integradas, além das políticas de reposição exploradas.

\section{3}

\section{Objetivos}

Os objetivos desta pesquisa estão divididos em dois níveis. O primeiro deles contém o objetivo geral. No segundo nível são apontados os objetivos específicos a serem alcançados para o atendimento do objetivo geral.

\subsection{1 \\ Objetivo Geral}

Esta dissertação tem como objetivo a proposição de um algoritmo (metaheurística) eficiente para a resolução do MIRP e a proposição de um modelo matemático englobando clientes que fazem parte do sistema de VMI (IRP) e clientes que não fazem parte, na distribuição física de mercadorias por uma frota heterogênea ou homogênea de veículos a partir de um centro de distribuição, considerando a minimização de custos de transporte e estoques.

\subsection{2}

\section{Objetivos específicos}

Para o alcance desse objetivo principal, os seguintes objetivos específicos serão considerados no desenvolvimento desse trabalho:

- Revisão da literatura dos modelos de IRP já existentes;

- Resolução do modelo matemático por meio da programação inteira;

- Validação do modelo proposto;

- Adaptar uma Meta-heurística para o modelo proposto;

- Validação da Meta-heurística proposta;

- Comparar os resultados da literatura com os do algoritmo proposto. 


\section{4}

\section{Hipótese}

A proposição de um algoritmo mais eficiente para a resolução do IRP e o modelo que englobe tanto os clientes que fazem parte do sistema de VMI quanto os clientes que não fazem parte do sistema, pode trazer ganhos de eficiência operacional e redução de custos.

Com a aplicação do modelo espera-se a alteração da ordem e número de clientes incluídos na rota de cada veículo, assim como a quantidade transportada para cada cliente seguindo um modelo de roteirização com estoques proposto e redução significativamente dos custos estimados da empresa em função de uma logística mais integrada. Com aplicação do algoritmo esperam-se resultados computacionais de tempo e eficiência satisfatórios haja vista que este é um problema NP-Difícil.

\section{5}

\section{Metodologia de pesquisa}

Segundo Silva e Menezes (2005) as pesquisas podem ser classificadas de acordo com sua caracterização, delineamento e suas etapas de concepção. Destarte este estudo baseou-se nesses preceitos para a estruturação e elaboração desta subseção.

\subsection{1 \\ Caracterização e delineamento da pesquisa}

Do aspecto natureza, existem dois tipos de pesquisa: básica e aplicada. A presente pesquisa pode ser categorizada como pesquisa aplicada, em função do seu objetivo prático de aplicar conhecimento pretendendo utilidade econômica e social voltada a resolução de problemas. Em relação à sua abordagem tendo em vista o problema pode-se denominar como quantitativa, pois considera-se que todos os parâmetros, perdas ou ganhos podem ser mensurados e quantificados, e então representados em modelo matemático de IRP. No que diz respeito aos objetivos, este estudo se classifica como exploratório, incluindo uma pesquisa bibliográfica. No tocante aos procedimentos técnicos pode-se dizer que este estudo é bibliográfico, pois é realizada uma revisão da literatura para os modelos e variações do IRP, e experimental, pois realizou-se experimentos computacionais. 


\subsection{2}

\section{Etapas de Concepção da Pesquisa}

Para alcançar os objetivos propostos por esta dissertação de mestrado foram necessárias as seguintes etapas:

- Definição, elaboração e apresentação do projeto de dissertação;

- Revisão da literatura compreendendo os modelos matemáticos de resolução de IRP e suas variações;

- Desenvolvimento do modelo matemático de IRP que considere os clientes que fazem parte do sistema de VMI e aos demais que não fazem parte;

- Implementação e resolução do modelo em pequenas instâncias, para análise e validação;

- Teste em instâncias de IRP e VRP para a validação do modelo híbrido;

- Adaptação Meta-heurística ao modelo proposto;

- Por último, elaboração de análises e conclusões e propostas para trabalhos futuros.

\section{6 \\ Estrutura da Pesquisa}

Esta pesquisa é composta por 6 capítulos, o primeiro e presente capítulo tem um caráter introdutório do tema e outros tópicos relevantes para a formulação desta dissertação.

O Capítulo 2 contém o referencial teórico sobre os temas considerados pertinentes como: Gestão da Cadeia de Suprimentos, Logística Empresarial, Distribuição Física, Roteirização de veículos, Sistemas de VMI e modelos de IRP e suas variações.

O Capítulo 3 contém o modelo proposto, onde se realiza a validação do modelo. Tal validação foi realizada através de testes com pequenas instâncias de VRP e IRP.

O Capítulo 4 contém a descrição detalhada da Meta-heurística utilizada, expondo as vizinhanças exploradas, as estratégias de solução e como funciona o seu mecanismo.

O Capítulo 5 contém os resultados dos experimentos computacionais e as análises sobre os resultados encontrados, juntamente com a comparação dos resultados exatos e das heurísticas existentes na literatura. 
Por fim no Capítulo 6 são expostas as considerações finais e possíveis extensões desta pesquisa. 


\section{2 \\ Referencial Teórico}

Este capítulo contém os principais tópicos teóricos que são essenciais para o desenvolvimento do estudo ou estão relacionados tema da presente dissertação. Os conceitos abordados nesse capítulo ajudam a entender o contexto na qual o problema estudado está inserido e sua importância. Estes também auxiliam na compreensão do problema e de sua complexidade de resolução do IRP abordado neste trabalho. Abordou-se os seguintes tópicos: Gestão da Cadeia de Suprimentos; Logística Empresarial; Distribuição Física; Vendor Managed Inventory; Roteirização de Veículos e Inventory Routing Problem.

\section{1}

\section{Gestão da Cadeia de Suprimentos}

O objetivo da gestão da cadeia de suprimentos (GCS) é aumentar a eficiência operacional, enquanto reduz simultaneamente os estoques armazenados ao longo de toda a cadeia de suprimentos e os custos operacionais (Goldratt, 2003).

A GCS realizada de forma integrada é a chave para as organizações obterem vantagens competitivas de forma efetiva segundo Simchi-Levi et al. (2010), o autor define Gestão da cadeia de suprimentos como:

\footnotetext{
Um conjunto de abordagens que integra, com eficiência, fornecedores, fabricantes, depósitos e pontos comerciais, de forma que a mercadoria é produzida e distribuída nas quantidades corretas, aos pontos de entrega e nos prazos corretos, com objetivo de minimizar os custos totais do sistema sem deixar de entender às exigências em termos de nível de serviço (2010, p.33).
}

Sanders (2012) afirma que a GCS é a integração por meio da colaboração entre os integrantes da cadeia para obter a melhor visibilidade dos processos que ocorrem à montante e à jusante na cadeia, com o objetivo de minimizar os custos totais de operação do sistema.

Slack et al. (2013) diz que GCS é uma abordagem holística para gerenciar além das fronteiras das empresas e dos processos. Segundo Bowersox et. al (2013) 
a GCS constitui-se em uma colaboração entre empresas para impulsionar o posicionamento estratégico e para melhorar a eficiência operacional. O mesmo autor desevolveu um framework (Figura 4) mostrando um exemplo de estrutura da cadeia de suprimentos integrada.

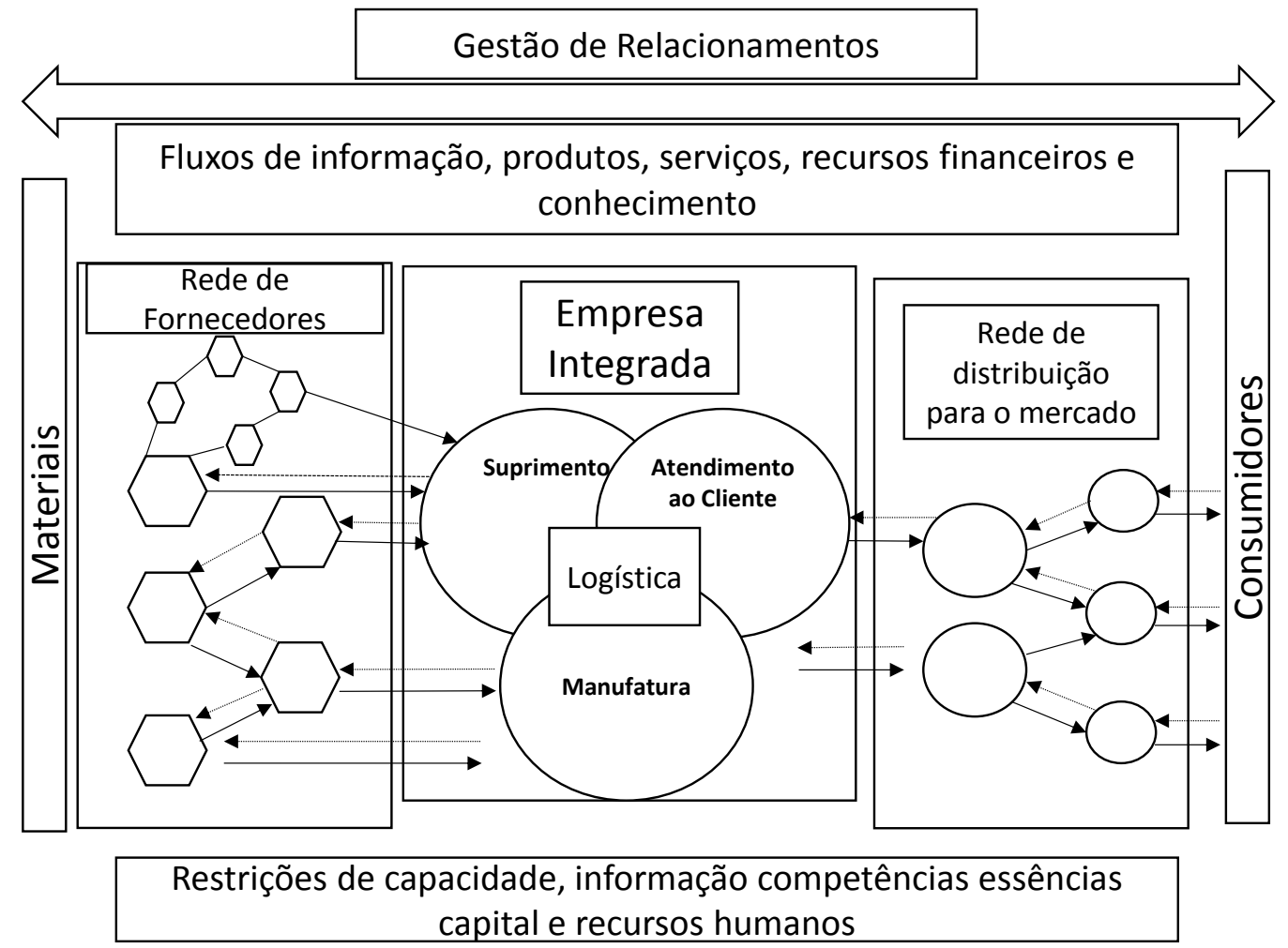

Figura 4 - Estrutura da cadeia de suprimentos integrada. Fonte: Bowersox et. al (2013)

Chopra e Meindl (2016) explicam que a cadeia de suprimentos são todas as partes envolvidas direta ou indiretamente no atendimento a demanda ou pedido de um cliente, incluindo não somente o fabricante e os fornecedores, mas também transportadoras, armazéns, varejistas e até mesmo os clientes.

O Council of Supply Chain Management Professionals (CSCMP, 2016) indica que a GCS é o planejamento e o gerenciamento das atividades envolvidas na compra e aprovisionamento, e todas as atividades de gerenciamento logístico.

Nesta pesquisa o problema estudado está denominando apenas a um dos elos da cadeia, dentro de umas das estratégias para GCS, no caso estratégias por métodos colaborativos, ou mais especificamente o VMI.

\section{2}

\section{Logística Empresarial}

Segundo Ballou (2010) a logística empresarial trata das atividades de movimentação, armazenagem e fluxo dos produtos desde a aquisição da matéria- 
prima até o local de consumo, inclui também os fluxos de informação envolvidos no processo, com o objetivo de atingir níveis de serviço adequados aos clientes a um custo razoável.

Bowersox et al. (2013), define a logística como um subconjunto mais estruturado e amplo da GCS. Pode ser entendida como o gerenciamento integrado de processos de negócios, através de um enfoque sistêmico de modo que o cliente final perceba a geração de valor ao longo da cadeia. O mesmo autor diz que a logística empresarial adquiriu a incumbência pela disponibilidade dos estoques de matérias-primas, de produtos semiacabados e dos produtos finais, no momento certo, local certo, na quantidade certa e ao menor custo possível.

Segundo o CSCMP (2016), a logística é uma parte da GCS que cuida do planejamento, implantação e controle do fluxo eficiente e eficaz de bens, serviços e das informações relativas, desde o ponto origem até o ponto de consumo, com o propósito de atender às necessidades dos clientes.

A análise de um sistema logístico deve basear-se no nível de serviço proposto aos clientes e nos custos logísticos inerentes às escolhas decisivas ligadas aos processos na cadeia de suprimentos (Ballou, 2006; Bowersox et al., 2013). A Figura 5 contém o Triângulo de Ballou que auxilia a tomada de decisão em sistemas logísticos, o qual indica que as estratégias de estocagem e transportes são duas das três mais importantes.

\begin{tabular}{|c|c|}
\hline $\begin{array}{l}\text { Estratégias da est } \\
\text {-Níveis dos estoqu } \\
\text {-Disposições dos e } \\
\text {-Métodos de contr }\end{array}$ & $\begin{array}{l}\text { Estratégias de transporte } \\
\text {-Meios de transportes } \\
\text {-Roteamento/cronograma dos } \\
\text { envios } \\
\text {-Tamanho/consolidação de } \\
\text { desembarques }\end{array}$ \\
\hline
\end{tabular}

Figura 5 - Triângulo de tomada de decisão logísticas. Fonte: Ballou (2006). 
2.3

Distribuição Física

O COUNCIL (2010), define a Distribuição Física como as atividades de transporte, manutenção de estoques, processamento de pedidos, programação de entrega de produtos, embalagem preventiva, o armazenamento, o controle de materiais e a manutenção de informações.

Novaes (2007) estende essa concepção, dizendo que um sistema de distribuição física abrange atividades como instalações físicas (centros de distribuição, armazéns etc.), estoque, veículos, informações, hardware e software, custos e pessoal.

Ballou (2006) diz que a distribuição física é uma parte da logística empresarial, que é responsável pela gestão integrada das atividades de movimentação, transporte e armazenagem. Neste contexto, o mesmo autor ressalta que as principais tarefas logísticas relacionadas à distribuição física estão ligadas à manutenção de estoque, processamento de pedidos, programação de produtos, embalagem, armazenamento, controle de materiais, manutenção de informações e transporte. A Figura 6 contém um paralelo que Ballou fez entre a logística e a distribuição física.

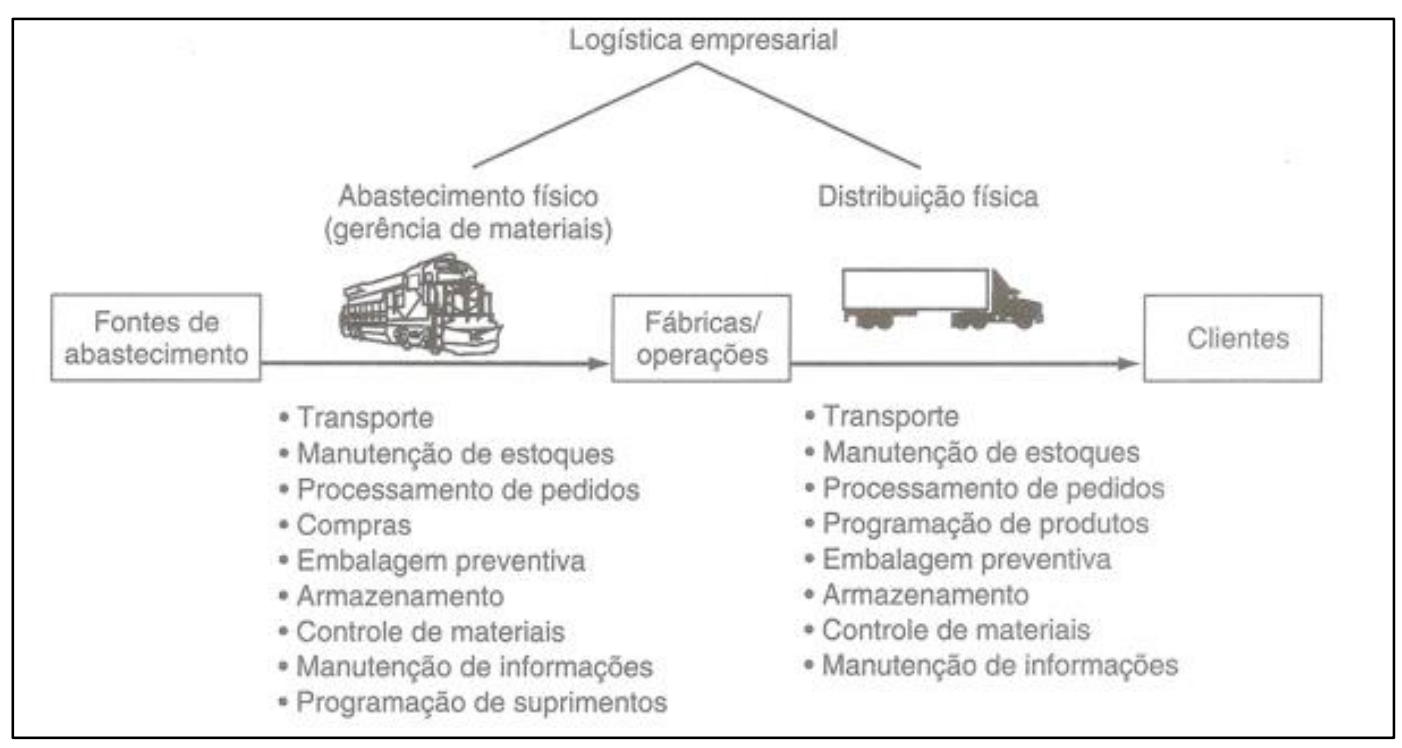

Figura 6 - Atividades logísticas na cadeia de suprimentos imediata da empresa. Fonte: Ballou (2006)

Pires (2011) define que a distribuição física, antecedida pelas etapas da logística de abastecimento e da logística interna, é a última etapa do processo da logística, envolvendo o sistema de distribuição, transportes e estoque. 


\section{4}

\section{Vendor Managed Inventory}

O Vendor Managed Inventory (VMI) é uma estratégia colaborativa entre cliente e fornecedor com o objetivo de otimizar a disponibilidade dos produtos e os custos de transportes e estoques para ambos. Kazmierczak e Stefen (2010) explicam que o VMI implementa uma alteração na lógica comum usada na relação entre cliente e fornecedor no que se refere à reposição de mercadorias. Nesta nova lógica, o fornecedor apropria-se da responsabilidade pela gestão de seus estoques no cliente. Os mesmos autores dizem que:

Para operacionalizar todo o processo de VMI se faz necessário a utilização de tecnologias da informação que realizarão, dentre outros, o processamento dos algoritmos de ressuprimento, o intercâmbio eletrônico dos dados entre cliente e fornecedor e a disponibilização de relatórios de performance (Kazmierczak e Stefen, 2010, p. 60).

Pires (2011) define o VMI como uma prática segundo a qual os fornecedores têm a responsabilidade de gerenciar o estoque de seus clientes, arcando com os custos de estoques e transporte. Belfiore et al. (2006) define como uma técnica segundo a qual o fornecedor controla os níveis de estoque de seus clientes. O fornecedor passa a ser responsável pelas decisões de quando e quanto entregar de mercadoria para cada cliente. Destarte, o cliente faz apenas um acompanhamento, mas não controla ou gerencia o processo.

Segundo Bani-Asadi e Zanjani (2017) o VMI é um dos métodos mais eficazes para reduzir efeito chicote e a incerteza sobre a demanda. Guimarães et al. (2015) diz que os sistemas de VMI são reconhecidos por criarem valor simultaneamente para o fornecedor e para o cliente, criando uma situação de benefício mútuo. $\mathrm{O}$ fornecedor tira proveito de maior acurácia no planejamento de sua distribuição de produtos, reduzindo as rupturas e elevando a eficiência de entregas.

O pesquisador Tang (2006) afirma que ao utilizar o VMI, ganha-se na redução dos níveis de estoque, com uma consequente redução de custos no processo, e ao mesmo tempo, eleva o nível de serviço prestado aos clientes. O mesmo autor ainda afirma que o fornecedor, através do VMI, consegue diminuir os custos de estoques e distribuição. Apesar do custo adicional com a manutenção de estoques, essa 
prática fideliza o cliente, além das informações adicionais sobre a demanda e mercado.

Devido à sua relevância prática dentro da cadeia de suprimentos e na gestão de estoques integrada com o fornecedor, o VMI vem sendo amplamente abordado em conjunto com o IRP nos últimos anos pela literatura. Alguns trabalhos se destacam como Bani-Asadi e Zanjani (2017) que cria um modelo matemático para VMI, no qual existem três elos da cadeia de suprimento, sendo: armazém central, múltiplos centros de distribuição e vários varejistas; os autores utilizam lógica fuzzy e meta-heurísticas. O estudo conclui que o algoritmo genético é o mais eficiente. Vidović et al. (2014) abordam a estratégia do VMI em uma distribuidora de combustíveis através Inventory Routing Problem (IRP) também conhecido como roteirização com estoques. Os autores propõem uma meta-heurísticas.

Guzmán-Camacho et al. (2014) estuda dois elos da Gestão da Cadeia de Abastecimento do leite em Sugamuxi (Colômbia), e avaliam o possível ganho no custo total de operação com o uso da política de abastecimento VMI.

Dong e Leung (2009) analisam as dificuldades encontradas por fornecedores que optam pelo VMI no abastecimento dos varejistas de vestuário na indústria têxtil. Os pesquisadores propõem um modelo de reposição baseado em simulação e um algoritmo genético para otimizar o desempenho da cadeia de suprimentos. $\mathrm{O}$ estudo trouxe ganhos de custo e nível de serviço.

Zhu et al. (2009) indicam um modelo VMI com demanda estocástica na cadeia de suprimento de produtos petrolíferos, o modelo gera estoque de segurança, nível de serviço e lead-time mais compatíveis com a realidade. O modelo se mostrou eficiente no apoio à decisão da gestão da cadeia de abastecimento; entre outros.

\section{5}

\section{O Problema de Roteirização de Veículos}

Ballou (2006), define a roteirização de veículos como a atividade que tem por objetivo encontrar os melhores trajetos que um veículo deve realizar por meio de uma malha. Tal atividade em geral tem como objetivo minimizar os custos de transportes.

Para Laporte et al. (2007) o Vehicle Routing Problem (VRP) consiste em definir roteiros de entregas por veículos que minimizem o custo total de 
atendimento da demanda. Cada veículo da frota inicia seu trajeto no depósito na base dos veículos, sendo que cada cliente deve ser visitado exatamente uma vez e a demanda total de qualquer rota não supere a capacidade do veículo.

Batistus (2009) debate em seu trabalho as questões que podem ser consideradas em problemas de roteirização. Ele diz que pode ser considerada a minimização dos custos de viagem, do número de veículos utilizados, do tempo de viagem, das penalidades por atraso ou maximizar o número de clientes atendidos, ou ainda, uma abordagem pode ser feita utilizando-se múltiplos objetivos.

Segundo Belfior (2006) o VRP pode ser diferenciado de acordo com os tipos de operações, de carga, de frota, localização dos clientes, tipo de restrições e função objetivo. A Figura 7 mostra um exemplo do VRP.

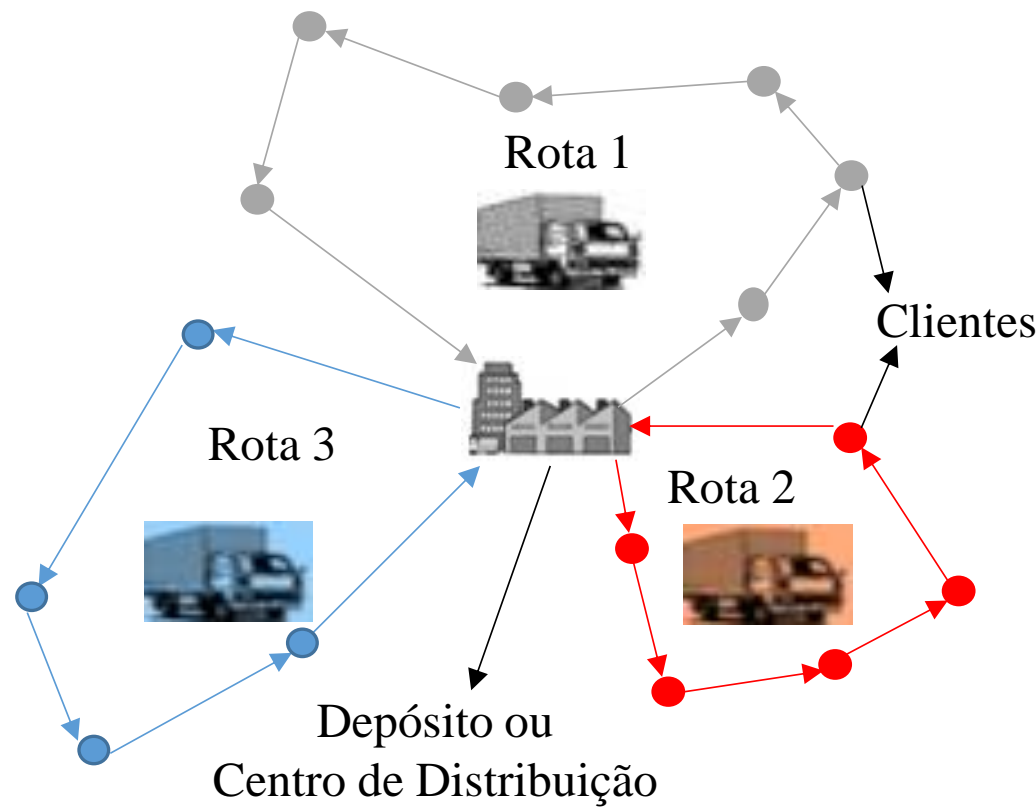

Figura 7 - Rotas da frota. Fonte: adaptado de Kwon et al. (2013)

Segundo Arenales et al. (2015), o VRP clássico é representado em um grafo orientado $G=(V, A)$ sendo $V=\{0,1, \ldots, N\}$ o conjunto de vértices e $A=\{(i, j): i, j$ $\epsilon \mathrm{V}, \mathrm{i} \neq \mathrm{j}\}$ o conjunto de arcos. O vértice 0 representa um depósito ao qual é alocado no máximo k veículos de capacidade $Q$. Cada cliente i $\epsilon \mathrm{V} \backslash\{0\}$ é associado a uma demanda não negativa $d_{i} \leq Q$. A matriz de custo $c_{i j}$ (simétrica, $\mathrm{c}_{\mathrm{ij}}=\mathrm{c}_{\mathrm{ji}}$ para todo $\mathrm{i}, \mathrm{j}$ ) é definida no conjunto de arco A. O tempo disponível para as rotas é representado por $D$. Pode-se também definir o problema num grafo não direcionado $\mathrm{G}=(\mathrm{V}, \mathrm{E})$, sendo $\mathrm{E}=\{(\mathrm{i}, \mathrm{j}): \mathrm{i}, \mathrm{j} \in \mathrm{V}, \mathrm{i}<\mathrm{j}\}$ o conjunto de arestas. Destarte o problema consiste em gerar um conjunto de rotas de veículo que começam e terminam no 
mesmo depósito de modo que minimizem o custo total. Cada cliente é visitado somente uma única vez e a demanda total de cada rota não pode exceder a capacidade $Q$ do veículo. Abaixo segue a notação e em seguida a formulação de programação inteira mista do VRP.

Parâmetros:

$K=$ número de veículos.

$N=$ total de clientes que a entrega deve ser feita. Clientes (1 ...N) depósito (0).

$Q=$ capacidade (peso ou volume) do veículo.

$D=$ tempo disponível para execução de entregas pelo veículo.

$d_{i}=$ tamanho ou peso da entrega para o cliente $i$.

$c_{i j}=$ custo da viagem direta do cliente $i$ para o cliente $j$.

$t_{i j}=$ duração da viagem direta do cliente $i$ para o cliente $j$.

Variáveis:

$x_{i j k}=1$, se o veículo $k$ viaja diretamente do cliente $i$ para o cliente $j$. Ou zero se não.

A formulação matemática do VRP clássico proposta por Arenales et al. (2015), define-se seguinte forma:

$$
\begin{array}{ll}
\operatorname{Min} \sum_{k \in K} \sum_{(i, j) \in E} c_{i j} x_{i j k} & \\
\sum_{k \in K} \sum_{j \in N\{0\}} x_{i j k}=1 & \forall i \in V \\
\sum_{i \in C} d_{i} \sum_{j \in N\{0\}} x_{i j k} \leq Q & \forall k \in K \\
\sum_{i \in N\{n+1\}} \sum_{j \in N\{0\}} x_{i j k} t_{i j} \leq D & \forall k \in K \\
\sum_{j \in N \backslash\{0\}} x_{0 j k}=1 & \forall k \in K \\
\sum_{i \in N \backslash\{n+1\}} x_{i h k}-\sum_{j \in N \backslash\{0\}} x_{h j k}=0 & \forall i \in V, k \in K \\
\sum_{i \in N \backslash 0} x_{i, n+1, k}=1 & \forall k \in K
\end{array}
$$




$$
\begin{array}{ll}
\sum_{i \in S} \sum_{j \in S} x_{i j k} \leq|S|-1, \quad S \subset C, \leq|S| \leq\left[\frac{n}{2}\right] & \forall k \in K \\
x_{i j k} \in B^{K \mid E} & \forall k \in K
\end{array}
$$

A função objetivo (2.1) visa a minimização do custo total de rotas. As restrições (2.2) asseguram que cada cliente i será incluindo na rota de um único veículo. As inequações (2.3) impedem que a demanda total de cada rota seja maior que a capacidade $\mathrm{Q}$ do veículo designado para a rota. As restrições (2.4) garantem que o tempo de duração de cada rota não seja maior que o limite D que é o tempo disponível para operação. As restrições (2.5), (2.6) e (2.7) são restrições de fluxo em redes, que garantem que cada veículo $k$ saia apenas do depósito (nó 0) somente uma vez, deixe o nó $h$ se e somente se entrar neste nó, e retorne ao depósito (nó n +1) somente uma vez. As restrições (2.7) são redundantes, mas Arenales et al. (2015) mantém com intuito de enfatizar a estrutura de redes. A inequação (2.8) garante que não haja subciclo e a restrição (2.9) indica o domínio das variáveis.

\section{6 \\ Inventory Routing Problem}

Os tópicos anteriores desse capítulo foram tratados em um caráter de fundamentação teórica, porém nesta seção que trata do problema central desta pesquisa.O qual é explorado o tema com uma revisão sistemática seguindo os critérios detalhados a seguir.

Usou-se como parâmetros de busca os temas "Inventory Routing Problema" ou "Inventory Routing", encontrou-se 463 artigos e após uma triagem que considerava apenas artigos de 2012 a 2017 (últimos 6 anos), e artigos de revistas que não foram explorados por Coelho et al. (2013), que explorou exaustivamente os artigos de IRP até 2012, chegou-se ao número de 202 artigos. Então realizou-se nova triagem considerando apenas artigos com fator de impacto (Journal Citation Reports - JCR) acima ou igual a um e Qualis da Coordenação de Aperfeiçoamento de Pessoal de Nível Superior do Brasil (CAPES) igual ou superior a B1. Por fim realizou-se uma terceira triagem para averiguar a adequação a temática deste trabalho, então selecionou-se 27 artigos para leitura completa. Então realizou-se a leitura de outros artigos citados pelos artigos selecionados. Então chegou-se ao objetivo desta etapa (informações consolidadas sobre o tema), através de uma revisão sistemática. As etapas da seleção dos estudos estão ilustrados na Figura 8. 


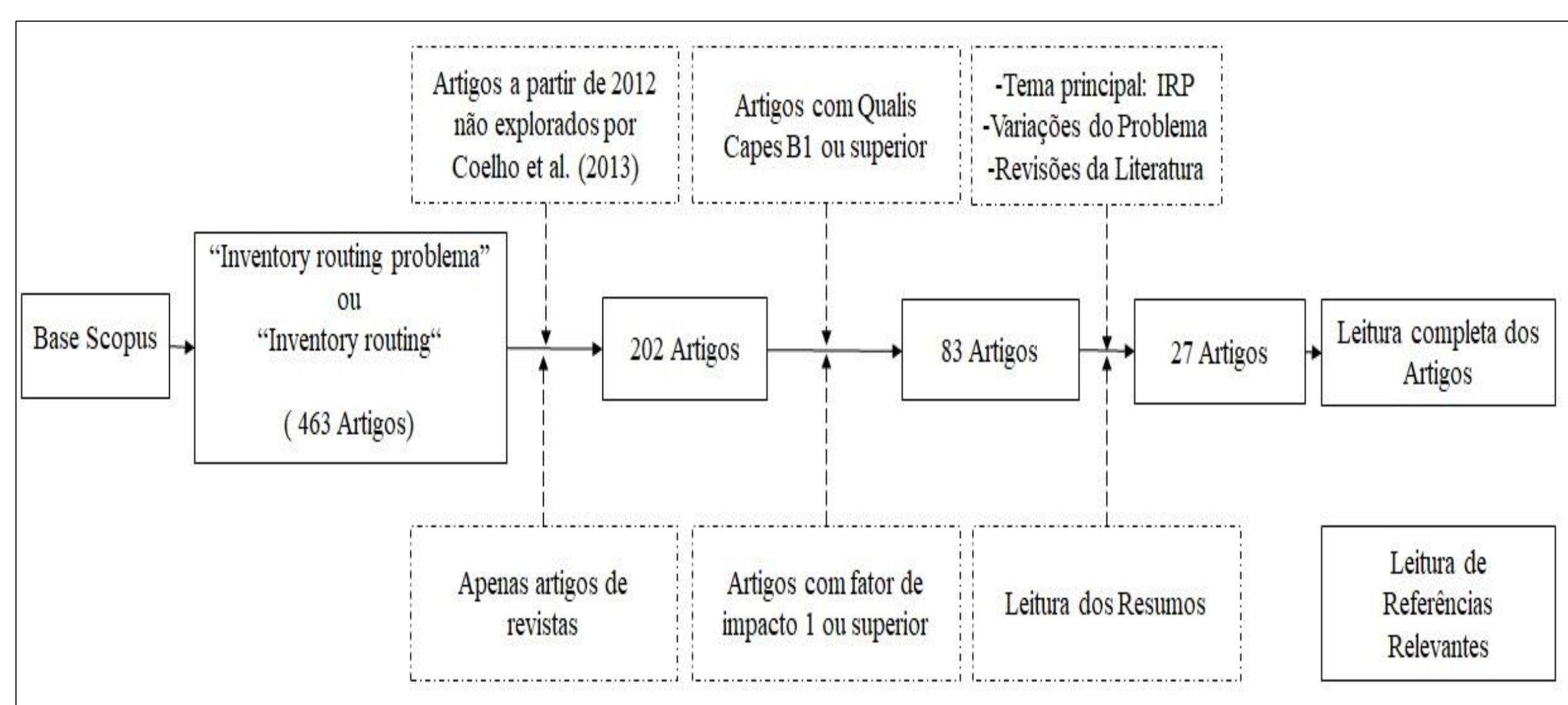

Figura 8 - Percurso de seleção de atigos. Fonte: Autor (2017). 
O autor que introduziu o IRP foi Bell et al. (1983), publicado há mais 30 anos. $\mathrm{O}$ autor desenvolveu sua pesquisa numa empresa que atuava na distribuição de gases industriais como oxigênio nitrogênio, hidrogênio etc. $O$ mesmo explica que a gestão de estoques era integrada com o planejamento de entregas, e nesse contexto surge o IRP, na época não existia o conceito de VMI.

Segundo Coelho et al. (2013c) o IRP integra o problema de gestão de estoques e o problema de roteamento de veículos (VRP) e as decisões de programação de entregas. Nesse contexto, o mesmo autor diz que o IRP faz três decisões simultâneas: (1) quando realizar uma entrega a um determinado cliente, (2) quanto entregar para esse cliente quando este é visitado, e (3) como combinar as visitas aos clientes nas rotas realizadas por cada veículo, de modo a minimizar custos de distribuição e estoques.

O IRP pode ser definido como um problema que indica as decisões de reposição de estoque para os varejistas ao mesmo tempo que as rotas para os veículos para os fornecedores que realizam essas reposições (Li et al., 2010).

As decisões relacionadas ao gerenciamento de estoques e roteamento de veículos (tratadas pelo IRP) são questões críticas para otimizar operações na cadeia de suprimentos (Andersson et al., 2010).

Para Archettia et al. (2014) o IRP está inserido em outra classe de VRPs. A maioria dos problemas de VRP assume que o período de entrega ou visita, e a quantidade que será entregue a cada cliente já foi decidido, portanto seu objetivo é otimizar a sequência de visita aos clientes.

Segundo Chen \& Lin (2009) a combinação do VRP e gestão de estoques é a definição comum para o IRP, a formulação deste problema geralmente assume a forma de um modelo inteiro complexo, portanto, é um problema NP-díficil. A Figura 9 contém uma breve ilustração do IRP. 


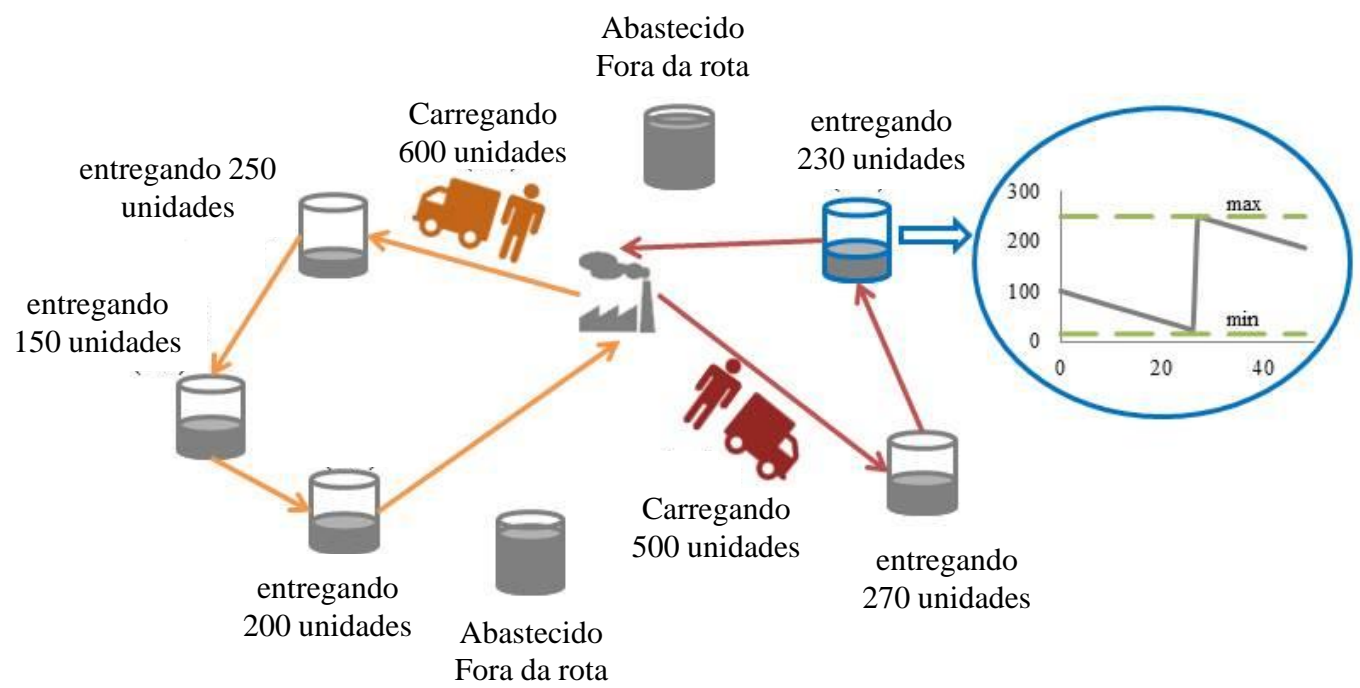

Figura 9 - Ilutração do IRP. Fonte: adaptado de Maravelias Group of University of Wisconsin Madison (2013)

Archetti et al. (2007) em sua pesquisa formulou o IRP da seguinte forma: um grafo completo e não orientado e simétrico $\mathrm{G}=(\mathrm{V}, \mathrm{A})$ de modo o conjunto de arcos e os nós são definidos respectivamente por $A=\{(i, j) \in V, i \neq j\}, M=\{0, \ldots, n\}$, sendo que o nó 0 é o centro de distribuição (CD), desse modo o conjunto de clientes é $\mathrm{S} \subseteq \mathrm{M}=\{1, \ldots, \mathrm{n}\}$. O IRP comtempla decisões durante um horizonte $\mathrm{T}=\{1, \ldots$, $\mathrm{H}$ \}. Para cada arco $\left(\mathrm{i}, \mathrm{j}\right.$ ) percorrido existe um custo associado $c_{i j}$. Sendo que $r_{s t}$ representa a demanda do cliente s no período t ( $r_{0 t}$ a demanda do CD). A variável $B_{t}$ representa o estoque no $\mathrm{CD}$ e $B_{0}$ o estoque inicial do período 1 . O cliente i tem demanda $d_{i}^{t}, \forall t \in T$, existe um custo de manutenção de estoque $h_{i}$ (para o $\operatorname{CD} h_{0}$ ) e uma capacidade de estocagem $C$. $\mathrm{O}$ fornecedor deve escolher em qual período $\mathrm{t}$ será realizada uma visita ao cliente, neste modelo se caso for decidido visitar o cliente sempre será transportado uma quantidade $U_{s}$, que seria uma quantidade que preencheria toda a capacidade de armazenagem do cliente (esta é uma das políticas de reposição do IRP que será comentada mais a frente). A quantidade que será transportada para cada cliente a fim de atender a demanda é representada pela variável $x_{s t}$. Se tratando de uma matriz simétrica e um grafo não orientado então o custo $c_{i j}=c_{j i}$. Abaixo o modelo de IRP de Archetti et al. (2007):

$$
\operatorname{Min} \sum_{t \in T} h_{0} B_{t}+\sum_{s \in M} \sum_{t \in T} h_{i} I_{i}^{t}+\sum_{i \in M} \sum_{j \in M, j<i} \sum_{t \in T} c_{i j} y_{i j}^{t}
$$




$$
\begin{aligned}
& B_{t}=B_{t-1}+r_{0 t-1}-\sum_{s \in M} x_{s t-1} \\
& \forall t \in T \\
& \sum_{s \in M} x_{s t-1} \leq B_{t} \\
& \forall t \in T \\
& I_{s t}=I_{s t-1}+x_{s t-1}-r_{s t-1} \quad \forall s \in M, t \in T \\
& I_{s t} \geq 0 \\
& \forall s \in M, t \in T \\
& x_{s t-1} \geq U_{s} z_{s t}-I_{s t} \quad \forall s \in M, t \in T \\
& x_{s t-1} \leq U_{s}-I_{s t} \quad \forall s \in M, t \in T \\
& x_{s t-1} \leq U_{s} z_{s t} \quad \forall s \in M, t \in T \\
& \sum_{s \in M} x_{s t} \leq C \\
& \sum_{s \in M} x_{s t} \leq C z_{0 t} \\
& \sum \sum y_{i j}^{t} \leq \sum z_{i t}-z_{k t} \quad \forall i \in M, t \in T \\
& x_{s t} \geq 0 \\
& \forall s \in M, t \in T \\
& y_{i j}^{t} \in\{0,1\} \\
& \forall i, j \in M, t \in T \\
& y_{i 0}^{t} \in\{0,1,2\} \\
& \forall j \in M, t \in T \\
& z_{i t} \in\{0,1\} \\
& \forall j \in M, t \in T
\end{aligned}
$$

A Função (2.10) minimiza os custos de estoques do CD, o custo de estoques do cliente e o custo total de transporte. As equações (2.11) e (2.13) fazem o balanceamento dos estoques dos clientes e CD, e garantem o atendimento da demanda de s no período t. As inequações (2.12) assegura que a quantidade transportada em cada período não exceda a quantidade disponível do produto no CD. As Inequações (2.14) garante a não negatividade das variáveis de decisão referente aos estoques dos clientes. As restrições (2.15), (2.16) e (2.17) fazem com 
que a quantidade transportada para cada cliente seja igual a seu respectivo $U_{S}$ (política de IRP comentada anteriormente, e que será abordada Seção 2.6.2). As inequações (2.18) asseguram que a quantidade entregue ao cliente s no período $t$ não ultrapasse sua capacidade disponível. A inequação (2.19) decide quais clientes serão visitados no período $t$. As inequações (2.20) garantem a continuidade de fluxo dos veículos e a restrição (2.21) assegura a não ocorrência de subciclos. As inequações (2.22) garantem a não negatividade das variáveis de decisão de quantidade transportada. Por fim, as restrições (2.23), (2.24) e (2.25) obrigam que às variáveis de decisão referente as rotas e de visitar ou não os clientes sejam binárias. Existe não linearidade nas restrições (2.15) e (2.17) nas quais contêm multiplicação de variáveis. Por não ser o foco deste estudo não será descrito como a autora tratou esse problema, mas em caso de interesse vide Archetti et al. (2007).

Inspirado no trabalho de Archetti et al. (2007), Coelho et al., (2013c) desenvolveu um modelo com menos variáveis e generalizou para que este considere mais de um veículo, ou seja uma frota (heterogênea ou homogênea). Destarte, o problema ficou conhecido como Multi-Vehicle Inventory Routing Problem (MIRP). O MIRP pode ser formulado da seguinte forma: um grafo completo e não-orientado $\mathrm{G}=(\mathrm{V}, \mathrm{E})$ de modo que o conjunto de vértices e o conjunto de arcos são definidos respectivamente por $\mathrm{V}=\{0, \ldots, \mathrm{n}\}$ e $\mathrm{E}=\{(\mathrm{i}, \mathrm{j}) \in \mathrm{V}, \mathrm{i} \neq \mathrm{j}\}$. O vértice 0 que pertencente a $\mathrm{V}$ sendo o centro de distribuição $(C D)$ e $V^{\prime}=\mathrm{V} \backslash 0$ retrata os clientes. Os arcos $(\mathrm{i}, \mathrm{j}) \in \mathrm{V}$ possuem um custo $c_{i j}>0$. O problema considera decisões em um horizonte $\mathrm{T}=\{0, \ldots, \mathrm{p}\}$. O cliente i demanda $d_{i}^{t}, \forall t \in T$, tem um custo de manutenção de estoque $h_{i}$ e uma capacidade de estocagem $C_{i}$. O fornecedor deve escolher em qual período t será atendida a demanda do cliente i a uma quantidade $q_{i k}^{t}$. Uma frota homogênea de $\mathrm{k}$ veículos, $\mathrm{K}=\{1, \ldots, \mathrm{k}\}$, com capacidade $Q_{k}$ está disponível no $\mathrm{CD}$. Cada veículo $\mathrm{k}$ faz uma única rota em cada período $\mathrm{t}$, visitando um certo número de clientes. As variáveis estão descritas abaixo:

$x_{i j k}^{t}=1$ se o arco $(\mathrm{i}, \mathrm{j})$ é percorrido no período t pelo veículo k senão $x_{i j k}^{t}=0$ $y_{i k}^{t}=1$ se o cliente $\mathrm{i}$ for visitado pelo veículo $\mathrm{k}$ no período t e 0 caso contrário $I_{i}^{t}=$ nível de estoque do cliente i no final do período $\mathrm{t}$ $I_{0}^{t}=$ nível de estoque no $\mathrm{CD}$ ao final do período $\mathrm{t}$ $q_{i k}^{t}=$ quantidade transportada para o cliente i no período t pelo veículo $\mathrm{k}$ $r^{t}=$ decisão de compra de itens para ressuprimeto do CD 
O MIRP tem como objetivo minimizar os custos totais de transporte e estoque, tendo em conta as seguintes restrições:

- O estoque $I_{i}^{t}$ do cliente i deve ser menor ou igual $C_{i}$

- A quantidade entregue pelo veículo k no período t não deve exceder sua capacidade $Q_{k}$.

- Cada veículo deve iniciar e terminar sua rota no depósito, cada veículo faz apenas uma rota por período e o número de rotas não pode superar a disponibilidade da frota.

- Cada cliente só pode ser visitado por no máximo um único veículo em cada período.

O MIRP baseado em Coelho et al., (2013c) pode ser descrito da seguinte forma:

$$
\begin{aligned}
& \operatorname{Min} \sum_{i \in v} \sum_{t \in T} h_{i} I_{i}^{t}+\sum_{i \in v} \sum_{j \in v, j<i} \sum_{k \in K} \sum_{t \in T} c_{i j} x_{i j}^{k t} \\
& I_{0}^{t}=I_{0}^{t-1}+r^{t}-\sum_{i \in V} \sum_{k \in K} q_{i}^{k t} \\
& \forall t \in T \\
& I_{0}^{t} \geq 0 \\
& \forall t \in T \\
& I_{i}^{t}=I_{i}^{t-1}+\sum_{k \in K} q_{i}^{k t}-d_{i}^{t} \\
& \forall i \in V, t \in T \\
& I_{i}^{t} \geq 0 \\
& \forall i \in V, t \in T \\
& I_{i}^{t} \leq C_{i} \\
& \forall i \in V, t \in T \\
& \sum_{k \in K} q_{i}^{k t} \leq C_{i}-I_{i}^{t-1} \\
& \forall i \in V, t \in T \\
& q_{i}^{k t} \leq C_{i} y_{i}^{k t} \\
& \forall i \in V, k \in K, t \in T \\
& \sum_{i \in v} q_{i}^{k t} \leq y_{i}^{k t} Q_{k} \\
& \forall k \in K, t \in T \\
& \sum_{j \in v, i<j} x_{i j}^{k t}+\sum_{j \in v, i>j} x_{j i}^{k t}=2 y_{i}^{k t} \quad \forall i \in V, k \in K, t \in T \\
& \sum_{i \in S, i<j} \sum_{j \in S,} x_{i j}^{k t} \leq \sum_{i \in S} y_{i}^{k t}-y_{m}^{k t} \quad S \subseteq \mathrm{V}, \forall k \in K, t \in T, i \in S
\end{aligned}
$$




$$
\begin{array}{ll}
x_{i 0}^{k t} \in\{0,1,2\} & \forall i \in V, k \in K, t \in T \\
q_{i}^{k t} \text { e } I_{i}^{t} \geq 0 & \forall i \in V, k \in K, t \in T \\
x_{i j}^{k t} \text { e } y_{i}^{k t} \in\{0,1\} & \forall i, j \in V, k \in K, t \in T
\end{array}
$$

A função (2.26) minimiza os custos de estoques do $\mathrm{CD}$, o custo de estoque do cliente e o custo total de transporte. As equações (2.27) e (2.29) fazem o balanceamento dos estoques dos clientes e CD, e garantem o atendimento da demanda i no período t. A Inequação (2.28) garante a não negatividade da variável de decisão referente ao estoque do CD. A Inequação (2.30) assegura a não negatividade das variáveis de decisão referente aos estoques dos clientes. As restrições (2.31) e (2.32) asseguram que a quantidade entregue ao cliente i no período t não ultrapasse sua capacidade disponível. A inequação (2.33) decide quais clientes serão visitados no período t. A Inequação (2.34) garante que o total transportado pelo veículo k não exceda sua própria capacidade. As Equações (2.35) e (2.36) garantem respectivamente a continuidade de fluxo dos veículos asseguram a não ocorrência de subciclos. A Inequação (2.38) garante a não negatividade das variáveis de decisão de estoques e quantidade transportada. Por fim, as Restrições (2.37) e (2.39) obrigam que as variáveis de decisão de rota e de visitar ou não os clientes sejam binários.

O autor Guemri et al. (2016) posteriormente usando a mesma notação de Coelho et al., (2013b), formulou o IRP frota homogênea e vários produtos, que ficou conhecido como Multi-product Multi-vehicle Inventory Routing Problem (MMIRP). A mudança em relação a notação de Coelho et al. (2013b) foi a inclusão de um novo conjunto $\mathrm{M}=\{1, \ldots, \mathrm{n}\}$ que representava a quantidade de produtos diferentes. O modelo de MMIRP de Guemri et al. (2016) está descrito abaixo:

$$
\begin{aligned}
& \operatorname{Min} \sum_{i \in V} \sum_{t \in T} h_{i}^{m} I_{i}^{m t}+\sum_{i \in V} \sum_{j \in V, i<j} \sum_{k \in K} \sum_{t \in T} c_{i j} x_{i j}^{k t} \\
& I_{0}^{m t}=I_{0}^{m t-1}+r^{m t}-\sum_{i} \sum_{k} q_{i}^{m k t} \quad \forall m \in M, t \in T
\end{aligned}
$$


$I_{i}^{m t}=+I_{i}^{m t-1}+\sum_{k} q_{i}^{m k t}-d_{i}^{m t} \quad \forall i \in V, m \in M, t \in T$

$I_{i}^{m t} \geq 0$

$\forall i \in V, t \in T,, m \in M$

$\sum_{m} I_{i}^{m t} \leq C_{i}$

$\forall i \in V, t \in T$

$\sum_{m} \sum_{k} q_{i}^{m k t} \leq C_{i}-\sum_{m} I_{i}^{m t-1} \quad \forall i \in V, t \in T$

$q_{i}^{m k t} \leq C_{i} y_{i}^{m k t}$

$\forall i \in V, m \in M, k \in K, t \in T$

$\sum_{i} \sum_{m} q_{i}^{m k t} \leq Q_{k} y_{0}^{m k t} \quad \forall t \in T, k \in K$

$\sum_{j \in v, i<j} x_{i j}^{k t}+\sum_{j \in v, i>j} x_{j i}^{k t}=2 y_{i}^{k t} \quad \forall i \in V, k \in K, t \in T$

$\sum_{i \in S, i<j} \sum_{j \in s,} x_{i j}^{k t} \leq \sum_{i \in s} y_{i}^{k t}-y_{m}^{k t} \quad \forall k \in K, t \in T$

$q_{i}^{m k t} \geq 0$

$\forall i \in V, m \in M, k \in K, t \in T$

$x_{i j}^{k t} e \in\{0,1,2\}$

$\forall i, j \in V, k \in K, t \in T$

$x_{i j}^{k t}$ e $y_{i}^{k t} \in\{0,1\}$

$\forall i, j \in V, k \in K, t \in T$

A função (2.40) minimiza os custos de estoques e custos de transporte. As equações (2.41) e (2.42) fazem o balanceamento dos estoques do CD e clientes. As inequações (2.43) fazem com que as variáveis de estoque não assumam valores negativos. As inequações (2.44) e (2.45) asseguram que a quantidade entregue ao cliente $i$ no período $t$ não ultrapasse sua capacidade disponível. A restrição (2.46) decide quais clientes serão visitados no período t. As restrições (2.47) asseguram que quantidade de produtos transportada por um certo veículo $\mathrm{k}$ não exceda a capacidade do mesmo. As equações (2.48) e as inequações (2.49) garantem respectivamente a continuidade de fluxo dos veículos e a não ocorrência de 
subciclos. As Inequações (2.50) garantem a não negatividade das variáveis de decisão de estoques e quantidade transportada. As últimas restrições (2.51) e (2.52) obrigam que as variáveis de decisão de rota e de visitar ou não os clientes sejam binários.

\subsection{1}

\section{Políticas do Inventory Routing Problem}

O IRP é abordado na literatura considerando diferentes políticas de abastecimento, que impõem condições na quantidade que deve ser entregue a cada visita ao cliente. As duas mais utilizadas são as políticas de Order-Up-to-Level (OU) e de Maximum Level (ML). A política OU, define que "se for decidido" visitar o cliente, a quantidade entregue ao mesmo deve preencher a capacidade máxima de seu estoque, desse modo vinculando a decisão da quantidade que deve ser entregue à diferença entre capacidade máxima e seu nível de estoque do cliente no período.

Essa política foi introduzida por Dror et al. (1985) com o intuito de simplificar o problema e obter boas soluções. Diferente do OU, a política ML considera que qualquer quantidade pode ser entregue considerando apenas a restrição de capacidade do cliente. A política de ML pode alcançar os mesmos resultados da OU, porém é mais flexível. Entretanto traz mais complexidade ao problema, haja visto que o número de variáveis de decisão é maior, porque a quantidade a ser entregue deixa de estar associada à simples diferença de capacidade e estoque do período.

Ambas políticas são extensamente abordadas na literatura vide Bertazzi et al. (2002), Archetti et al. (2007), Solyali e Süral (2011), Adulyasak et al. (2014b), Archetti et al. (2012), Coelho et al. (2012a), Coelho et al. (2012b), Michel e Vanderbeck (2012), Coelho e Laporte (2013a), Coelho e Laporte (2013b), Hewitt et al. (2013), entre outros. Recentemente os pesquisadores Coelho e Laporte (2013b) introduziram na literatura a política de Optimized Target Level (OTL).

A política de OTL é parecida com a política OU, porém a quantidade a ser transportada não deve preencher a capacidade de estoque do cliente, mas sim chegar a um nível ótimo de estoque que é definido pelo modelo matemático, sendo calculado simultaneamente para todos os clientes. A política de OU pode ser representada com a adição das inequações (2.53) e (2.54) ao mdelo de Coelho et al. (2013c). 


$$
\begin{array}{ll}
q_{i}^{k t} \leq C_{i}-I_{i}^{t-1} & \forall i \in V, k \in K, t \in T \\
q_{i}^{k t} \geq C_{i} y_{i}^{k t}-I_{i}^{t-1} & \forall i \in V, k \in K, t \in T
\end{array}
$$

A política de OTL cria uma variável nova $L_{c}$, que seria o nível ótimo de estoque do cliente, a OTL pode ser representada com a adição das inequações (2.55), (2.56) e (2.57) ao modelo de Coelho et al. (2013c).

$$
\begin{array}{ll}
0 \leq q_{i}^{k t} \leq L_{i}-I_{i}^{t} & \forall i \in V, k \in K, t \in T \\
q_{i}^{k t} \leq C_{i} y_{i}^{k t} & \forall i \in V, k \in K, t \in T \\
q_{i}^{k t} \geq L_{i}-I_{i}^{t}-\left(1-y_{i}^{k t}\right) C_{i} & \forall i \in V, k \in K, t \in T
\end{array}
$$

\section{7}

\section{Extensões do Inventory Routing Problem}

O autor Coelho et al. (2013c) faz uma revisão da literatura sobre os problemas de IRP no qual ele destaca algumas variações como: As versões específicas do IRP incluem um único cliente (Bertazzi e Speranza, 2002; Solyalı e Süral, 2008), o IRP com múltiplos clientes (Archetti et al., 2007; Bell et al., 1983; Coelho e Laporte 2013b, Coelho et al. 2012c), o IRP com multiproduto (Bausch et al. 1998; Qu et al., 1999; Sindhuchao et al., 2005), o IRP com vários depósitos e clientes (Benoist et al. 2011), e o IRP com frota heterogênea (Chien et al., 1989; Christiansen, 1999; Coelho e Laporte, 2013b; Persson e Göthe-Lundgren, 2005).

Algumas versões do MIRP já citado nesta pesquisa, IRP com diversos produtos também foram tratados como: Popovi'c et al. (2012); Moin et al. (2011); Mjirda et al. (2012); Ramkumar et al. (2012) Coelho e Laporte (2013a e 2013b); Adulyasak et al. (2014b); Guemri et al. (2016); Lmariouh et al. (2017) e Hasni et al. (2017).

Outra variação que foi bastante explorada na literatura é o IRP com entregas diretas, versão simplificada do problema que elimina a otimização de transporte através do melhor roteiro de entrega, uma vez que as entregas para os clientes não são realizadas mais em uma sequência, sendo que o veículo vai no cliente e volta 
ao CD. Vários estudos são desenvolvidos, vide Kleywegt et al. (2002); Bertazzi (2008); Gallego e Simchi-Levi (1990, 1994); Li et al. (2010); Herer e Roundy (1997); Zhao et al. (2007), Viswanathan e Mathur (1997); Roundy (1985).

A variação mais recente que vem sendo tratada na literatura é o Green Inventory Routing Problem (GIRP), que considera em sua otimização as questões ambientais na qual existem diferentes abordagens. Nesta área ainda existem poucos trabalhos como os de Xiao e Rao (2016); Soysal et al (2016, Prelo); Soysal (2016); Cheng et al. (2016); Cheng et al. (2017) e Rahimi et al. (2017). Além das variações citadas anteriormente existem algumas outras que são mais relevantes e interessantes quem merecem atenção e destaque.

A Tabela 1 contém um sumário dos artigos que trataram o IRP, as características do problema tratado e método de solução. As siglas ou abreviações encontradas na Tabela 1 que ainda não foram citados anteriormente tem os seguintes significados: E: Exato; EOQ: Economic order quantity (Lote de compra); H: Heurística ou Metaheuristica; Het. : Heterogênea; Hom. : Homogênea; L: Limite inferior. 
Tabela 1 - Sumário de variantes do IRP e suas características. Fonte: Autor (2018)

\begin{tabular}{|c|c|c|c|c|c|c|c|c|c|}
\hline \multirow[b]{2}{*}{ Autores } & \multicolumn{2}{|c|}{ Produção } & \multicolumn{2}{|c|}{ Estoque } & \multicolumn{3}{|c|}{ Transporte } & \multicolumn{2}{|r|}{ Método de solução } \\
\hline & $\mathrm{CD}$ & Produto & Política & Cap. & Frota & Veículos & Cap. & Tipo & Abordagem \\
\hline Bertazzi e Speranza (2002) & Único & Múltiplo & ML & Não & Hom. & Limitado & Sim & $\mathrm{E}$ & MIP \\
\hline Sindhuchao et al. (2005) & Único & Único & EOQ & Sim & Het. & Limitado & Sim & $\mathrm{E}$ & Geração de Colunas e Heurística \\
\hline Persson e Göthe-Lundgren (2005) & Múltiplo & Múltiplo & ML & Sim & Het. & Ilimitado & Sim & $\mathrm{E} / \mathrm{H}$ & Geração de Colunas e Heurística \\
\hline Archetti et al. (2007) & Único & Único & OU & Não & Hom. & Limitado & Sim & $\mathrm{E}$ & Branch-and-Cut \\
\hline Solyalı e Süral (2008) & Múltiplo & Único & $\mathrm{OU}$ & Cap. & Hom. & Limitado & Sim & $\mathrm{E}$ & MIP \\
\hline Moin et al. (2011) & Único & Múltiplo & ML & Sim & Hom. & Limitado & Sim & $\mathrm{H}$ & Híbrido com Algoritmo Genético \\
\hline Mjirda et al. (2012) & Único & Múltiplo & ML & Sim & Hom. & Limitado & Sim & $\mathrm{H}$ & VNS \\
\hline Ramkumar et al. (2012) & Múltiplo & Múltiplo & ML & Sim & Hom. & Limitado & Sim & $\mathrm{E}$ & MIP \\
\hline Popovi'c et al. (2012) & Único & Múltiplo & ML & Sim & Hom. & Limitado & Sim & $\mathrm{H}$ & VNS \\
\hline $\begin{array}{l}\text { Coelho et al. (2012a)- CIRP; } \\
\text { (2012b)-SIRP; (2012c)-IRPT }\end{array}$ & Único & Único & $\mathrm{ML} / \mathrm{OU}$ & Sim & Hom. & Limitado & Sim & $\mathrm{H}$ & ALNS \\
\hline Coelho e Laporte (2013a) & Único & Múltiplo & ML & Sim & Hom. & Limitado & Sim & $\mathrm{E}$ & Brand-and-Cut \\
\hline $\begin{array}{l}\text { Coelho e Laporte (2013b) } \\
\text { *Múltiplos Casos do IRP }\end{array}$ & Único & Múltiplo & $\mathrm{ML} / \mathrm{OU}$ & Sim & $\begin{array}{l}\text { Hom./ } \\
\text { Het. }\end{array}$ & Limitado & $\operatorname{sim}$ & $\mathrm{E}$ & Brand-and-Cut \\
\hline Coelho e Laporte (2013c) & - & - & - & - & - & - & - & - & Revisão da Literatura \\
\hline Adulyasak et al. (2014b) & Único & Múltiplo & $\mathrm{ML} / \mathrm{OU}$ & Sim & $\begin{array}{l}\text { Hom./ } \\
\text { Het. }\end{array}$ & Múltiplo & Sim & $\mathrm{E} / \mathrm{H}$ & Branch-and-cut / ALNS \\
\hline Desaulniers et al.(2015) & Único & Único & ML & Sim & Hom. & Múltiplos & Sim & $\mathrm{E}$ & Branch-Price-and-Cut \\
\hline Guemri et al. (2016) & Único & Múltiplo & ML & Sim & Hom. & Limitado & Sim & $\mathrm{H}$ & GRASP \\
\hline Xiao e Rao (2016) & Único & Múltiplo & ML & Sim & Hom. & Limitado & Sim & $\mathrm{H}$ & Algoritmo Fuzzy Genético \\
\hline Soysal et al (2016, Prelo) & Múltiplo & Múltiplo & ML & Sim & Het. & Limitado & Sim & $\mathrm{E}$ & MIP \\
\hline Soysal (2016) & Único & Múltiplo & ML & Sim & Hom. & Limitado & Sim & $\mathrm{E}$ & MIP \\
\hline Cheng et al. (2016) & Único & Múltiplo & ML & Sim & Hom. & Limitado & Sim & $\mathrm{H}$ & Híbrido com Algoritmo Genético \\
\hline Cheng et al. (2017) & Único & Único & ML & Sim & Het. & Limitado & Sim & $\mathrm{H}$ & Branch-and-Cut \\
\hline Lmariouh et al. (2017) & Múltiplo & Múltiplo & ML & Sim & Hom. & Limitado & Sim & $\mathrm{E}$ & MIP \\
\hline Hasni et al. (2017) & Único & Múltiplo & ML & Sim & Het. & Múltiplo & Sim & $\mathrm{H}$ & VNS \\
\hline Rahimi et al. (2017) & Múltiplo & Múltiplo & ML & Sim & Het. & Múltiplo & Sim & $\mathrm{H}$ & Fuzzy e NSGA-II \\
\hline
\end{tabular}




\subsection{1}

\section{The Production-Routing Problem}

Segundo Adulyasak et al. (2014), o Production-Routing Problem (PRP) ou em português problema de roteamento de produção é a junção do problema de tamanho de lote e o problema do roteamento de veículos, o autor explica que o PRP tem o objetivo de otimizar simultaneamente as decisões referentes a produção, estoque e distribuição, destarte, este é uma generalização do IRP.

O autor Coelho et al. (2013c) diz que o PRP integra as decisões relacionadas a estoque e dimensionamento de lote de produção em um determinado horizonte de planejamento juntamente com os roteiros de entregas dos veículos. Os primeiros a integrar as decisões de produção ao IRP foram Chandra (1993) e Chandra e Fisher (1994). Posteriomente Chandra e Fisher (1994); Herer e Roundy (1997); Fumero e Vercellis (1999); Bertazzi et al. (2005); Lei et al. (2006); Boudia et al. (2007 e 2008); Boudia e Prins (2009); Solyalı e Süral (2009); Bard e Nananukul (2009, 2010); Ruokokoski et al. (2010); Armentano et al. (2011); Archetti et al. (2011); Adulyasak et al. (2012a, 2014a, 2014b e 2015); Absi et al. (2014); Kumar et al. (2016); Brahimi e Aouam (2016). Os trabalhos mais recentes foram os de Miranda et al. (2017); Qiu et al. (2017) e Zhang et al. (2017). Nesta seção optou-se por não formalizar matematicamente o problema por sair do foco desta pesquisa. $\mathrm{Na}$ próxima página contém Tabela 2 com um sumário dos artigos que trataram o PRP, características do problema tratado e método de solução. As siglas ou abreviações encontradas na Tabela 2 que ainda não foram citados anteriormente tem os seguintes significados: E: Exato; EOQ: Economic order quantity (Lote de compra); H: Heurística ou Metaheuristica; Het. : Heterogênea; Hom. : Homogênea; L: Limite inferior 
Tabela 2 - Sumário de trabalhos sobre PRP e suas características. Fonte: Autor (2017).

\begin{tabular}{|c|c|c|c|c|c|c|c|c|c|c|}
\hline \multirow[t]{2}{*}{ Autores } & \multicolumn{3}{|c|}{ Produção } & \multicolumn{2}{|c|}{ Estoque } & \multicolumn{3}{|c|}{ Transporte } & \multicolumn{2}{|r|}{ Método de solução } \\
\hline & $\mathrm{CD}$ & Produto & Cap. & Política & Cap. & Frota & Veículos & Cap. & Tipo & Abordagem \\
\hline Chandra (1993) & Único & Múltiplo & $\operatorname{sim}$ & $\mathrm{ML}$ & Não & Hom. & Ilimitado & Sim & $\mathrm{H}$ & Decomposição \\
\hline Chandra e Fisher (1994) & Único & Múltiplo & $\operatorname{sim}$ & $\mathrm{ML}$ & Não & Hom. & Ilimitado & Sim & $\mathrm{H}$ & Decomposição \\
\hline Herer e Roundy (1997) & Único & Múltiplo & $\operatorname{sim}$ & EOQ & Cap. & Hom. & Ilimitado & Não & $\mathrm{H}$ & Heuristics \\
\hline Fumero e Vercellis (1999) & Único & Múltiplo & $\operatorname{sim}$ & ML & Não & Hom. & limitado & Sim & $\mathrm{H} / \mathrm{L}$ & Relaxação Lagrangiana \\
\hline Bertazzi et al. (2005) & Único & Único & $\operatorname{sim}$ & ML/OU & Sim & Hom. & limitado & Sim & $\mathrm{H}$ & Decomposição \\
\hline Lei et al. (2006) & Múltiplo & Único & $\operatorname{sim}$ & ML & Sim & Het. & limitado & Sim & $\mathrm{H}$ & Decomposição \\
\hline Boudia et al. (2007) & Único & Único & $\operatorname{sim}$ & ML & Sim & Hom. & limitado & Sim & $\mathrm{H}$ & GRASP \\
\hline Boudia et al. (2008) & Único & Único & $\operatorname{sim}$ & ML & Sim & Hom. & limitado & Sim & $\mathrm{H}$ & Decomposição \\
\hline Boudia e Prins (2009) & Único & Único & $\operatorname{sim}$ & ML & Sim & Hom. & limitado & Sim & $\mathrm{H}$ & Memetic \\
\hline Bard e Nananukul (2009) & Único & Único & $\operatorname{sim}$ & ML & Sim & Hom. & limitado & Sim & $\mathrm{H}$ & Tabu search \\
\hline Solyali e Süral (2009) & Único & Único & não & $\mathrm{OU}$ & Sim & Hom. & limitado & Sim & $\mathrm{H} / \mathrm{L}$ & Relaxação Lagrangiana \\
\hline Bard e Nananukul (2010) & Único & Único & $\operatorname{sim}$ & ML & Sim & Hom. & limitado & Sim & $\mathrm{H} / \mathrm{L}$ & Relaxação Lagrangiana \\
\hline Ruokokoski et al. (2010) & Único & Único & não & ML & Não & Hom. & único & Não & $\mathrm{E}$ & Brand-and-cut \\
\hline Armentano et al. (2011) & Único & Múltiplo & $\operatorname{sim}$ & $\mathrm{ML}$ & Sim & Hom. & limitado & Sim & $\mathrm{H}$ & Tabu search \\
\hline Archetti et al. (2011) & Único & Único & não & $\mathrm{ML} / \mathrm{OU}$ & Sim & Hom. & único & Sim & $\mathrm{E} / \mathrm{H}$ & Branch-and-cut e Heurist. \\
\hline Adulyasak et al. (2012a) & Único & Único & $\operatorname{sim}$ & ML & Sim & Hom. & múltiplo & Sim & $\mathrm{E}$ & Benders-base branch-and-cut \\
\hline Adulyasak et al. (2014a) & Único & Único & $\operatorname{sim}$ & ML & Sim & Hom. & múltiplo & Sim & $\mathrm{H}$ & ALNS \\
\hline Adulyasak et al. (2014b) & Único & Múltiplo & $\operatorname{sim}$ & ML & Sim & Hom. & múltiplo & Sim & $\mathrm{E} / \mathrm{H}$ & Branch-and-cut / ALNS \\
\hline Adulyasak et al. (2015) & - & - & - & - & - & - & - & - & - & Revisão da Literatura \\
\hline Absi et al. (2014) & Único & Único & não & ML & Sim & Hom. & múltiplo & Sim & $\mathrm{H}$ & Interative MIP heuristic \\
\hline Kumar et al. (2016) & Único & Único & $\operatorname{sim}$ & ML/OU & Sim & Hom. & múltiplo & Sim & $\mathrm{H}$ & NSGA-II \\
\hline Brahimi e Aouam (2016) & Único & Múltiplo & $\operatorname{sim}$ & OU & Sim & Hom. & múltiplo & Sim & $\mathrm{H}$ & HRF e Relax-and-fix heuristic \\
\hline Miranda et al. (2017) & Único & Múltiplo & $\operatorname{sim}$ & ML & Não & Hom. & limitado & Sim & $\mathrm{H}$ & MIP-Based heuristic \\
\hline Qiu et al. (2017) & Único & Único & $\operatorname{sim}$ & ML & Sim & Hom. & múltiplo & Sim & $\mathrm{E}$ & Branch-and-price \\
\hline Zhang et al. (2017) & Único & Múltiplo & $\operatorname{sim}$ & ML & Não & Hom. & limitado & Sim & $\mathrm{H}$ & MILP-based heuristic \\
\hline
\end{tabular}




\subsection{2}

\section{Inventory Routing Problem With Transshipment}

O autor Shen et al. (2011) foi quem introduziu primeiro modelo de IRP com transbordo (IRPT) na literatura, seu modelo foi aplicado em um estudo de caso em transporte de petróleo bruto, no qual o petróleo bruto é transportado de um centro de abastecimento para múltiplos portos de clientes para satisfazer suas demandas em vários períodos. Shen et al. (2011) considerou em seu estudo múltiplos modos de transporte, uma frota heterogênea de petroleiros (navios). Para a resolução do problema o mesmo utilizou Multiplicadores de Lagrange e a aplicou uma heurística. Tal problema por ser tratar de roteirização de navios tem algumas especificidades diferentes do IRP clássico para veículos.

Coelho et al. (2012c) posteriormente introduziu um modelo de IRP com transbordo nas variações do IRP para veículos. Tal modelo considerava decisões de transbordo planejadas dentro de um quadro determinista como forma de reduzir os custos de distribuição. O autor também propôs algumas instâncias para o problema. O modelo de IRPT de Coelho et al., (2012c) está descrito abaixo, porém para uma frota e não apenas para um veículo.

$$
\begin{array}{cl}
\operatorname{Min} \sum_{t \in T} I_{0}^{t} h_{0}+\sum_{i \in V} \sum_{t \in T} I_{i}^{t} h_{i}+\sum_{i \in V} \sum_{j \in V, i<j} \sum_{k \in K} \sum_{t \in T} x_{i j}^{k t} c_{i j} & \\
+\sum_{i \in V} \sum_{j \in V} \sum_{t \in T} \beta_{i j}^{k t} b_{i j} & \\
I_{0}^{t}=I_{0}^{t-1}+r^{t}-\sum_{i} \sum_{k} q_{i}^{k t}-\sum_{i} \sum_{k} \beta_{0 i}^{k t} & \forall t \in T \\
I_{0}^{t} \geq 0 & \forall t \in T \\
I_{i}^{t}=+I_{i}^{t-1}+\sum_{k} q_{i}^{k t}+\sum_{j} \sum_{k} \beta_{j i}^{k t}-d_{i}^{t} & \forall i \in V, t \in T \\
-\sum_{j} \sum_{k} \beta_{i j}^{k t-1} &
\end{array}
$$

$I_{i}^{t} \geq 0$

$\forall t \in T$

$I_{i}^{t} \leq C_{i}$

$\forall i \in V, t \in T$ 


$$
\begin{aligned}
& \sum_{k} q_{i}^{k t}+\sum_{j} \sum_{k} \beta_{i j}^{k t-1} \leq C_{i}-I_{i}^{t-1} \\
& \forall i \in V, t \in T \\
& \sum_{k} q_{i}^{k t} \leq \sum_{j} \sum_{k} x_{i j}^{k t} C_{i} \\
& \sum_{i} q_{i}^{k t} \leq Q_{k} \\
& q_{i}^{k t} \leq y_{i}^{k t} C_{i} \\
& \forall i \in V, t \in T \\
& \sum_{i} x_{i j}^{k t}=y_{i}^{k t} \\
& \forall i \in V, k \\
& \in K, t \in T \\
& \sum_{j} x_{0 j}^{k t} \leq 1 \\
& \forall k \in K, t \in T \\
& w_{i j}^{k t}-w_{j i}^{k t}+Q_{k} x_{i j}^{k t} \leq Q_{k}-q_{i}^{k t} \\
& \forall i, j \in V, k \\
& \in K, t \in T \\
& q_{i}^{k t} \leq w_{i j}^{k t} \leq C_{k} \\
& \forall i, j \in V, k \\
& \in K, t \in T \\
& q_{i}^{k t} \text { e } I_{i}^{t} \geq 0 \\
& \forall i \in V, k \\
& \in K, t \in T \\
& x_{i j}^{k t} \text { e } y_{i}^{k t} \in\{0,1\} \\
& \forall i, j \in V, k \\
& \in K, t \in T
\end{aligned}
$$

A função (2.58) minimiza os custos de estoques do $\mathrm{CD}$, o custo de estoques do cliente e o custo total de transporte e transbordos. As equações (2.59) fazem o balanceamento de estoque do $\mathrm{CD}$, as inequações (2.60) evitam que este estoque assuma valores negativos. A equação (2.61) realiza o balanceamento dos estoques nos clientes. As inequações (2.62) asseguram que os estoques dos produtos no cliente não assumam valores negativos. As restrições (2.63) asseguram que a quantidade de estoque em cada cliente não exceda a capacidade do mesmo. As inequações (2.64) e (2.65) garantem que a quantidade entregue a cada cliente não exceda a capacidade do cliente. As inequações (2.66) asseguram que o total de produtos transportados pelo veículo $\mathrm{k}$ não exceda a capacidade do veículo. A restrição (2.67) decide quais clientes serão visitados no período t. As equações (2.68) garantem a continuidade de fluxo dos veículos. As restrições (2.69) 
certificam-se que cada cliente seja visitado por apenas um veículo em t. As restrições (2.70) e (2.71) asseguram a não ocorrência de subciclos. As inequações (2.72) garantem a não negatividade das variáveis de decisão de estoques e quantidade transportada. As restrições (2.73) obrigam que as variáveis de decisão de rota e de visitar ou não os clientes sejam binárias.

Coelho et al. (2012b) voltou a abordar o tema de transbordo por duas vezes a segunda foi em seu trabalho sobre Dynamic Stochastic Inventory-Routing, no qual o autor tratou o transbordo como uma maneira de mitigar rupturas quando a demanda excede o estoque disponível. Afirmando que os transbordos de emergência podem ser uma excelente opção para diminuir consideravelmente as faltas de estoques, e reduzindo significativamente os custos de distribuição. Coelho e Laporte (2013b) abordaram o tema novamente o IRPT, em seu trabalho que propôs um método exato de resolução para diversas variações do IRP sendo uma delas o IRPT. Outros autores também abordaram o transbordo no contexto do IRP vide Jemai et al. (2013) e Azadeh et al. (2017).

\subsection{3}

\section{The Consistent Inventory Routing Problem}

Tal variação ganha um grande destaque por tratar da prática e implementação dos resultados gerados por modelos de otimização (no caso do IRP) que muitas das vezes, mesmo sendo economicamente o mais viável, deixa explícito que o modelo não incorpora situações práticas das operações.

Dado a importância do assunto diversos autores que abordam o tema do IRP “Consistente" ou "Compatível”, Coelho et al. (2013c) explica o problema dizendo que algumas vezes o resultado gerado pelo o modelo de IRP (melhor solução econômica) pode resultar em alguns inconvenientes tanto para os clientes como para os fornecedores. Um exemplo de solução inconveniente para o fornecedor, segundo o autor, é que pode ser a solução com menor custo fazer entregas com um mix de veículos quase cheios e quase vazios, o que causa balanceamento de carga inadequado que resulta em irritação de alguns motoristas que terminam por ser mais exigidos no serviço. Outro exemplo, agora um pouco desfavorável para o cliente dessa vez é quando ocorrem entregas muito pequenas em dias consecutivos, seguido de uma entrega muito grande, após o qual o cliente não é visitado por um longo período. 
Coelho et al. (2013c) afirma que é possível mitigar alguns desses problemas, adicionando algumas restrições como já realizado antes em alguns casos de VRP, vide Barlett e Ghoshal (2002); Zhong et al. (2007).

Beamon (1999) fez um estudo sobre performance na cadeia de suprimentos o qual abordava flexibilidade em entregas. Neste estudo ele propôs um modelo que controla as quantidades entregues aos clientes a fim de evitar grandes variações ao longo do tempo, que segundo o autor são percebidas de forma negativa pelos clientes. Ohlmann et al. (2008) apresenta um modelo que assegura a consistência em relação aos espaçamentos de entregas aos clientes.

Coelho et al. (2012a) propôs o modelo mais completo existente na literatura que assegura soluções compatíveis em relação a três aspectos diferentes: tamanho de entrega, frequência de entregas e gestão da mão de obra. Posteriormente Coelho e Laporte (2013a) propuseram um algoritmo exato para a resolução do Consitent IRP, e Coelho e Laporte (2013b) propuseram um branch-and-cut para a resolução do Consistent MMIRP.

\subsection{4}

\section{Stochastic Inventory Routing Problem}

Coelho et al. (2013c) em sua pesquisa explica que no Stochastic Inventory Routing Problem (SIRP), o fornecedor conhece uma probabilidade associada a demanda do cliente. $\mathrm{O}$ autor diz que quando referisse a demanda estocástica inferese que podem ocorrer rupturas no estoque. De modo que para evitar ou desencorajar que isso ocorra existe, uma penalidade que é imposta sempre que um cliente fica sem estoque, tal penalidade geralmente é ponderada através de uma proporção de venda perdida.

O objetivo do SIRP, assim como no problema determinista, ainda é a minimização de custos, mas agora o modelo incorpora a incerteza inerente a demanda, ou custos de eventuais faltas de estoques, ou possível custo de entrega atrasada dependendo do caso. O fornecedor também deve definir políticas de entrega para tratar da incerteza de parâmetros futuros estocásticos e desconhecidos, tais problemas são abordados na literatura com um horizonte de planejamento finito ou infinito. 
As primeiras aplicações do SIRP surgem na indústria de petróleo e gás nos quais a incerteza da industrial é demasiada, vide Federgruen e Zipkin (1984); Trudeau e Dror (1992) e Bard et al. (1998).

A maior parte da literatura aborda o problema com heurísticas e horizonte finito, vide Golden et al. (1984); Federgruen et al. (1986); Bard et al. (1998); Jaillet et al. (2002); Li (2007); Liu e Lee (2011); Vonolfen et al. (2013); Bertazzi et al. (2013) e Nolz et al. (2014a e 2014b).

Outros trabalhos trataram com horizontes infinitos, utilizando-se heurísticas: Minkoff (1993); Campbell et al. (1998); Qu et al. (1999); Berman e Larson (2001); Kleywegt et al. (2002, 2004); Adelman (2004); Hvattum e Løkketangen (2009); Hvattum et al. (2009) e Huang e Lin (2010);

Pode-se encontrar na literatura a abordagem com Otimização Robusta para lidar com a incerteza, Aghezzaf (2008) utilizou deste método para trabalhar um problema com horizonte infinito, o autor usou de simulação de Monte Carlo e outras técnicas. Outra abordagem por meio de Otimização robusta foi a de Solyali et al. (2012) que propôs um método exato para o SIRP.

\subsection{5}

\section{Dynamic and Stochastic Inventory-Routing Problem}

No Dynamic and Stochastic Inventory-Routing Problem (DIRP) a demanda do cliente é descoberta gradualmente ao longo dos períodos (Bertazzi et al., 2013 e Coelho et al., 2013c), na maioria dos casos no final de cada período. Destarte é necessário resolver o problema repetidamente com a nova informação agora revelada. No IRP dinâmico e estocástico (DSIRP), tem-se a informação da probabilidade da demanda, e a demanda vai sendo descoberta ao longo do tempo (Coelho et al., 2013c). Algumas soluções para esse problema NP-Difícil vem sendo estudas e propostas veja Psaraftis (1998); Ghiani et al. (2003); Berbeglia et al. (2010).

Coelho et al. (2012b) e Bertazzi et al. (2013) propuseram novos métodos de solução para lidar com DSIRP. O artigo de Bertazzi et al. (2013) propõe uma heurística e os autores usam uma abordagem de geração cenários de demanda para o período corrente e para as demandas dos períodos futuros utiliza uma média. $\mathrm{O}$ autor considerou em seu estudo a política de OU, utilizou também geração de 
cortes, seu algoritmo resolveu instâncias com até 35 clientes e três períodos, 15 clientes e seis períodos, e 10 clientes e nove períodos.

Coelho et al. (2012b) expos um método diferente, eles utilizaram um histórico de dados baseado em previsões para lidar com a incerteza, destarte em casos em que a demanda apresenta uma tendência ou sazonalidade o problema é resolvido de forma eficiente. A heurística proposta pelo autor considerou um horizonte de tempo dinâmico e políticas OU e ML, o algoritmo chegou a resolver instancias de 200 clientes e 20 períodos.

Os trabalhos de DSIRP mais recentes sobre o DSIRP são os de Coelho et al. (2014) e de Roldán et al. (2016), Coelho et al. (2014) propôs diferentes políticas heurísticas para lidar com DSIRP, os autores geravam instâncias aleatoriamente para comparar as políticas heurísticas propostas. Neste estudo os autores adicionaram restrições de consistência ao DSIRP, implementando o consistente DSIRP, mostrando que este ao longo do tempo aumenta o custo das soluções mais do que em uma configuração de um problema estático.

A pesquisa de Roldán et al. (2016) desenvolveu políticas adaptativas para selecionar clientes a serem reabastecidos em cada período. As políticas que os autores propuseram foram: prioridade aos grandes pedidos, clientes com menor capacidade de armazenamento, e clientes com desconto de quantidade igual. Cada uma dessas políticas constrói um subconjunto diferente de clientes para serem atendidos em cada período. Em comparação com alguns outros resultados de soluções do DSIRP da literatura o algoritmo dos autores trouxe economias significativas.

\subsection{6}

\section{Meta-heurísticas para o IRP}

As primeiras heurísticas para o problema de IRP utilizavam de muitas aproximações e desconsideravam alguns fatores, como por exemplo no trabalho de Dror et al. (1985), que desconsiderou os custos de transporte para resolver o problema.

Atualmente o problema é abordado com algoritmos mais inteligentes que buscam resultados de elevada qualidade, tais como meta-heurísticas, que têm capacidade de fugir de ótimos locais através de buscas inteligentes no espaço solução. 
Ribeiro e Lourenço (2003) propõe para a resolução do IRP a meta-heurística Iterated Local Search (ILS) tanto para demanda determinística quanto para estocástica.

Mjirda et al. (2012) propôs uma meta-heurística para o IRP baseada em variable neighborhood search (VNS). Seu algoritmo era dividido em duas fases, na qual a primeira utilizava o VNS como um método de inserção para criar uma solução inicial. Nesta fase inicial a meta-heurística utiliza apenas vizinhanças de VRP e com isso otimiza apenas os custos de transporte do IRP. Na segunda fase, o algoritmo o otimiza os custos de estoque e transporte simultaneamente.

Zhang et al. (2014) apresentou uma meta-heurística híbrida para o IRP com múltiplos depósitos. O algoritmo era composto de duas etapas, a primeira era a inserção de quais depósitos seriam usados para o atendimento dos clientes. A segunda etapa era composta da meta-heurística Tabu Search (TS) para o problema de roteirização, e um MIP para o problema de gestão de estoques.

Coelho (2012c) propôs uma meta-heurística para o IRP, MIRP, IRPT e MIRPT. O autor utiliza Descida em Vizinhança Variável Aleatória (Random Variable Neighborhood Descent - RVND) e quando o algoritmo encontra um ótimo local e os movimentos de melhoria não são permitidos é utilizado Simulated Annealing (SA) como critério de aceitação de soluções. $\mathrm{O}$ autor utiliza buscas nas vizinhanças, sendo um total de 12 vizinhanças.

Archetti et al. (2012) propôs uma heurística híbrida para o IRP usando a metaheurística TS aliada a dois MIPS para as políticas de ML e OU. A autora nomeou a meta-heurística de HAIR (Hybrid Approach to Inventory Routing). O primeiro MIP recebe os resultados do TS então o MIP executa trocas das rotas entre os períodos sem alterar a rota apenas o período que esta se encontra. O segundo MIP faz remoção e inserção de clientes nas rotas.

Guemri et al. (2016) apresentou uma meta-heurística para o IRP baseada na meta-heurística GRASP (Greedy Randomized Adaptive Search Procedure) o qual o mesmo nomeou de GRASP-based heuristic (GBH). Cada iteração da metaheurística tinha duas fases, a primeira era o GRASP sem a busca local e a segunda fase os autores utilizavam a meta-heurística TS até que o critério da busca fosse atendido.

O autor Santos (2014) propôs uma heurística híbrida em duas fases utilizando na primeira fase o ILS aliado ao RVND em suas buas locais para o problema de 
transporte e na segunda fase para o problema de estoques eles utilizavam um algoritmo exato. Os autores primeiramente tratavam o problema para um período e iniciando com uma heurística construtiva com estratégia de fugir da inviabilidade no problema de estoque, mas também levando em consideração os custos de transporte tendo critério para inserção e remoção de clientes na rota. Posteriormente os autores inicializavam o ILS juntamente com RVND, então encerrasse a primeira fase. Na segunda fase o autor utiliza de programação linear para resolver o problema de estoques considerando os inputs da primeira fase.

Archetti et al. (2017) apresenta novamente uma heurística híbrida para o IRP e para o MIRP. O algoritmo proposto pelos autores tem três fases: geração da solução inicial, Busca tabu e Melhoria da solução. As fases 1 e 3 são MIPS e a 2 é meta-heurística TS mencionada anteriormente. Atualmente esta meta-heurística é a que apresenta os melhores resultados da literatura para as instâncias largest.

Peres et al. (2017) introduz na literatura uma nova meta-heurística híbrida para IRP, MIRP, IRPT e MIRPT que se baseia em buscas nas vizinhanças para o problema de roteamento e no algoritmo simplex na rede para o problema de estoques. Os autores modelam o problema de estoques como se fosse um fluxo máximo a custo mínimo e assim aplica o algoritmo de otimalidade, desse modo a cada iteração são realizados os movimentos indicados pelas buscas locais para melhorar o custo de roteirização e, então é realizado a aplicação do algoritmo simplex na rede para encontrar o ótimo custo de estoque para aquela roteirização indicada. Inspirado Coelho et al. (2012c) o algoritmo proposto também utiliza o RVND e SA como critério para aceitação de soluções, visando fugir de ótimos locais quando uma solução melhor é encontrada durante a busca, o RVND é reiniciado. O algoritmo foi aplicado em uma indústria de varejo no Brasil, porém não foi testado em instâncias clássicas.

A meta-heurística proposta nesta dissertação se inspira no trabalho de Peres et al. (2017) no que diz respeito ao algoritmo ótimo de fluxo máximo a custo mínimo para o problema de estoque. 


\section{3 \\ Formulação para o Problema de Roteirização MultiVeículos com a Opção de Estoques}

O objetivo deste capítulo é expor e detalhar o modelo matemático de IRP que foi desenvolvido. A Seção 3.1 trata da caracterização do problema estudado e expõe detalhadamente a formulação do modelo explicando as restrições, e suas respectivas funções. Na Seção 3.2 é apresentada a validação do modelo. Finalizando o capítulo, a Seção 3.3 contém o cronograma de atividades do projeto e atividades futuras.

\section{1}

\section{Caracterização do Problema e Formulação do Modelo}

De maneira geral, o objetivo da elaboração do modelo e desta pesquisa é generalizar mais o IRP, já que em muitos contextos de sistemas de VMI o fornecedor tem clientes que não fazem parte do sistema. Neste caso as roteirizações são realizadas separadamente alcançando possivelmente um resultado subótimo. Realizar a roteirização para ambos os tipos de clientes possivelmente causará impactos tanto na roteirização tanto quanto nos estoques e nível de serviço prestado aos clientes. Em outras palavras, este trabalho busca comprovar os ganhos de integrar as duas roteirizações através deste modelo híbrido. A seguir a definição formal do problema.

Dado um grafo completo e orientado $\mathrm{G}=(\mathrm{V}, \mathrm{A})$ de modo que o conjunto de vértices e o conjunto de arcos são definido respectivamente por $\mathrm{V}=\{0, \ldots, \mathrm{n}\}$ e $\mathrm{A}=$ $\{(\mathrm{i}, \mathrm{j}) \in \mathrm{V}, \mathrm{i} \neq \mathrm{j}\}$. O conjunto de vértices $\mathrm{V}^{\prime}=\mathrm{V} \backslash 0$ representa os clientes. Tal conjunto é dividido em outros três subconjuntos (C; E; D) sendo C para os clientes pertencentes ao sistema de VMI(IRP) e E clientes fora do sistema associados ao problema de VRP. O subconjunto D representa o centro de distribuição (CD). Os $\operatorname{arcos}(\mathrm{i}, \mathrm{j}) \in$ A possuem um custo $c_{i j}>0$. Existe um horizonte $\mathrm{T}=\{0, \ldots, \mathrm{p}\}$ no qual os clientes $i$ têm demanda $d_{i}^{t}, \mathrm{t} \in T$. Existe um custo de manutenção de estoque $h_{c}$ e uma capacidade de estocagem $C_{c}$ para os clientes do subconjunto C (VMI). Uma frota heterogênea de $k$ veículos, $\mathrm{K}=\{1, \ldots, \mathrm{k}\}$, com capacidade $Q_{k}$ está disponível no 
CD. O fornecedor deve escolher em qual período $t$ será atendida a demanda do cliente c a uma quantidade $q_{i}^{k t}$. O fornecedor deve atender a demanda do cliente. Cada veículo $k$ faz uma única rota em cada período $\mathrm{T}$, visitando um certo número de clientes. As variáveis estão descritas abaixo. Utilizou-se a notação de Coelho et al. (2013).

Tabela 3 - Conjuntos e índices do Modelo. Fonte: Autor. (2017).

\begin{tabular}{lcc}
\hline Conjuntos & Conjuntos & Índices \\
\hline Clientes IRP & $\mathrm{C}$ & $\mathrm{c}$ \\
Clientes VRP & $\mathrm{E}$ & $\mathrm{e}$ \\
$\mathrm{CD}$ & $\mathrm{D}$ & $\mathrm{d}$ \\
Nós & $\mathrm{V}$ & $\mathrm{i}, \mathrm{j}$ \\
Veículos & $\mathrm{K}$ & $\mathrm{k}$ \\
\hline
\end{tabular}

Tabela 4 - Parâmetros do Modelo. Fonte: Autor. (2017).

\begin{tabular}{cl}
\hline Parâmetros & \multicolumn{1}{c}{ Descrição } \\
\hline$h_{i}$ & Custo de estoque por unidade no cliente i \\
$c a_{i j}$ & Custo da aresta i,j \\
$d_{i}^{t}$ & Demanda do cliente i no período t \\
$L_{c}$ & Capacidade de armazenagem do cliente c \\
$Q_{k}$ & Capacidade de transporte do veículo k \\
\hline
\end{tabular}

Tabela 5 - Variáveis do Modelo. Fonte: Autor. (2017)

\begin{tabular}{clc}
\hline Variáveis & \multicolumn{1}{c}{ Descrição } & Domínio \\
\hline$x_{i j}^{k t}$ & 1 se o arco $(\mathrm{i}, \mathrm{j})$ é percorrido no período t pelo veículo k senão 0 & $\{0 ; 1\}$ \\
$y_{i}^{k t}$ & $\begin{array}{l}\text { 1 se o cliente i for visitado pelo veículo k no período t e 0 caso } \\
\text { contrário }\end{array}$ & $\{0 ; 1\}$ \\
$I_{i}^{t}$ & Nível de estoque do cliente i no final do período t & $Z^{+}$ \\
$q_{i}^{k t}$ & Quantidade transportada para o cliente i no período t pelo veículo k & $Z^{+}$ \\
$r^{t}$ & Decisão de compra de itens para ressuprimeto do CD no período t & $Z^{+}$ \\
$w_{i j}^{k t}$ & Fluxo para j a partir i no período t, com veículo k & $Z^{+}$ \\
\hline
\end{tabular}

A seguir a formulação do modelo proposto:

$\operatorname{Min} \sum_{i \in D} \sum_{t \in T} I_{d}^{t} h_{d}+\sum_{i \in C} \sum_{t \in T} I_{c}^{t} h_{c}+\sum_{i \in C} \sum_{j \in C} \sum_{k \in K} \sum_{t \in T} x_{i j}^{k t} c a_{i j}$ 
$\sum_{k} y_{e}^{k t}=1$

$\sum_{k} q_{e}^{k t}=d_{e}^{t}$

$q_{e}^{k t} \leq y_{e}^{k t} d_{e}^{t}$

$I_{e}^{t}=0$

$I_{d}^{t}=I_{d}^{t-1}+r^{t}-\sum_{j} \sum_{k} q_{j}^{k t}$

$I_{c}^{t}=I_{c}^{t-1}+\sum_{k} q_{c}^{k t}-d_{c}^{t}$

$\sum_{k} q_{c}^{k t} \leq L_{c}-I_{c}^{t-1}$

$\sum_{i} q_{i}^{k t} \leq Q_{k}$

$q_{c}^{k t} \leq y_{c}^{k t} L_{c}$

$\sum_{j} x_{i j}^{k t}=y_{i}^{k t}$

$\sum_{j} x_{d j}^{k t} \leq 1$

$\sum_{k} y_{c}^{k t} \leq 1$

$w_{i j}^{k t}-w_{j i}^{k t}+L_{i} x_{i j}^{k t} \leq L_{j}-q_{i}^{k t}$

$q_{i}^{k t} \leq w_{i j}^{k t} \leq L_{i}$

$q_{d}^{k t}=0$

$q_{i}^{k t} e I_{i}^{t} \geq 0$

$x_{c j}^{k t}$ e $y_{c}^{k t} \in\{0,1\}$ $\forall i \in E, t \in T \mid d_{e}^{t}>0$

$\forall i \in E, t \in T \mid d_{e}^{t}>0$

$\forall i \in E, k \in K, t \in T$

$\forall i \in E, t \in T$

$\forall i \in D, t \in T$

$\forall i \in C, t \in T$

$\forall i \in C, t \in T$

$\forall k \in K, t \in T$

$\forall c \in V, k \in K, t \in T$

$\forall i \in V, k \in K, t \in T$

$\forall k \in K, t \in T, d \in D$

$\forall i \in C, t \in T$

$\forall i, j \in V, k \in K, t \in T$

$\forall i, j \in V, k \in K, t \in T$

$\forall i \in D, k \in K, t \in T$

$\forall i \in V, k \in K, t \in T$

$\forall c, j \in V, k \in K, t \in T$ 
A função (3.1) tem o objetivo de minimizar os custos de estoques do CD, o custo de estoques do cliente e o custo total de transporte para todos os clientes. As equações (3.2) asseguram que todo o cliente do conjunto "E" que são os clientes fora do sistema de VMI sejam visitados desde que estes tenham demanda no período. As equações (3.3) fazem com que a quantidade transportada para os clientes do conjunto "E" seja igual a demanda do cliente. As inequações (3.4) associam a quantidade transportada a cada cliente do conjunto "E" a sua própria demanda, evitando que ocorra quantidade transportada sem haver demanda. As restrições (3.5) fazem com que as variáveis de estoques para os clientes do conjunto “E” assumam valores iguais a zero. As restrições (3.6) fazem o balanceamento de estoque do $\mathrm{CD}$, as equações (3.7) realizam o balanceamento dos estoques dos clientes do conjunto " $\mathrm{C}$ ”. As inequações (3.8) asseguram que a quantidade de estoque em cada cliente do conjunto "C" não exceda a capacidade do mesmo. As inequações (3.9) asseguram que o total de produtos transportados pelo veículo $\mathrm{k}$ não exceda a capacidade do veículo. As restrições (3.10) decidem quais clientes do conjunto "C" serão visitados no período t. As equações (3.11) e (3.12) garantem a continuidade de fluxo dos veículos. As restrição (3.13) certificam-se que cada cliente do conjunto " $C$ ” seja visitado por no máximo um veículo em t. As restrições (3.14) e (3.15) asseguram a não ocorrência de subciclos. As restrições (3.16) fazem com que não haja quantidade transportada para o próprio CD. As inequações (3.17) garantem a não negatividade das variáveis de decisão de estoques e quantidade transportada. As últimas restrições (3.18) obrigam que as variáveis de decisão de rota e de visitar ou não os clientes sejam binárias.

\section{2}

\section{Validação do Modelo}

Para validar o novo modelo proposto de IRP foram realizados 3 testes com o intuito de comprovar que o modelo atende simultaneamente problema de MIRP e MVRP. O primeiro teste foi realizado com duas instâncias de MIRP de Archetti et al. (2007) no qual o modelo chegou ao ótimo da literatura. O segundo teste foi realizado com duas instâncias de MVRP de Arenales et al. (2015), no qual o modelo também chegou ao ótimo da literatura. A seguir nos próximos testes (tabelas 10 e 11) realizaram-se as junções das 4 instâncias testadas para gerar mais duas instâncias com um mix dos dois problemas. 
Para todos os testes aqui realizados, de maneira exata, utilizou-se o software AIMMS e o solver CPLEX 12.6, e um computador Intel Core i3 1,7 Ghz e 4GB de memória RAM. Abaixo nas Tabelas $(6 ; 7 ; 8 ; 9 ; 10 ; 11)$ estão os detalhes das instâncias utilizadas para os testes.

Tabela 6 - Instâncias de MIRP abs1n5. Fonte: Archetti et al. (2007).

\begin{tabular}{ccccccc}
\hline Nós & $\mathrm{X}$ & $\mathrm{Y}$ & Capacidade & E.Inicial & Demanda & C.Estoque \\
\hline 0 & 154.0 & 417.0 & Ilimitado & 510 & 193 & 0.30 \\
1 & 172.0 & 334.0 & 195 & 130 & 65 & 0.23 \\
2 & 267.0 & 87.0 & 105 & 70 & 35 & 0.32 \\
3 & 148.0 & 433.0 & 116 & 58 & 58 & 0.33 \\
4 & 355.0 & 444.0 & 72 & 48 & 24 & 0.23 \\
5 & 38.0 & 152.0 & 22 & 11 & 11 & 0.18 \\
Veículos & 2 & Capacidade & 145 & Períodos & 3 & - \\
\hline
\end{tabular}

Tabela 7 - Instâncias de MIRP abs2n5. Fonte: Archetti et al. (2007).

\begin{tabular}{ccccccc}
\hline Nós & $\mathrm{X}$ & $\mathrm{Y}$ & Capacidade & E.Inicial & Demanda & C.Estoque \\
\hline 0 & 309.0 & 334.0 & Ilimitado & 462 & 158 & 0.30 \\
1 & 345.0 & 168.0 & 93 & 62 & 31 & 0.35 \\
2 & 34.0 & 174.0 & 180 & 120 & 60 & 0.14 \\
3 & 297.0 & 367.0 & 51 & 34 & 17 & 0.17 \\
4 & 211.0 & 389.0 & 114 & 76 & 38 & 0.36 \\
5 & 76.0 & 304.0 & 24 & 12 & 12 & 0.25 \\
Veículos & 2 & Capacidade & 119 & Períodos & 3 & - \\
\hline
\end{tabular}

Tabela 8 - Instâncias de MVRP dois veículos. Fonte: Arenales et al. (2015).

\begin{tabular}{ccccccccccc}
\hline Nós & 0 & 1 & 2 & 3 & 4 & 5 & 6 & 7 & 8 & 9 \\
\hline $\mathrm{X}$ & 50 & 16 & 23 & 40 & 9 & 97 & 78 & 20 & 71 & 64 \\
$\mathrm{Y}$ & 50 & 32 & 1 & 65 & 77 & 71 & 24 & 26 & 98 & 55 \\
Demanda & 107 & 11 & 35 & 2 & 9 & 3 & 18 & 8 & 10 & 11 \\
Veículos & 2 & Capacidades & 54 e 53 & Períodos & 1 & & & & & \\
\hline
\end{tabular}

Tabela 9 - Instâncias de MVRP três veículos. Fonte: Arenales et al. (2015).

\begin{tabular}{ccccccccccc}
\hline Nós & 0 & 1 & 2 & 3 & 4 & 5 & 6 & 7 & 8 & 9 \\
\hline $\mathrm{X}$ & 50 & 16 & 23 & 40 & 9 & 97 & 78 & 20 & 71 & 64 \\
$\mathrm{Y}$ & 50 & 32 & 1 & 65 & 77 & 71 & 24 & 26 & 98 & 55 \\
Demanda & 107 & 11 & 35 & 2 & 9 & 3 & 18 & 8 & 10 & 11 \\
Veículos & 3 & Capacidades & $54 ; 42$ e 11 & Períodos & 1 & & & & & \\
\hline
\end{tabular}


Tabela 10 - Instâncias do Modelo proposto 10 clientes. Fonte: Autor (2017).

\begin{tabular}{ccccccc}
\hline Nós & $\mathrm{X}$ & $\mathrm{Y}$ & Capacidade & E.Inicial & Demanda & C.Estoque \\
\hline 0 & 154.0 & 417.0 & Ilimitado & 510 & 193 & 0.3 \\
1 & 172.0 & 334.0 & 195 & 130 & 65 & 0.23 \\
2 & 267.0 & 87.0 & 105 & 70 & 35 & 0.32 \\
3 & 148.0 & 433.0 & 116 & 58 & 58 & 0.33 \\
4 & 355.0 & 444.0 & 72 & 48 & 24 & 0.23 \\
5 & 38.0 & 152.0 & 22 & 11 & 11 & 0.18 \\
6 & 16.0 & 32.0 & - & - & 11 & - \\
7 & 23.0 & 1.0 & - & - & 35 & - \\
8 & 40.0 & 65.0 & - & - & 2 & - \\
9 & 9.0 & 77.0 & - & - & 9 & - \\
10 & 97.0 & 71.0 & - & - & 3 & - \\
Veículos & 2 & Capacidades & 145 & Períodos & 3 & - \\
\hline
\end{tabular}

Tabela 11 - Instâncias do Modelo proposto 14 clientes. Fonte: Autor (2017).

\begin{tabular}{ccccccc}
\hline Nós & $\mathrm{X}$ & $\mathrm{Y}$ & Capacidade & E.Inicial & Demanda & C.Estoque \\
\hline 0 & 154.0 & 417.0 & Ilimitado & 510 & 193 & 0.3 \\
1 & 172.0 & 334.0 & 195 & 130 & 65 & 0.23 \\
2 & 267.0 & 87.0 & 105 & 70 & 35 & 0.32 \\
3 & 148.0 & 433.0 & 116 & 58 & 58 & 0.33 \\
4 & 355.0 & 444.0 & 72 & 48 & 24 & 0.23 \\
5 & 38.0 & 152.0 & 22 & 11 & 11 & 0.18 \\
6 & 16.0 & 32.0 & - & - & 11 & - \\
7 & 23.0 & 1.0 & - & - & 35 & - \\
8 & 40.0 & 65.0 & - & - & 2 & - \\
9 & 9.0 & 77.0 & - & - & 9 & - \\
10 & 97.0 & 71.0 & - & - & 3 & - \\
11 & 78 & 24 & - & - & 18 & - \\
12 & 20 & 26 & - & - & 8 & - \\
13 & 71 & 98 & - & - & 10 & - \\
14 & 64 & 55 & - & - & 11 & - \\
Veículos & 2 & Capacidades & 145 & Períodos & 3 & - \\
\hline
\end{tabular}




\section{4 \\ Uma Heurística Iterated Local Search para o Problema de Roteirização Multi-Veículos com Estoques}

Este capítulo descreve em detalhes a heurística utilizada para resolução do problema exposto. A Seção 4.1 descreve as estruturas de vizinhanças que foram exploradas para construção da solução inicial e pela Meta-heurística proposta. $\mathrm{Na}$ Seção 4.2 onde está exposto o subproblema de gestão de estoques utilizou-se o algoritmo Simplex na Rede para a resolução do problema de Fluxo Máximo a Custo Mínimo. Após isso na Seção 4.3 descreve-se o algoritmo de Descida em Vizinhança Variável Aleatória (Random Variable Neighborhood Descent - RVND). Por fim a Meta-heurística utilizada Iterated Local Search (ILS) para causar perturbações na solução inicial com intuito de melhorar a solução e fugir de ótimos locais e seguidas de buscas na vizinhança é descrita na Seção 4.4.

\section{1}

\section{Vizinhanças}

No IRP existem dois subproblemas que são a roteirização de veículos e a gestão de estoques. A roteirização será tratada por meio de buscas em um conjunto de possíveis soluções. A busca local consiste em uma procura por novas soluções vizinhas com intuito de melhorar o valor da função objetivo (solução atual). Essas soluções vizinhas são geradas através de movimentos e cada tipo de movimento é considerado uma estrutura de vizinhança. Desse modo também temos a busca na vizinhança que consiste em fazer vários tipos de movimentos com o mesmo propósito da busca local que é melhorar a função objetivo. Nos problemas de roteirização multiveículo existem vizinhanças inter-rota que são movimentos entre rotas distintas e intra-rota, que são movimentos na mesma rota. A Tabela 12 contém os índices que ainda não foram citados anteriormente e são utilizados nas descrições das estruturas de vizinhanças que foram exploradas. 
Tabela 12 - Indices das estruturas de vizinhança. Fonte: Autor. (2018).

\begin{tabular}{cl}
\hline Índices & \multicolumn{1}{c}{ Descrição } \\
\hline Pos & Posição na rota do veículo k no período t \\
$k_{1}$ & Veículo associado a $t_{1}$ e $P_{0 s_{1}}$ \\
$k_{2}$ & Veículo associado a $t_{2}$ e Pos $_{2}$ \\
$t_{1}$ & Período associado a $K_{1}$ e Pos $_{1}$ \\
$t_{2}$ & Período associado a $K_{2}$ e Pos $_{2}$ \\
$P_{o S_{1}}$ & Posição associada a $K_{1}$ e $t_{1}$ \\
$P_{o S_{2}}$ & Posição associada a $K_{2}$ e $t_{2}$ \\
$A_{i j}$ & Primeiro $A r c o_{i j}$ do veículo $k$ no período a ser retirado \\
$A_{i^{\prime} j^{\prime}}$ & Segundo $A r c o{ }_{i j}^{\prime} j^{\prime}$ do veículo $k$ no período a ser retirado \\
\hline
\end{tabular}

- INSERT (i,Pos, $k, t)$ : A vizinhança de Insert ou Inserir consiste em um movimento de inserir um cliente $i$, em uma determinada posição Pos, na rota do veículo $k$, no período $t$. É um movimento intra-rota. Na Figura 10 está ilustrado um exemplo do Insert. Sendo um movimento intra-rota.
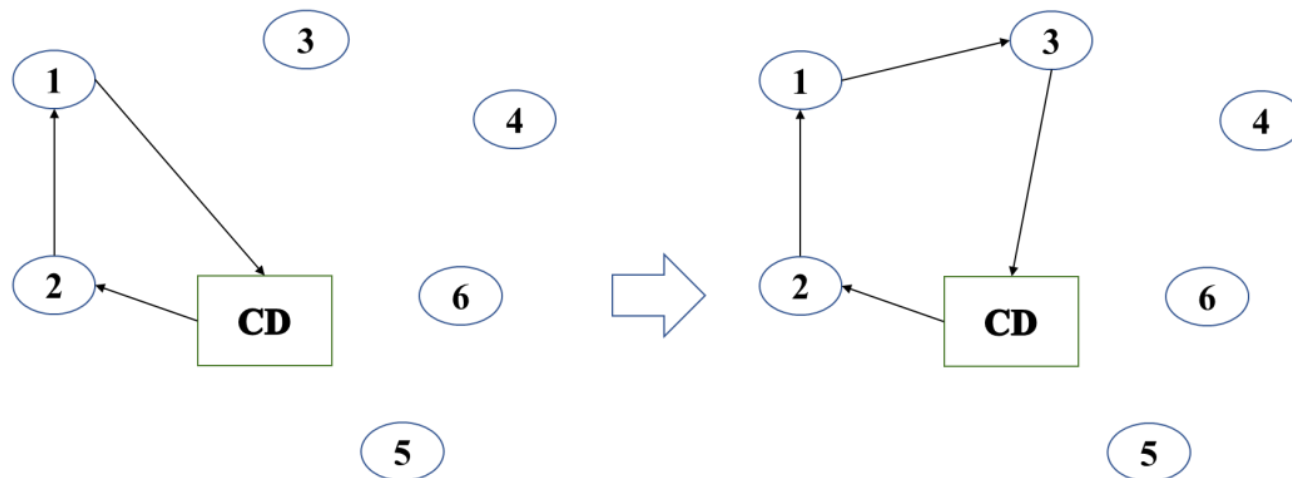

7
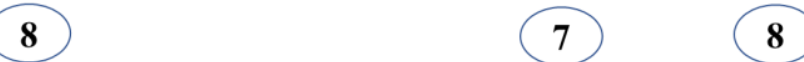

Figura 10 - Exemplo da estrutura de vizinhança Insert. Fonte: Autor (2018)

- REMOVE $(P o s, k, t)$ : Esta vizinhança é justamente o movimento inverso do Insert, de modo que ao invés de inserir, ela remove clientes da rota, a posição Pos da rota do veículo $k$ no período $t$. A Figura 11 contém um exemplo do Remove. Igualmente ao Insert é um movimento intra-rota. 


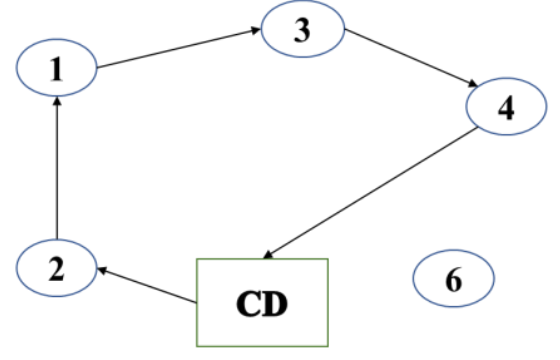

5

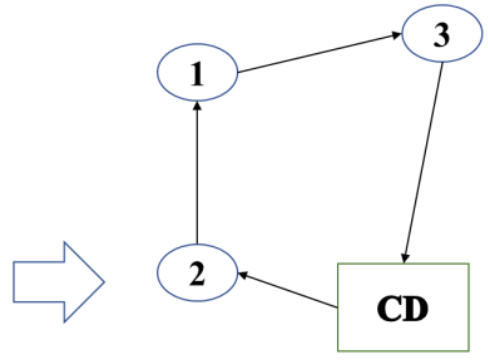

5

\section{7}

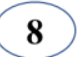

7

8

Figura 11 - Exemplo da estrutura de vizinhança Remove. Fonte: Autor (2018)

- SHIFT (Pos, $k, t)$ : Tal vizinhança é intra-rota e seu movimento é de mudar a posição de dois clientes sempre trocando o cliente da posição Pos pelo da posição Pos +1 rota do veículo $k$ no período $t$. Na Figura 12 abaixo está ilustrado um exemplo do Shift. Sendo um movimento intra-rota.

\section{3}
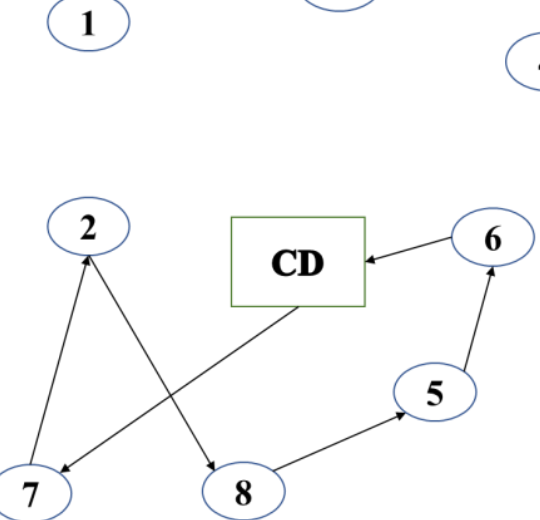

4

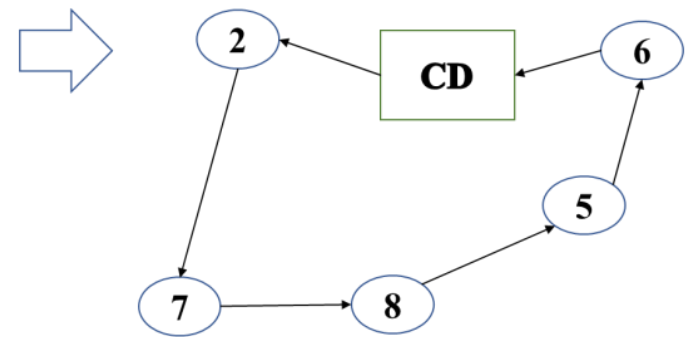

3

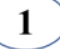

Figura 12 - Exemplo da estrutura de vizinhança Shift. Fonte: Autor (2018)

- SWAP $\left(\operatorname{Pos}_{1}, k_{1}, t_{1}, \operatorname{Pos}_{2}, k_{2}, t_{2}\right)$ : Nesta vizinhança os movimentos são realizados com a troca das posições entre clientes, sendo a troca do cliente na $P o s_{1}$ na rota de $k_{1}$ no período $t_{1}$, com o cliente na posição $P o s_{2}$ da rota $k_{2}$ no período $t_{2,}$. Podendo ser um movimento intra-rota ou inter-rota. A Figura 13 contém um exemplo do Swap. 


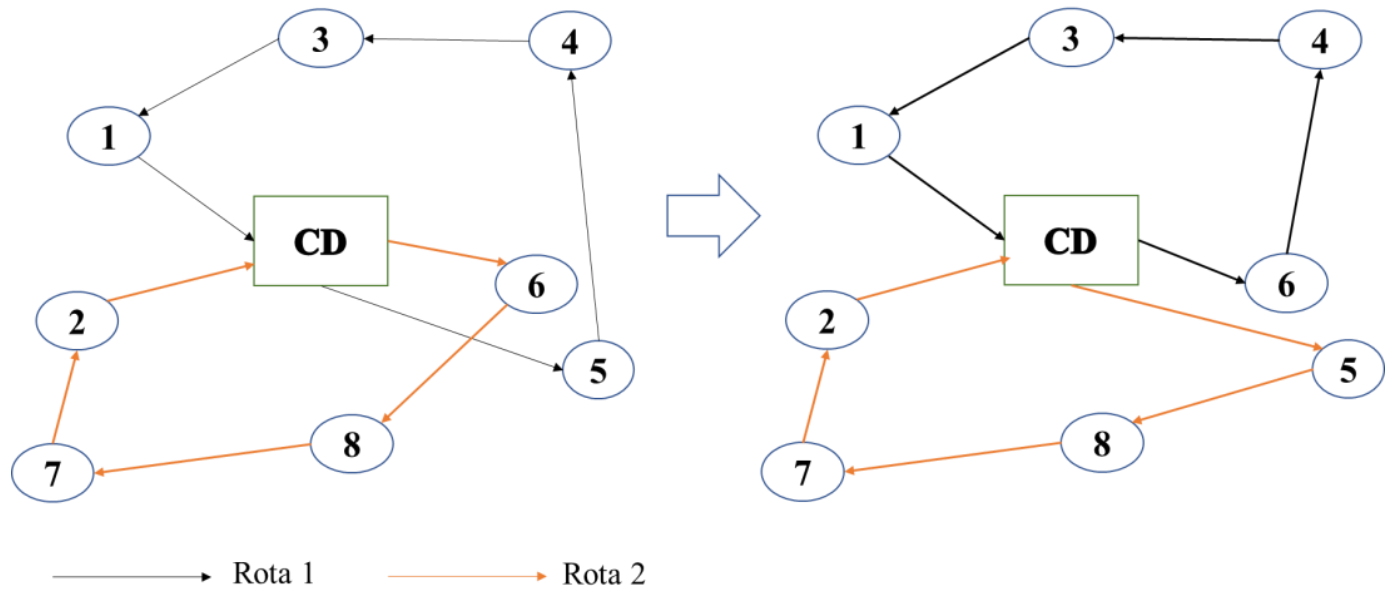

Figura 13 - Exemplo da estrutura de vizinhança Swap. Fonte: Autor (2018)

- RELOCATE $\left(\operatorname{Pos}_{1}, k_{1}, t_{1,}, \operatorname{Pos}_{2}, k_{2}, t_{2}\right)$ : Esta estrutura de vizinhança remove um cliente na posição $\operatorname{Pos}_{1}$ da rota de $k_{1}$ no período $t_{1}$, e insere o cliente

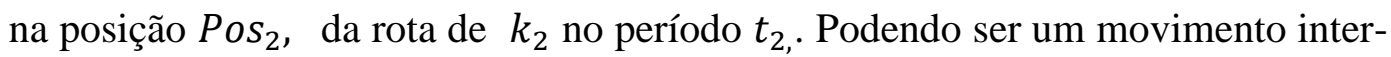
rota ou intra-rota. Na Figura 14 está ilustrado um exemplo do Relocate.
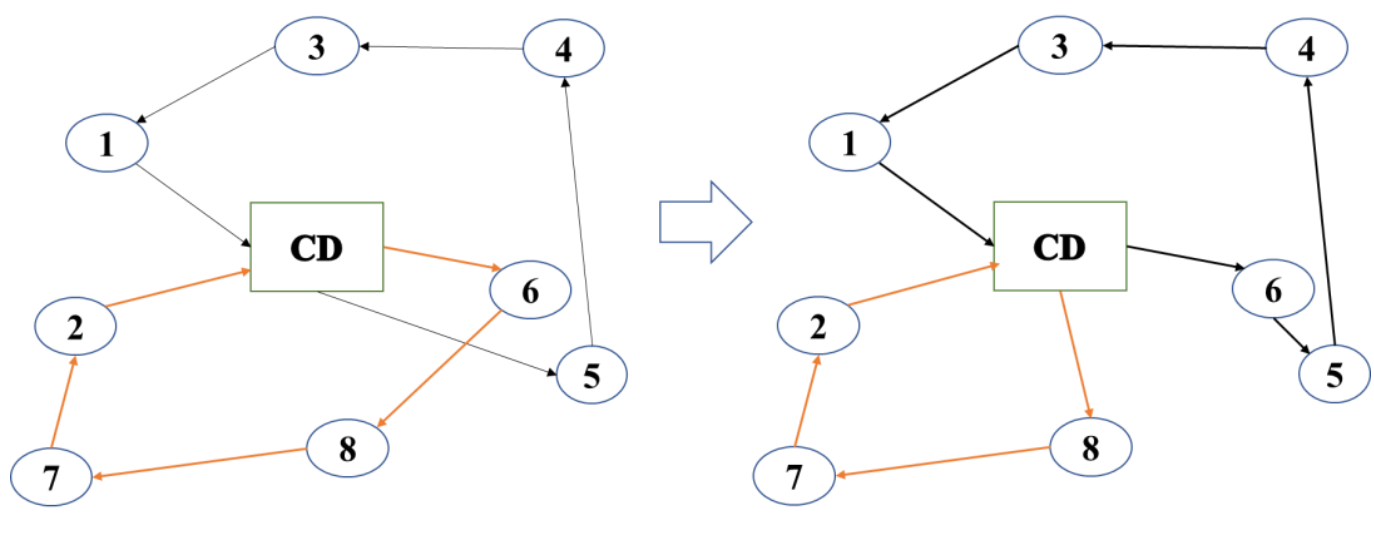

- Rota 1

Rota 2

Figura 14 - Exemplo da estrutura de vizinhança Relocate. Fonte: Autor (2018)

- 2-OPT $\left(A_{i j}, A_{i^{\prime} j^{\prime}}, k, t\right)$ : Esta é uma vizinhança intra-rota e seu movimento seleciona dois arcos da rota de $k$ do perído $t$ para serem removidos e insere dois novos arcos no lugar, trocando a posição dos clientes envolvidos. Desse modo seleciona um arco $(i, j)$ e um arco $\left(i^{\prime}, j^{\prime}\right)$ para serem substituídos pelos novos arcos $\left(i, i^{\prime}\right)$ e $\left(j, j^{\prime}\right)$. Sendo um movimento intra-rota. Na Figura 15 está ilustrado um exemplo do 2-opt. 

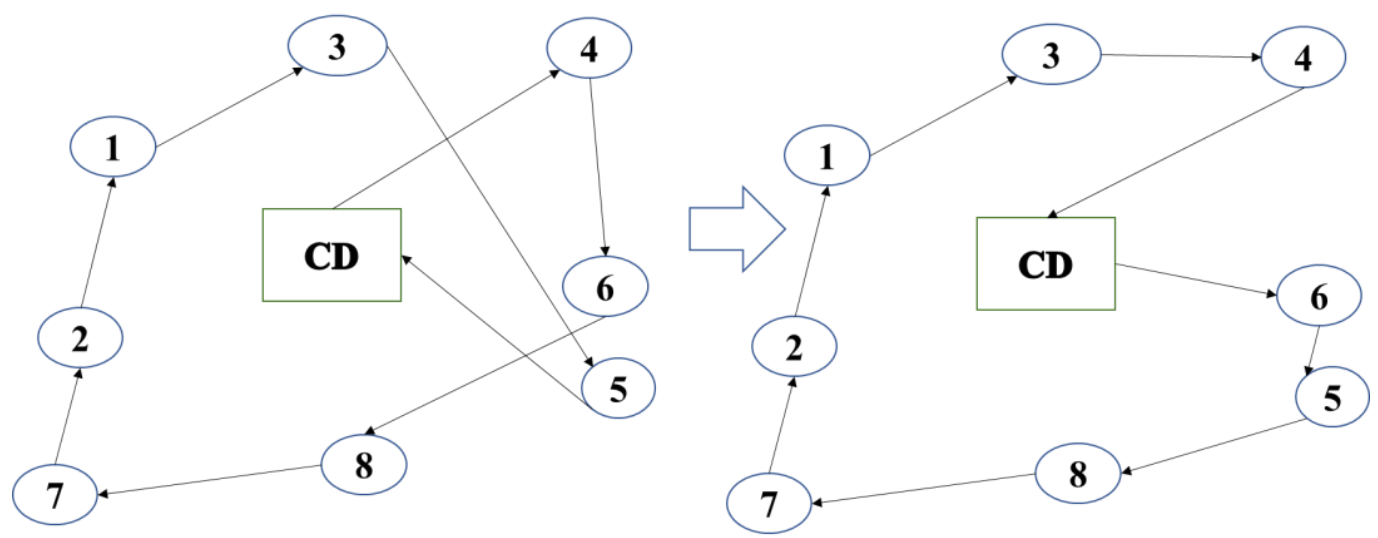

Figura 15 - Exemplo da estrutura de vizinhança 2opt. Fonte: Autor (2018)

\section{2}

\section{Fluxo Máximo a Custo Mínimo}

O subproblema de gestão de estoques com múltiplos períodos do IRP foi tratado como um problema de Fluxo Máximo a Custo Mínimo. O problema de Fluxo Máximo a Custo mínimo consiste em definir o maior valor de fluxo possível que pode ser enviado de um nó a outro em uma rede com o menor custo possível. Desse modo considerando o problema aplicado ao IRP um Grafo G (N, E), temos um vértice de origem (CD) com capacidade indeterminada de fluxo (produto) no período inicial. No qual temos dois tipos de arestas, o primeiro tipo está conectado novamente com o próprio vértice de origem $(\mathrm{CD})$ que está localizado no $t+1$. Isso se repete até o fim dos períodos do problema em questão de modo que o último vértice é fictício criado apenas para destinação final dos fluxos. O outro tipo de aresta que está ligada ao vértice de origem faz a conexão com os vértices representam o conjunto de k veículos e suas respectivas capacidades. Esses vértices que representam um conjunto de $\mathrm{k}$ veículos têm arestas com fluxo de produtos sendo entreque aos clientes. Então o fluxo de produto chega ao seu destino que é o vértice cliente o qual onde existe consumo de demanda do cliente, de modo que pode haver estoque no cliente em questão caso a soma do total transportado e o estoque inicial do período e sejam maiores que as demanda do mesmo. Havendo estoques estes gerariam arestas as quais são associados os custos de estoque (estoques de um período para o outro no mesmo cliente). O problema apresenta as seguintes características:

- Capacidade máxima de fluxo nos arcos ou nós (veículos e clientes);

- Demanda de mínima de produto em nós do grafo (clientes); 
- Custo por unidade de fluxo enviada no arco de um nó para o outro (estoques de um período para o outro).

O algoritmo utilizado para a resolução do problema foi o Network simplex (NS) ou Simplex de Rede, tal algoritmo é uma especialização do método Simplex para aplicação em problemas de programação linear de fluxo em redes.

O NS se mostra superior ao Simplex por fazer um menor número de iterações para se atingir o ótimo e maior velocidade para realizar tais iterações, desse modo mostrando-se um método bastante eficiente para a resolução de problemas de fluxo em redes (BAZARAA et al., 1990). A Figura 16 contém a ilustração do grafo para o problema do IRP.

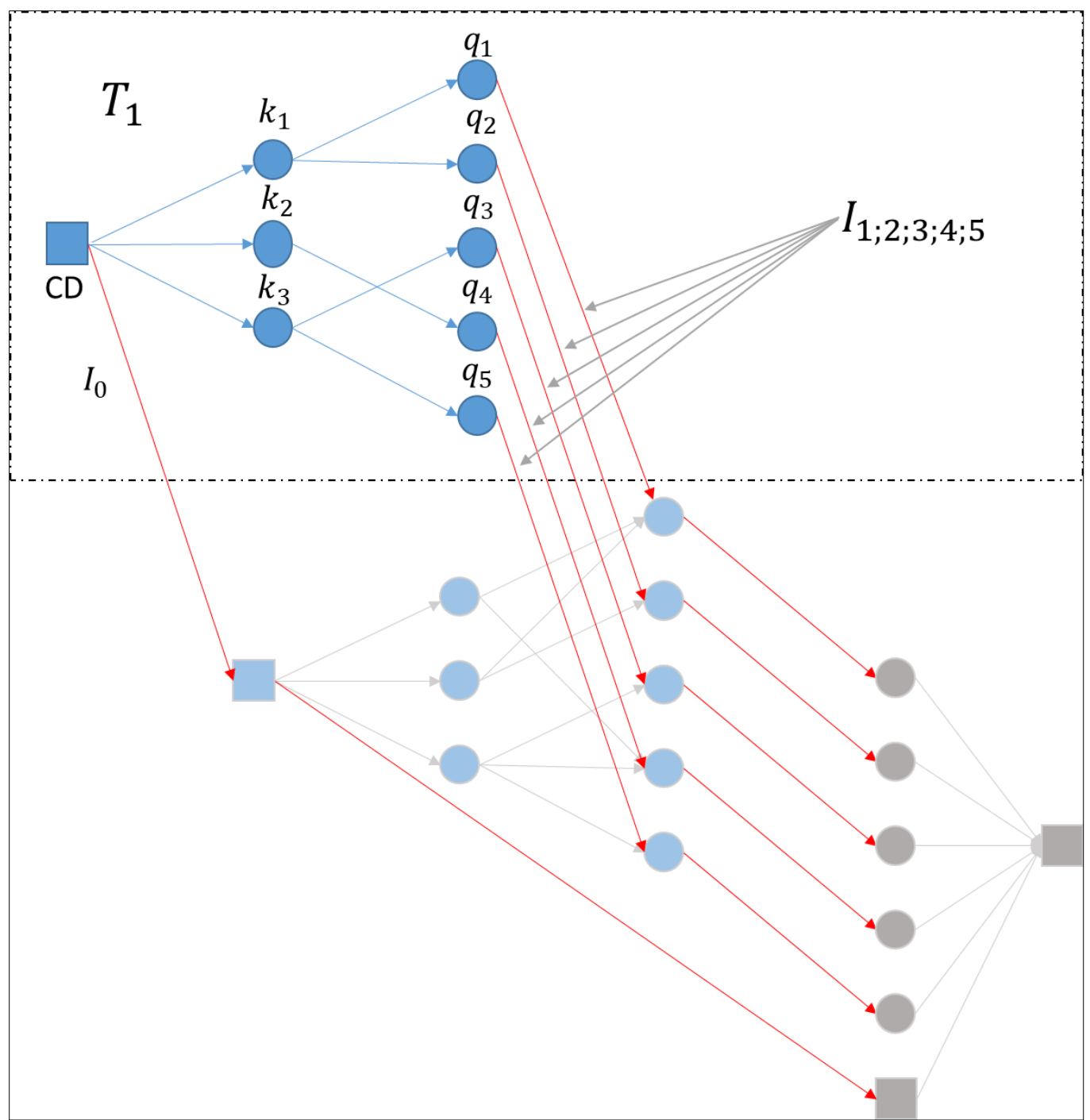

Figura 16 - Ilustração do Fluxo Máximo a custo mínimo para o IRP. Fonte: Autor (2018) 
4.3

\section{Descida em Vizinhança Variável Aleatória}

Mladenovic e Hansen (1997) em seu estudo propuseram um algoritmo designado de Descida em Vizinhança Variável (Variable Neighborhood Descent VND), que consiste na realização em sequência de vizinhanças (inter-rota e intrarota). Inspirado no VND, Subramanian (2012) propôs uma variação do VND nomeada de Descida em Vizinhança Variável Aleatória (Random Variable Neighborhood Descent - RVND). A versão proposta por Subramanian (2012) usa um número aleatório para ordenar as vizinhanças que a serem executadas. No caso de a vizinhança escolhida aleatoriamente ser bem-sucedida, buscas locais são realizadas nas rotas alteradas, caso contrário, a vizinhança é retirada da lista de buscas entre rotas.

Então seja $N=\left\{N^{1}, N^{2}, N^{3} \ldots N^{z}\right\}$ um conjuto de estrutura de vizinhanças, quando uma estrutura de vizinhança não tem sucesso em melhorar a solução o algoritmo elege aleatoriamente uma nova estrutura de vizinhança pertencente ao mesmo conjunto e assim sucessivamente.

Nesta dissertação a cada iteração do RVND cria-se uma lista com as vizinhanças descritas anteriormente na Seção 4.1, a ordem de vizinhanças na lista é realizada de maneira aleatória. A partir da ordem definida, o algoritmo percorre as vizinhanças em buscas de melhorias. É utilizado também o First Improvement, que no português seria a primeira melhoria de modo que, a cada vez que uma vizinhança era explorada, o primeiro movimento de melhoria encontrado é aplicado e em seguida o algoritmo segue para a próxima vizinhança da lista, de modo a ser executado até que não haja melhorias.

Para definir o melhor movimento a ser aplicado seguindo o conceito do First Improvement, assim que um movimento é testado por alguma vizinhança de roteirização, o algoritmo de Fluxo máximo a custo mínimo á iniciado para calcular o custo de estoque e comparar com o melhor custo anterior, além de comparar o trade-off dos custos de estoques e de roteirização gerado pelo movimento. A Tabela 13 contém a descrição do algoritmo. 
Tabela 13 - Algoritmo RVND. Fonte: Adaptado de Silva Junior. (2013).

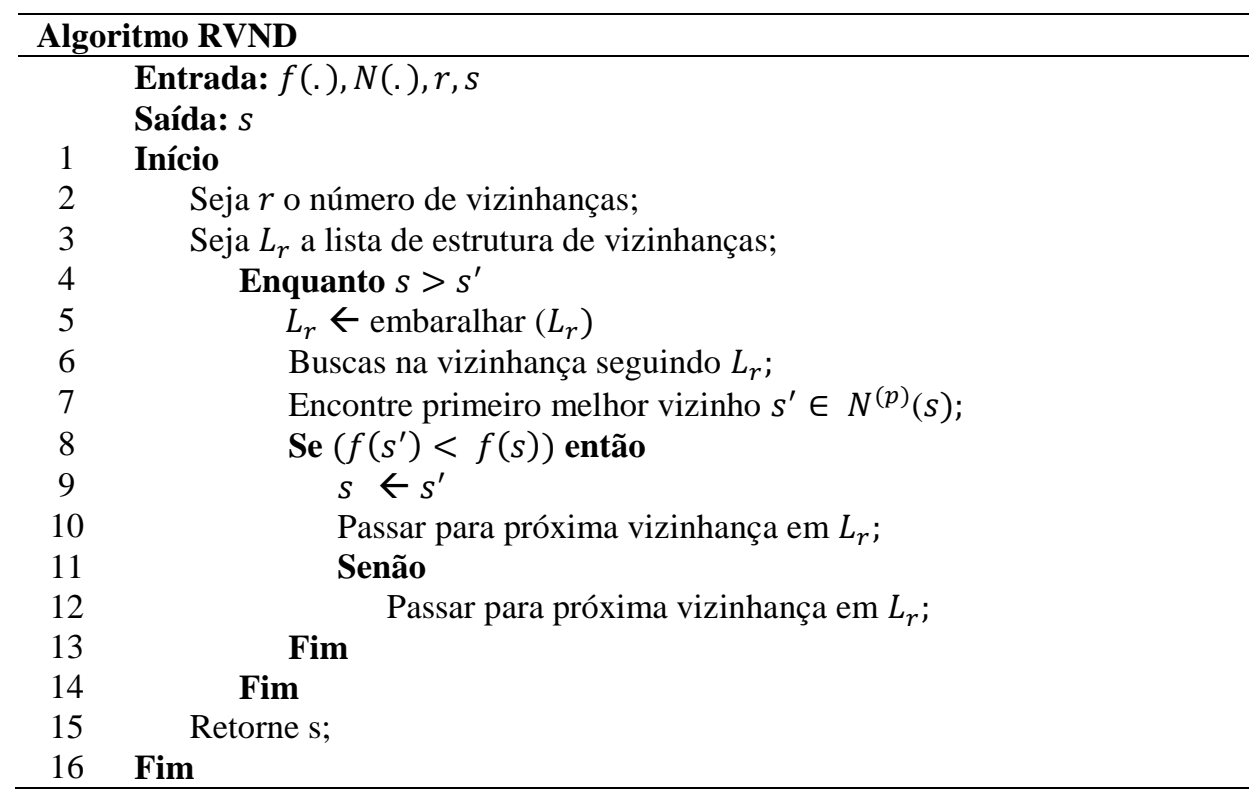

\section{4}

Iterated Local Search

A Meta-heurística Iterated Local Search (ILS) deriva dos algoritmos de buscas locais nas estruturas de vizinhanças. O ILS tem o objetivo de melhorar as soluções obtidas pelas buscas e tentar sair de ótimos locais afim de encontrar ótimos globais, para isso o ILS utiliza de perturbações na solução atual. A Figura 17 contém uma ilustração do objetivo do algoritmo.

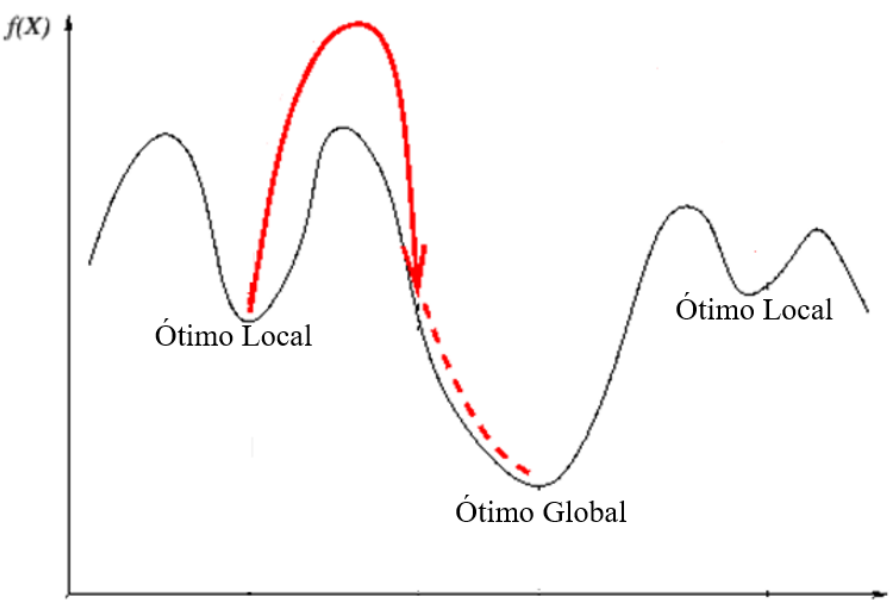

Figura 17 - Ilutsração do ILS. Fonte: Autor (2018)

A eficiência desta meta-heurística está associada às perturbações na solução atual considerando os critérios de aceitação e aos procedimentos de busca local. A Tabela 14 contém a descrição do algoritmo. 
Tabela 14 - Algoritmo ILS. Fonte: Autor. (2018).

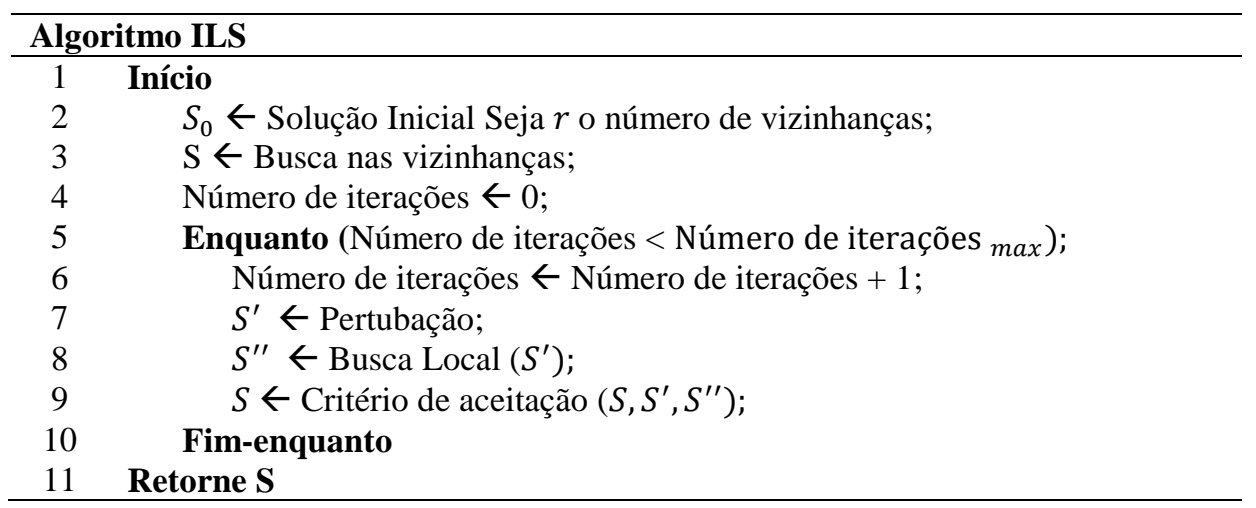

A solução inicial do algoritmo é vazia, ou seja, com nenhum cliente sendo visitado. Com isso as demandas não são atendidas. O não-atendimento é penalizado na função objetivo de minimização sendo multiplicando por uma constante com um valor grande.

Então inicia-se as buscas nas vizinhanças referente ao ILS que são realizadas através do RVND (descrito na Seção 4.3) até que não hajam mais movimentos de melhoria, tal que a solução encontrada é guardada. Então a perturbação é aplicada na solução corrente escolhendo aleatoriamente um movimento. $\mathrm{O}$ movimento escolhido aleatoriamente pode gerar uma solução inviável, então o RVND recomeça, e pára novamente assim que uma solução melhor que a corrrente seja encontrada ou que o algoritmo encontre um novo ótimo local. Então o algoritmo se repete até que o critério de parada seja atendido. A Tabela 15 contém a descrição do algoritmo.

Tabela 15 - Algoritmo ILS. Fonte: Autor. (2018).

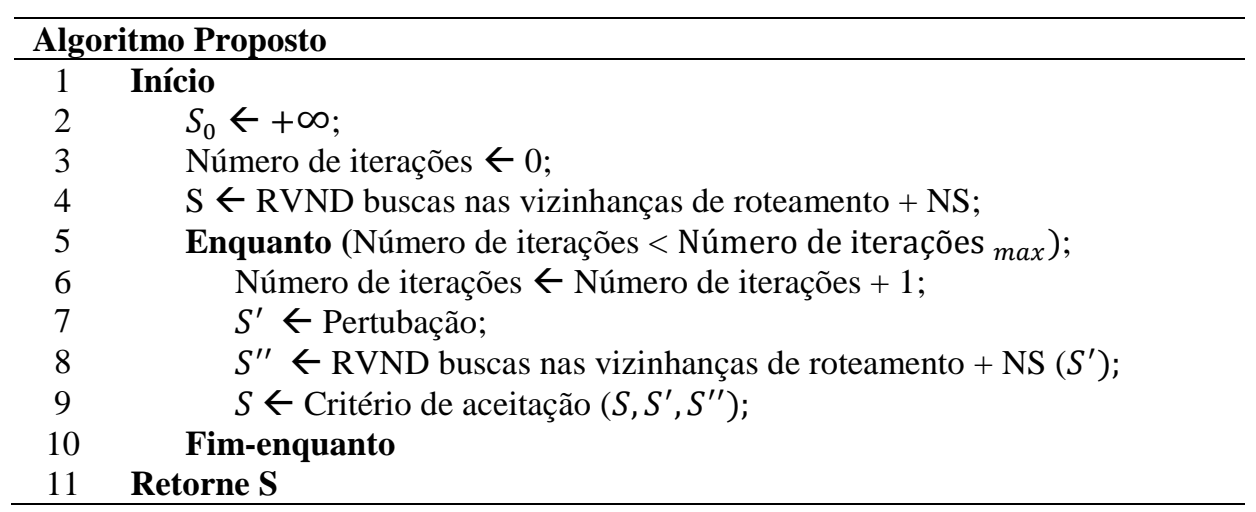

Na seção 2.7.6 foi descrita a heurística que foi proposta por Santos (2014) que também utilização ILS e RVND para o problema do IRP, os dois algoritmos 
proposto pelo autor diferem do proposto nesta pesquisa. As vizinhanças utilizadas pelo algoritmo proposto por esta pesquisa são diferentes das de Santos (2014). As outras diferenças de algoritmo estão descritas na Tabela 16.

Tabela 16 - Comparação entre Algoritmos ILS e RVND. Fonte: Autor. (2018).

\begin{tabular}{lcc}
\hline & Comparação entre heurísticas com ILS e RVND \\
\hline & Algoritmo Proposto & Santos (2014) \\
Algoritmo & Híbrido & Híbrido \\
Solução inicial (SI) & Método de inserção & Heurística construtiva \\
Problema de Transporte & Buscas nas vizinhanças & Buscas nas vizinhanças \\
Problema de estoque & Algoritmo de fluxo em redes & Programação linear \\
\hline
\end{tabular}




\section{5 \\ Experimentos computacionais}

Este capítulo expõe os resultados obtidos pelo o algoritmo proposto. Na Seção 5.1 é apresentado o resumo geral dos resultados gerados pelo algoritmo e uma comparação geral com os melhores resultados conhecidos da literatura mostrando a eficiência do algoritmo. Esta seção também descreve a linguagem utilizada e as configurações do computador utilizado para os testes realizados. A Seção 5.2 contém os melhores resultados da literatura e do algoritmo proposto para as instâncias clássicas de seis períodos e cinco veículos tanto para custos baixos e elevados e de estoques.

\section{1}

\section{Sumário dos Resultados}

Para implementação do algoritmo proposto utilizou-se a linguagem Julia usando o compilador Atom. Para resolver o problema de Fluxo Máximo a Custo Mínimo através do Network Simplex utilizou-se a biblioteca LEMON Graph Library (Dezsö et al., 2011).

Os testes foram executados em um computador Intel® ${ }^{\circledR}$ Core $^{\mathrm{TM}} 2$ i7-3960X, 3.30 GHz com $64 \mathrm{~GB}$ de memória principal. O sistema operacional utilizado foi o Linux Operating System .

Para testes iniciais e validação do algoritmo utilizou-se as instâncias existentes da literatura disponibilizadas no trabalho de Coelho et al. (2012a) com o objetivo de averiguar a consistência e desempenho algoritmo. (instâncias disponíveis em http://www.leandro-coelho.com/intances).

As características destas instâncias têm frota homogênea variando de 2 a 5 veículos. Apresenta dois horizontes de planejamento de entregas sendo um de 3 períodos e outro de 6. Contém dois grupos com diferentes custos de estoques o grupo high para custos elevados e low para baixos, tem apenas um produto. Por fim o conjunto de clientes que seria $C=\{5 ; 10 ; 15 ; 20 ; 25 ; 30 ; 35 ; 40 ; 45 ; 50\}$. 
Comparou-se os resultados gerados com o algoritmo branch-and-cut de Coelho et al. (2012a), com os algoritmos o heurístico ALNS e branch-and-cut de Adulyasak et al. (2014a) e (2014b), com o algoritmo Branch-Price-and-Cut de Desaulniers et al. (2015), o algoritmo de decomposição e separação de cortes de Avella et al. (2015) e os algoritmos heurísticos baseados em ILS e AS de Alvarez et al. (2018) que é o trabalho mais recente.

Os resultados gerados pelos trabalhos de Archetti et al. (2017) e Santos (2014) não foram usados nesta pesquisa para efeito de comparação de resultados. O trabalho de Archetti et al. (2017) utilizou instâncias diferentes. Logo a comparação não faria sentido. Os algoristmos heurísticos ILS e SA de Santos (2014) não foram considerados por se tratar de literatura cinza.

Foram criadas tabelas com intuito de resumir e facilitar o entendimento dos resultados. A Tabela 17 contém o resumo do resultado de todas as instâncias, a Tabela 18 contém um resumo dos resultados que não conseguiram superar ou igualar os resultados da literatura. As Tabelas de 19 a 22 têm os resumos respectivamente dos veículos de 2 a 5 .

A Tabela 17 mostra que o algoritmo proposto melhorou 36 instâncias da literatura sendo $6 \%$ do total, e outras 128 chegaram ao ótimo igualando com a literatura representando $20 \%$ do total. O algoritmo não consegue superar 476 instâncias representando 74\%. O Gap médio das instâncias que foram melhorados é de $6.39 \%$ sendo superior as de que não foram que foi de $3,84 \%$.

Das 476 instâncias que não foram superadas ou igualadas foram analisadas seguindo as faixas de Gap como critério. De modo que se utilizou 1\%, 5\% e $10 \%$. Na Tabela 18 contém os resultados dá análise, e mostra 93 das 476 ficaram a abaixo de $1 \%$ do Gap representando 19,54\% essas ainda contendo um Gap médio de 0,4\%. Outros 267 ficaram entre 1\% e abaixo de 5\% representando 56,09\% e Gap médio de 2,59\%. De modo das 476 instâncias mais de 75\% delas tiveram o Gap abaixo de $5 \%$. Outras 74 ficaram abaixo de $10 \%$ totalizando $15,55 \%$ e apenas 42 acima de $10 \%$ representando $8,82 \%$. O que demonstra eficiência do algoritmo proposto pelo estudo. 
Tabela 17 - Resumo do resultado de todas as instâncias. Fonte: Autor. (2018).

\begin{tabular}{lcccc}
\hline \multicolumn{1}{c}{} & Quant. & Quant.(\%) & Ótimo & Média Gap \\
\hline Superior & 36 & $6 \%$ & - & $-6,39 \%$ \\
Igual & 128 & $20 \%$ & 128 & $0,00 \%$ \\
Inferior & 476 & $74 \%$ & - & $3,84 \%$ \\
Total & 640 & $100 \%$ & 128 & - \\
\hline
\end{tabular}

Tabela 18 - Resumo do resultado acima dos encontrados na literatura. Fonte: Autor. (2018).

\begin{tabular}{cccc}
\hline \multicolumn{1}{c}{ Faixa } & Quant. & Quant.(\%) & Média Gap \\
\hline Abaixo de 1\% & 93 & $19,54 \%$ & $0,40 \%$ \\
Abaixo de 5\% & 267 & $56,09 \%$ & $2,59 \%$ \\
Abaixo de 10\% & 74 & $15,55 \%$ & $6,75 \%$ \\
Acima de 10\% & 42 & $8,82 \%$ & $13,80 \%$ \\
Total & 476 & $100 \%$ & - \\
\hline
\end{tabular}

A Tabela 19 mostra os resultados para a frota até 2 veículos que foi o único caso no qual o algoritmo proposto não conseguiu melhorar nenhuma das 160 instâncias testadas, no entanto encontrou o ótimo 44 vezes (28\%) igualando com a literatura.

Tabela 19 - Resumo do resultado das instâncias para 2 veículos. Fonte: Autor. (2018).

\begin{tabular}{lcccc}
\hline \multicolumn{1}{c}{$\mathrm{K}=2$} & Quant. & Quant.(\%) & Ótimo & Média Gap \\
\hline Superior & 0 & $0 \%$ & - & $0,00 \%$ \\
Igual & 44 & $28 \%$ & 44 & $0,00 \%$ \\
Inferior & 116 & $73 \%$ & - & $2,99 \%$ \\
Total & 160 & $100 \%$ & 44 & - \\
\hline
\end{tabular}

A Tabela 20 apresenta os resultados para a frota de 3 veículos no qual foram 160 instâncias e 2 delas foram melhoradas representando $1 \%$ e o Gap médio foi de $0.21 \%$. Outras 30 encontraram o ótimo igualando com a literatura representando 19\%. O algoritmo foi inferior a 128 instâncias (80\%), e Gap foi de apenas 4,38\%.

Tabela 20 - Resumo do resultado das instâncias para 3 veículos. Fonte: Autor. (2018).

\begin{tabular}{lcccc}
\hline \multicolumn{1}{c}{$\mathrm{K}=3$} & Quant. & Quant. $(\%)$ & Ótimo & Média Gap \\
\hline Superior & 2 & $1 \%$ & - & $0,21 \%$ \\
Igual & 30 & $19 \%$ & 30 & $0,00 \%$ \\
Inferior & 128 & $80 \%$ & - & $4,38 \%$ \\
Total & 160 & $100 \%$ & 30 & - \\
\hline
\end{tabular}


A Tabela 21 contém os resultados para a frota de 4 veículos no qual 10 instâncias foram melhoradas representando $6 \%$ e o Gap médio foi de 10,58\%. Note que o aumento da quantidade de veículos, causa ganho na utilização de estruturas de vizinhanças pois ocorrem mais combinações de cargas entre veículos. A quantidade testes realizados foram 160. Para outras 28 instâncias o algoritmo encontrou o ótimo igualando com a literatura representando $18 \%$. O algoritmo foi inferior a 122 instâncias (76\%), e Gap médio foi de apenas 4,06\%.

Tabela 21 - Resumo do resultado das instâncias para 4 veículos. Fonte: Autor. (2018).

\begin{tabular}{lcccc}
\hline \multicolumn{1}{c}{$\mathrm{K}=4$} & Quant. & Quant.(\%) & Ótimo & Média Gap \\
\hline Superior & 10 & $6 \%$ & - & $-10,58 \%$ \\
Igual & 28 & $18 \%$ & 28 & $0,00 \%$ \\
Inferior & 122 & $76 \%$ & - & $4,06 \%$ \\
Total & 160 & $100 \%$ & 28 & - \\
\hline
\end{tabular}

Estão expostos na Tabela 22 os resultados da frota de 5 veículos o qual o algoritmo teve melhor desempenho superando 24 instâncias da literatura um total de $15 \%$ sendo seu Gap médio de 5,15\%. Outra vez com o aumento da quantidade de veículos ocorreu um ganho de desempenho. A quantidade de instâncias testadas também foi 160. O algoritmo foi inferior a 111 instâncias (69\%), e Gap médio foi de apenas 3,93\%. Para outras 25 instâncias o algoritmo encontrou o ótimo igualando com a literatura representando $16 \%$.

Tabela 22 - Resumo do resultado das instâncias para 5 veículos. Fonte: Autor. (2018).

\begin{tabular}{lcccc}
\hline \multicolumn{1}{c}{$\mathrm{K}=5$} & Quant. & Quant.(\%) & Ótimo & Média Gap \\
\hline Superior & 24 & $15 \%$ & - & $-5,15 \%$ \\
Igual & 25 & $16 \%$ & 25 & $0,00 \%$ \\
Inferior & 111 & $69 \%$ & - & $3,93 \%$ \\
Total & 160 & $100 \%$ & 28 & - \\
\hline
\end{tabular}

\section{2}

\section{Resultados}

Esta seção contém um comparativo dos resultados gerados pelo algoritmo proposto com os resultados da literatura para algumas instâncias. Nas primeiras colunas das Tabelas 23 e 24 estão os nomes das instâncias comparadas, na segunda coluna estão o número de veículos e na terceira está a média de valores gerados pelo algoritmo. Na quarta coluna está o melhor valor encontrado pelo Algoritmo 
Proposto(AP), na quinta está o tempo médio que o algoritmo levou para encontrar a solução, na sexta o melhor resultado da literatura e na sétima o Gap entre o resultado do algoritmo e literatura. O método foi rodado 10 vezes para cada instância.

Tabela 23 - Resultados do AP x Literatura $\mathrm{K}=5$ e H = 6 HighCost. Fonte: Autor. (2018).

\begin{tabular}{|c|c|c|c|c|c|c|}
\hline Instâncias & Vc. & Média & AP & Tempo & Literatura & Gap \\
\hline h6-highcost-5-abs $1 \mathrm{n} 10$ & 5 & 14535.33 & 14349.54 & 60.01 & 14146.09 & $1,44 \%$ \\
\hline h6-highcost-5-abs $1 \mathrm{n} 15$ & 5 & 15928.39 & 15723.05 & 180.91 & 15610.30 & $0,72 \%$ \\
\hline h6-highcost-5-abs 1 n20 & 5 & 20657.08 & 20376.23 & 386.70 & 20309.00 & $0,33 \%$ \\
\hline h6-highcost-5-abs1n25 & 5 & 19531.23 & 19308.34 & 655.25 & 18928.70 & $2,01 \%$ \\
\hline h6-highcost-5-abs 1 n30 & 5 & 29373.07 & 29215.89 & 1234.47 & 30430.80 & $-3,99 \%$ \\
\hline h6-highcost-5-abs 1 n5 & 5 & 9042.98 & 9042.98 & 13.56 & 9042.98 & $0,00 \%$ \\
\hline h6-highcost-5-abs2n10 & 5 & 15345.53 & 15192.42 & 61.49 & 14949.48 & $1,63 \%$ \\
\hline h6-highcost-5-abs2n15 & 5 & 15859.32 & 15647.56 & 179.80 & 15555.90 & $0,59 \%$ \\
\hline h6-highcost-5-abs 2 n20 & 5 & 17371.17 & 17090.54 & 333.06 & 16967.10 & $0,73 \%$ \\
\hline h6-highcost-5-abs2n25 & 5 & 23055.49 & 22777.42 & 648.38 & 29760.62 & $-23,46 \%$ \\
\hline h6-highcost-5-abs2n30 & 5 & 25239.78 & 24758.31 & 1075.38 & 25076.12 & $-1,27 \%$ \\
\hline h6-highcost-5-abs2n5 & 5 & 8302.70 & 8298.86 & 12.72 & 8298.86 & $0,00 \%$ \\
\hline h6-highcost-5-abs3n10 & 5 & 12226.82 & 12177.30 & 61.29 & 12054.30 & $1,02 \%$ \\
\hline h6-highcost-5-abs3n15 & 5 & 18334.78 & 18156.42 & 157.96 & 18008.90 & $0,82 \%$ \\
\hline h6-highcost-5-abs3n20 & 5 & 18691.05 & 18535.19 & 332.90 & 18383.20 & $0,83 \%$ \\
\hline h6-highcost-5-abs3n25 & 5 & 25292.58 & 24859.46 & 729.25 & 25317.60 & $-1,81 \%$ \\
\hline h6-highcost-5-abs3n30 & 5 & 27364.10 & 27078.82 & 1012.70 & 27420.74 & $-1,25 \%$ \\
\hline h6-highcost-5-abs3n5 & 5 & 13699.12 & 13399.13 & 10.51 & 13399.10 & $0,00 \%$ \\
\hline h6-highcost-5-abs4n10 & 5 & 14137.51 & 13916.45 & 64.32 & 13754.90 & $1,17 \%$ \\
\hline h6-highcost-5-abs4n15 & 5 & 15078.44 & 14828.14 & 174.43 & 14655.90 & $1,18 \%$ \\
\hline h6-highcost-5-abs 4 n20 & 5 & 21163.78 & 21015.85 & 340.20 & 21217.90 & $-0,95 \%$ \\
\hline h6-highcost-5-abs4n25 & 5 & 20562.94 & 20199.03 & 590.06 & 20100.30 & $0,49 \%$ \\
\hline h6-highcost-5-abs4n30 & 5 & 23223.03 & 22698.78 & 1094.39 & 23624.53 & $-3,92 \%$ \\
\hline h6-highcost-5-abs4n5 & 5 & 8179.58 & 8179.58 & 12.13 & 8179.58 & $0,00 \%$ \\
\hline h6-highcost-5-abs5n10 & 5 & 12208.51 & 12123.02 & 54.00 & 12068.49 & $0,45 \%$ \\
\hline h6-highcost-5-abs5n15 & 5 & 16012.51 & 15809.55 & 165.97 & 15657.20 & $0,97 \%$ \\
\hline h6-highcost-5-abs5n20 & 5 & 23933.44 & 23554.66 & 353.51 & 23387.30 & $0,72 \%$ \\
\hline h6-highcost-5-abs5n25 & 5 & 26659.84 & 26360.04 & 631.23 & 27041.50 & $-2,52 \%$ \\
\hline h6-highcost-5-abs5n30 & 5 & 24157.58 & 23504.26 & 1121.07 & 24281.36 & $-3,20 \%$ \\
\hline h6-highcost-5-abs5n5 & 5 & 9095.34 & 9093.52 & 10.52 & -- & Impossible \\
\hline
\end{tabular}

Na Tabela 23 contém uma comparação utilizando instâncias com seis períodos com altos custos de estoques e 5 veículos. Das 30 instâncias uma é inviável, e em 9 casos o algoritmo superou a literatura. Em 4 casos o algoritmo empatou com literatura no ótimo. Em 16 casos a literatura foi superior ao algoritmo. 
Apesar da literatura ter sido superior ao algoritmo, ainda assim o maior Gap a favor da literatura foi de $2.01 \%$ e o maior Gap a favor do algoritmo foi de $23,46 \%$.

Tabela 24 - Resultados do AP x Literatura K = 5 e H = 6 LowCost. Fonte: Autor (2018).

\begin{tabular}{|c|c|c|c|c|c|c|}
\hline Instâncias & Vc. & Média & $\mathrm{AP}$ & Tempo & Literatura & Gap \\
\hline h6-lowcost-5-abs 1 n10 & 5 & 10263.22 & 10206.25 & 59.52 & 9993.84 & $2,13 \%$ \\
\hline h6-lowcost-5-abs1n15 & 5 & 9334.31 & 9135.74 & 161.05 & 8966.03 & $1,89 \%$ \\
\hline h6-lowcost-5-abs 1 n20 & 5 & 12614.34 & 12428.49 & 346.10 & 12030.00 & $3,31 \%$ \\
\hline h6-lowcost-5-abs 1 n25 & 5 & 11340.52 & 10628.79 & 625.09 & 10637.10 & $-0,08 \%$ \\
\hline h6-lowcost-5-abs 1 n30 & 5 & 14803.67 & 14387.27 & 1165.32 & 14824.81 & $-2,95 \%$ \\
\hline h6-lowcost-5-abs 1 n5 & 5 & 6445.68 & 6445.68 & 12.52 & 6445.68 & $0,00 \%$ \\
\hline h6-lowcost-5-abs 2 n10 & 5 & 11911.94 & 11692.95 & 56.46 & 11633.77 & $0,51 \%$ \\
\hline h6-lowcost-5-abs2n15 & 5 & 9558.34 & 9265.09 & 159.98 & 9073.30 & $2,11 \%$ \\
\hline h6-lowcost-5-abs 2 n20 & 5 & 8996.28 & 8760.78 & 308.96 & 8386.88 & $4,46 \%$ \\
\hline h6-lowcost-5-abs2n25 & 5 & 13787.42 & 13470.11 & 569.21 & 20533.47 & $-34,40 \%$ \\
\hline h6-lowcost-5-abs 2 n30 & 5 & 13255.79 & 12854.27 & 986.70 & 12614.88 & $1,90 \%$ \\
\hline h6-lowcost-5-abs2n5 & 5 & 6013.89 & 6009.40 & 12.06 & 6009.40 & $0,00 \%$ \\
\hline h6-lowcost-5-abs3n10 & 5 & 8447.84 & 8377.33 & 58.34 & 8239.62 & $1,67 \%$ \\
\hline h6-lowcost-5-abs3n15 & 5 & 10927.88 & 10739.26 & 151.33 & 10584.20 & $1,47 \%$ \\
\hline h6-lowcost-5-abs 3 n20 & 5 & 11208.49 & 10848.61 & 321.06 & 10963.20 & $-1.05 \%$ \\
\hline h6-lowcost-5-abs3n25 & 5 & 15026.49 & 14773.02 & 614.15 & 15054.70 & $-1.87 \%$ \\
\hline h6-lowcost-5-abs3n30 & 5 & 12548.14 & 12024.57 & 1011.22 & 12583.70 & $-4,44 \%$ \\
\hline h6-lowcost-5-abs3n5 & 5 & 11435.75 & 11282.69 & 11.19 & 11282.69 & $0,00 \%$ \\
\hline h6-lowcost-5-abs4n10 & 5 & 10532.53 & 10228.22 & 56.86 & 10092.50 & $1,34 \%$ \\
\hline h6-lowcost-5-abs 4 n15 & 5 & 9921.01 & 9558.77 & 157.86 & 9553.43 & $0,06 \%$ \\
\hline h6-lowcost-5-abs4n20 & 5 & 14259.09 & 13830.21 & 334.77 & 13762.50 & $0,49 \%$ \\
\hline h6-lowcost-5-abs4n25 & 5 & 11976.00 & 11707.57 & 589.45 & 11129.10 & $5,20 \%$ \\
\hline h6-lowcost-5-abs4n30 & 5 & 13545.63 & 13247.47 & 931.82 & 13673.77 & $-3,12 \%$ \\
\hline h6-lowcost-5-abs4n5 & 5 & 6285.00 & 6285.00 & 11.94 & 6285.00 & $0,00 \%$ \\
\hline h6-lowcost-5-abs5n10 & 5 & 7363.68 & 7259.97 & 52.12 & 7214.49 & $0,63 \%$ \\
\hline h6-lowcost-5-abs5n15 & 5 & 11008.43 & 10783.03 & 156.00 & 10731.90 & $0,48 \%$ \\
\hline h6-lowcost-5-abs5n20 & 5 & 15365.34 & 14966.70 & 329.22 & 15268.00 & $-1,97 \%$ \\
\hline h6-lowcost-5-abs5n25 & 5 & 15222.10 & 14849.97 & 602.65 & 14987.80 & $-0,92 \%$ \\
\hline h6-lowcost-5-abs5n30 & 5 & 12592.65 & 11852.44 & 1143.42 & 13261.28 & $-10,62 \%$ \\
\hline h6-lowcost-5-abs5n5 & 5 & 7009.25 & 7009.10 & 10.45 & -- & impossible \\
\hline
\end{tabular}

$\mathrm{Na}$ Tabela 24 contém uma comparação utilizando instâncias com seis períodos com baixos custos de estoques e 5 veículos. Das 30 instâncias uma é inviável, e em 10 casos o algoritmo superou a literatura. Em 4 casos o algoritmo empatou com literatura no ótimo. Em 15 casos a literatura foi superior ao algoritmo. Apesar da literatura ter sido superior ao algoritmo, ainda assim o maior Gap a favor da literatura foi de 4,46\% e o maior Gap a favor do algoritmo foi de 34,40\%. 


\section{6 \\ Considerações finais}

Nesta dissertação foi realizada uma revisão extensa e exaustiva da literatura sobre o IRP e suas variações, políticas e métodos de resolução do problema, após isso observou-se um pequeno Gap de uma variação que ainda não tinha sido abordada. Então foi proposto um modelo para resolução do problema, o qual não foi encontrando um modelo similar na busca realizada. Também foi desenvolvido um método heurístico híbrido para a resolução um problema de estoque e roteamento de veículos. O método, consiste em um algoritmo híbrido baseado em buscas nas vizinhanças para o subproblema de transporte. Para o outro subproblema de estoques modelou-se como um problema de fluxo máximo a custo mínimo e para sua resolução usou-se o algoritmo Network Simplex. Para fugir de ótimos locais aplicou-se a meta-heurística ILS que, durante a fase de buscais nas vizinhanças, utiliza um procedimento RVND.

Foram utilizadas seis estruturas de vizinhanças. Para avaliar a performance do algoritmo foram realizados testes computacionais com 640 instâncias da literatura de três e seis períodos de 5 a 50 clientes variando de 5 em 5 .

Os resultados gerados pelo método proposto pela pesquisa mostram a sua eficiência visto que 6\% (36 instâncias) dos resultados da literatura foram superados outros $20 \%$ chegaram ao melhor valor igualando aos resultados da literatura e dos outros resultados que não foram superiores ou iguais o da literatura mais de $75 \%$ desses tinham um Gap inferior a $5 \%$.

Trabalhos futuros incluem a incorporação de mais estruturas de vizinhanças com o objetivo de aumentar a eficiência do algoritmo. Adaptar a heurística para algumas variações do IRP, tais como IRPT, PRP, MMIRP e outras. Além disso, realizar testes com outros algoritmos de resolução do problema de fluxo máximo a custo mínimo com objetivo de aumentar eficiência do algoritmo. 


\section{7 \\ Referências bibliográficas}

ARENALES, M.; ARMENTANO, V.; MORABITO, R.; YANASSE, H. Pesquisa Operacional: Para Cursos de Engenharia. 2a ed. Rio de janeiro: Campus, 2015.

ABSI, N.; ARCHETTI, C.; DAUZÈRE-PÉRÈS, S.; FEILLET, D. A Two-Phase Iterative Heuristic Approach for the Production Routing Problem. Transport Sci. v.29, n.4, 784-795, 2014.

ADELMAN, D. A price-directed approach to stochastic inventory/routing. Oper. Res. v.52, n.4, p.499-514, 2004.

ADULYASAK, Y.; CORDEAU, J-F.; JANS, R. Benders decomposition for production routing under demand uncertainty. GERAD Technical Report G2012-57, HEC Montréal, Canada; 2012.

ADULYASAK, Y.; CORDEAU, J-F.; JANS, R. Formulations and branch and cut algorithms for multi-vehicle production and inventory routing problems. Inf. J. Comput. v.26, n.1, p.103-20, 2014b.

ADULYASAK, Y.; CORDEAU, J-F.; JANS, R. Optimization-based adaptive large neighborhood search for the production routing problem. Transport Sci. v.48, n.1, p.20-45, 2014a.

ADULYASAK, Y.; CORDEAU, J-F.; JANS, R. The production routing problem: A review of formulations and solution algorithms. Computers and Operations Research. v.55, p.141-152, 2015.

AGHEZZAF, E-H. Robust distribution planning for the suppliermanaged inventory agreements when demand rates and travel times are stationary. J. Oper. Res. Soc. v.59, n.8, p.1055-1065, 2008.

ANDERSSON, H.; HOFF, A.; CHRISTIANSEN, M.; HASLE, G.; LØKKETANGEN, A. Industrial aspects and literature survey: Combined inventory management and routing. Comput. Operation Research, v.37, n.9, p.1515-1536, 2010.

ARCHETTI C.; BERTAZZI, L.; HERTZ, A.; SPERANZA, M. G. A hybrid heuristic for an inventory routing problem. INFORMS J. Comput. v.24, n.1, p.101-116, 2012.

ARCHETTI, C.; BERTAZZI, L.; LAPORTE, G.; SPERANZA, M. G. A branchand-cut algorithm for a vendor-managed inventory-routing problem. Transportation Sci. v.41, n.3, p.382-391, 2007. 
ARCHETTI, C.; BERTAZZI, L.; PALETTA, G.; SPERANZA, M. G. Analysis of the maximum level policy in a production-distribution system. Comput. Operation Research. v.12, n.38, p.731-1746, 2011.

ARCHETTI, C.; BIANCHESSI, N.; IRNICH, S.; SPERANZA, M.G. Formulations for an inventory routing problem. International Transactions in Operational Research. v.21, n.3, p.353-374, 2014.

ARMENTANO, V. A.; SHIGUEMOTO, A. L.; LØKKETANGEN, A. Tabu search with path relinking for an integrated production-distribution problem. Comput Oper Res. v.38, n.8, p.1199-209, 2011.

AZADEH, A.; ELAHI, S.; HOSSEINABADI M. F.; NASIRIAN, B. A genetic algorithm-Taguchi based approach to inventory routing problem of a single perishable product with transshipment. Computers \& Industrial Engineering, v. 104 p.124-133, 2017.

BALLOU, R. H. Gerenciamento da Cadeia de Suprimentos/Logística Empresarial. 5a ed. Porto Alegre: Bookman, 2006.

BALLOU, R. H. Logística Empresarial, Transportes, Administração de Materiais, Distribuição Física. São Paulo: Atlas, 2010.

BAZARAA M. S.; JARVIS J. J.; SHERALI H. D. Linear programming and networkflows. New York: John Wiley \& Sons, 1990.

BANI-ASADI, H.; ZANJANI, H. J. Vendor managed inventory in multi level supply chain. Decision Science Letters. v.6 p.67-76, 2017.

BARD, J. F.; NANANUKUL, N. Heuristics for a multiperiod inventory routing problem with production decisions. Comput. Indust. Engrg, v.57, n.3, p.713-723, 2009.

BARD, J. F.; NANANUKUL, N. A branch-and-price algorithm for na integrated production and inventory routing problem. Comput. Oper. Res. v.37, n.12, p.2202-2217, 2010.

BARD, J.F.; HUANG, L.; JAILLET, P.; DROR, M. A decomposition approach to the inventory routing problem with satellite facilities. Transportation Sci. v.32, n.2, p.189-203, 1998.

BARLETT, C. A.; GHOSHAL, S. Building competitive advantage through people. MIT Sloan Management Rev. v.43, n.2, p.34-41, 2002.

BATISTUS, D. R. O Problema de Roteirização de Veículos com Restrições de Janelas de Tempo: Uma Proposta de Solução por meio da Metaheurística Scatter Search. 2009. 234 p. Tese (Doutorado em Engenharia de Produção) - Programa de Pós-Graduação em Engenharia de Produção, UFSC, Florianópolis.

BAUSCH, D. O.; BROWN, G. G.; RONEN, D. Scheduling short-term marine transport of bulk products. Maritime Policy Management, v.25, n.4, p.335-348, 1998. 
BEAMON, B. M. Measuring supply chain performance. Internat. J. Oper. Production Management, v.19, n.3, p.275-292, 1999.

BELFIORE, P. P., COSTA, O. L. V., FÁVERO, L. P. L. Problema de estoque e roteirização: revisão bibliográfica. Produção, v.16, n.3, p.42-454, 2006.

BELL, W. J.; DALBERTO L. M.; FISHER M. L.; GREENFIELD A. J.; JAIKUMAR, R.; KEDIA, P.; MACK, R. G.; PRUTZMAN, P.J. Improving the distribution of industrial gases with an on-line computerized routing and scheduling optimizer. Interfaces v.13, n.6, p.4-23, 1983.

BENOIST, T.; GARDI, F.; JEANJEAN, A.; ESTELLON, B. Randomized local search for real-life inventory routing. Transportation Sci. v.45, n.3, p.381-398, 2011.

BERMAN, O.; LARSON, R. C. Deliveries in an inventory/routing problem using stochastic dynamic programming. Transportation Sci. v.35, n.2, p.192-213, 2001.

BERTAZZI, L.; BOSCO, A.; GUERRIERO, F.; LAGANÀ, D. A stochastic inventory routing problem with stock-out. Transportation Research Part C: Emerging Technologies. v.27, p.89-107, 2013.

BERTAZZI, L.; SPERANZA, M. G. Continuous and discrete shipping strategies for the single link problem. Transportation Sci. v.36, n.3, p.314-325, 2012.

BERTAZZI, L.; PALETTA, G.; SPERANZA, M. G. Deterministic order-upto level policies in an inventory routing problem. Transportation Sci. v.36, n.1, p.119132, 2002.

BERTAZZI, L.; PALETTA, G.; SPERANZA, M. G. Minimizing the total cost in an integrated vendor-managed inventory system. J. Heuristics 11(5-6):393-419, 2005 .

BERTAZZI, L.; SAVELSBERGH, M.; SPERANZA, M. G. Inventory routing. Golden BL, Raghavan S, Wasil EA, eds. The Vehicle Routing Problem: Latest Advances and New Challenges. New York: Springer, p.49-72, 2008.

BOWERSOX, D. J.; CLOSS, D. J.; COOPER, M. B.; BOWERSOX, C. J. Gestão da cadeia de suprimentos e logística. $4^{\mathrm{a}}$ ed. Rio de Janeiro: McGraw-Hill, 2014.

BOUDIA, M.; LOULY, M. A. O.; PRINS, C. A reactive GRASP and path relinking for a combined production-distribution problem. Comput Oper Res. v.34, n.11, p.3402-19, 2007.

BOUDIA, M.; LOULY, M. A. O.; PRINS, C. Fast heuristics for a combined production planning and vehicle routing problem. Prod Plan Control. v.19, n.2, p.85-96, 2008.

BOUDIA, M.; PRINS. C. A memetic algorithm with dynamic population management for an integrated production-distribution problem. Eur J Oper Res. v.195, n.3, p.703-15, 2009. 
BRAHIMI, N.; AOUAM, T. Multi-item production routing problem with backordering: A MILP approach. International Journal of Production Research. v.54, n.4, p. 1076-1093, 2016.

CAMPBELL, A. M.; SAVELSBERGH, M. W. P. A decomposition approach for the inventory-routing problem. Transportation Sci. v.38, n.4, p.488-502, 2004.

CAMPBELL, A. M.; CLARKE, L.; KLEYWEGT, A. J.; SAVELSBERGH, M. W. $\mathrm{P}$. The inventory routing problem. Crainic TG, Laporte $G$, eds. Fleet Management and Logistics. Boston:Springer, p. 95-113, 1998.

CARTER, M. W.; FARVOLDEN, J. M.; LAPORTE, G.; XU, J. Solving an integrated logistics problem arising in grocery distribution. INFOR v.34, n.4, p.290-306, 1996.

CHANDRA, P. A dynamic distribution model with warehouse and customer replenishment requirements. J. Oper. Res. Soc. v.44, n.7, p.681-692, 1993.

CHANDRA, P.; FISHER, M. L. Coordination of production and distribution planning. Eur. J. Oper. Res. v.72, n.3, p.503-517, 1994.

CHEN, Y. M., \& LIN, C. T. A coordinated approach to hedge the risks in stochastic inventoryrouting problem. Computers \& Industrial Engineering, v.56, n.3, p.1095-1112, 2009.

CHENG, C.; QI, M.; WANG, X.; ZHANG, Y. Multi-period inventory routing problem under carbon emission regulations. International Journal of Production Economics. v.182, p.263-275, 2016.

CHENG, C.; YANG, P.; QI, M.; ROUSSEAU, L. M. Modeling a green inventory routing problem with a heterogeneous fleet. Transportation Research Part E: Logistics and Transportation Review. v.97, p. 97-112, 2017.

CHIEN, T. W.; BALAKRISHNAN, A.; WONG, R. T. An integrated inventory allocation and vehicle routing problem. Transportation Sci. v.23, n., p.67-76, 1989.

CHOPRA, S.; MEINDL, P. Supply Chain Management: Strategy, Planning, and Operation, $6^{a}$ ed. New York: Pearson Education, 2016.

CHRISTIANSEN M. A decomposition of a combined inventoryand time constrained ship routing problem. Transportation Sci. v.33, n.1, p.3-16, 1999.

COELHO, L. C.; CORDEAU, J-F.; LAPORTE, G. Consistency in multivehicle inventory-routing. Transportation Research Part C: Emerging Technologies, v.24 n.1, p. 270-287, 2012a.

COELHO, L. C.; CORDEAU, J-F; LAPORTE, G. Dynamic and stochastic inventory-routing. Technical report, CIRRELT-2012-37, Montreal, Canada, 2012b.

COELHO, L. C.; CORDEAU, J-F; LAPORTE, G. Heuristics for dynamic and stochastic inventory-routing. Computers and Operations Research. v.52 p.55-67, 2014. 
COELHO, L. C.; CORDEAU, J-F; LAPORTE, G. The inventoryrouting problem with transshipment. Comput. Oper. Res. v.39, n.11, p.2537-2548, 2012c.

COELHO, L. C.; CORDEAU, J-F; LAPORTE, G. Thirty Years of Inventory Routing. Transportation Science. v.48, n.1, p.1-19, $2013 \mathrm{c}$.

COELHO, L. C.; LAPORTE, G. A branch-and-cut algorithm for the multi-product multi-vehicle inventory-routing problem. International Journal of Production Research, v.51, n.23, p.7156-7169, 2013a.

COELHO, L.C.; LAPORTE, G. The exact solution of several classes of inventoryrouting problems. Computers \& Operations Research, v.40 n.2, p. 558-565 $2013 b$.

COUNCIL OF SUPPLY CHAIN MANAGEMENT PROFESSIONALS (CSCMP). CSCMP Supply chain management definitions and glossary. Disponível em: <https://cscmp.org/supply-chain-management-definitions>. Acesso em: 11 jun. 2017.

DESAULNIERS, G.; RAKKE, J. G.; COELHO, L. C. A Branch-Price-and-Cut Algorithm for the Inventory Routing Problem. Transportation Science, p. 17, 2015

DEZSÖ, B.; JÜTTNER, A.; KOVÁCS, P. LEMON - an open source C++ graph template library. Electron. Notes Theor. Comput. Sci. v.264 p.23, 2011.

DONG, A. H.; LEUNG, S. Y. S. A Simulation-Based Replenishment Model for the Textile Industry. Textile Research Journal, v.79, n.13, p.1188-1201, 2009.

DROR, M.; BALL, M.O.; GOLDEN, B. L. A computational comparison of algorithms for the inventory routing problem. Ann. Operational Research, v.4, p.3, 1986.

DROR, M.; BALL, M. O. Inventory/routing: Reduction from an annual to a shortperiod problem. Naval Res. Logist. v.34, n.6, p.891-905, 1987.

FEDERGRUEN, A.; ZIPKIN, P. A combined vehicle routing and inventory allocation problem. Oper. Res. v.32, n.5, p.1019-1037, 1984.

FEDERGRUEN, A.; PRASTACOS, G.; ZIPKIN, P. H. An allocation and distribution model for perishable products. Oper. Res. v.34, n.1, p.75-82, 1986.

FUMERO, F.; VERCELLIS, C. Synchronized development of production, inventory, and distribution schedules. Transp Sci. v.33, n.3, p.330-40, 1999.

GALLEGO, G.; SIMCHI-LEVI, D. On the effectiveness of direct shipping strategy for the one-warehouse multi-retailer r-systems. Management Sci. v.36, n.2, p.240243, 1990.

GALLEGO, G.; SIMCHI-LEVI, D. Rejoinder to "A note on bounds for direct shipping costs.” Management Sci. v.40, n.10, p.1393, 1994.

GOLDEN, B. L.; ASSAD, A. A.; DAHL, R. Analysis of a large-scale vehiclerouting problem with an inventory component. Large Scale Systems Inform. Decision Tech. v.7, n.2, p.181-190, 1984. 
GOLDRATT, E. M. Necessária, Sim, Mas Não Suficiente. São Paulo, Editora: Nobel, 2003.

GUIMARÃES, T., SCARPIN, C., STEINER, M. T. Políticas de distribuição com lote econômico de entrega em problemas de roteirização com estoque gerenciado pelo fornecedor e sistema logístico em três níveis. Gestão da Produção. v.22, n.1, p.133-148, 2015.

GUZMÁN-CAMACHO, C. H., SALAZAR-SANABRIA H. F., ADARMEJAIMES W. Coordinating inventory in collecting raw milk. Case Region Sugamuxi - Colombia. DYNA, v.81, n.186, p.259-266, 2014.

GUEMRI, O.; BEKRAR, A.; BELDJILALI, B. TRENTESAUX, D. GRASP-based heuristic algorithm for the multi-product multi-vehicle inventory routing problem. 4OR-Q J Oper Res, v.14 p. 377-404, 2016.

HALL, R. W. A note on bounds for direct shipping cost. Management Sci. v.38, n.8, p.1212-1214, 1992.

HASNI, S.; TOUMI, S.; JARBOUI, B.; MJIRDA, A. GVNS based heuristic for solving the multi-product multi-vehicle inventory routing problem. Electronic Notes in Discrete Mathematics. v.58, p.71-78, 2017.

HERER, Y. T.; ROUNDY, R. Heuristics for one-warehouse multiretailer distribution problem with performance bounds. Oper. Res. v.45, n.1, p.102-115, 1997.

HEWITT, M.; NEMHAUSER, G. L.; SAVELSBERGH, M. W. P.; Song, J-H. A branch-and-price guided search approach to maritime inventory routing. Comput. Oper. Res. v.40, n.5, p.1410-1419, 2013.

HUANG, S-H.; LIN, P-C. A modified ant colony optimization algorithm for multiitem inventory routing problems withdemand uncertainty. Transportation Res. Part E: Logist. Transportation Rev. v.46, n.5, p.598-611, 2010.

HVATTUM, L. M.; LØKKETANGEN, A. Using scenario trees and progressive hedging for stochastic inventory routing problems. J. Heuristics. v.15, n.6, p.527$557,2009$.

HVATTUM, L. M.; LØKKETANGEN, A.; LAPORTE, G. Scenario treebased heuristics for stochastic inventory-routing problems. INFORMS J. Comput. v.21, n.2, p.268-285, 2009.

INSTITUTO DE LOGÍSTICA E SUPPLY CHAIN (ILOS). Custos logísticos no Brasil. 2014. Disponível em: <http://www.ilos.com.br/web/analise-demercado/relatorios-de-pesquisa/custos-logisticos-no-brasil/>. Acesso em: 04 jun. 2017.

JEMAI, Z.; REKIK, Y.; KALAÏ, R. Inventory routing problems in a context of vendormanaged inventory system with consignment stock and transshipment. Production Planning \& Control: The Management of Operations, v. 24 n.8-9, p.671-683, 2013. 
KAZMIERCZAK, E. N.; STEFEN, D. A. VMI - Estoque gerenciado pelo fornecedor. Revista Mundo Logística v. 14, p.56-63, 2010.

KLEYWEGT, A. J.; NORI, V. S.; SAVELSBERGH, M. W. P. The stochastic inventory routing problem with direct deliveries. Transportation Sci. v.36, n.1, p.94-118, 2002.

KLEYWEGT, A. J.; NORI, V. S.; SAVELSBERGH, M. W. P. Dynamic programming approximations for a stochastic inventory routing problem. Transportation Sci. v.38, n.1, p.42-70, 2004.

KUMAR, R. S.; KONDAPANENI, K.; DIXIT, V.; GOSWAMI, A.; THAKUR, L. S.; TIWARI, M. K. Multi-objective modeling of production and pollution routing problem with time window: A self-learning particle swarm optimization approach.

Computers and Industrial Engineering. v.99, p.29-40, 2016.

JAILLET, P.; BARD, J. F.; HUANG, L.; DROR, M. Delivery cost approximations for inventory routing problems in a rolling horizon framework. Transportation Sci. v.36, n.3, p.292-300, 2002.

LAPORTE, G. What You Should Know about the Vehicle Routing Problem. Naval Research Logistics, v.54, n.8, p.811-819, 2007.

LEI, L.; LIU, S.; RUSZCZYNSKI, A.; PARK, S. On the integrated production, inventory, and distribution routing problem. IIE Trans. v.38, n.11, p.955-70, 2006.

LMARIOUH, J.; BOUAMI, D.; JAMALI, A.; MOZHER, A. Solving a multi-depot inventory routing problem arising in the Moroccan food Market. Journal of Theoretical and Applied Information Technology. v.84, n.1, p.24-30, 2016.

LMARIOUH, J.; COELHO, L. C.; ELHACHEMI, N.; JAMALI, A.; BOUAMI, D. Solving a vendor-managed inventory routing problem arising in the distribution of bottled water in Morocco. European Journal of Industrial Engineering. v.11, n.2, p.168-184, 2017.

LI, J.; CHEN, H.; CHU, F. Performance evaluation of distribution strategies for the inventory routing problem. European Journal Operation. Research. v.202, n.2 p.412-419, 2010.

LI, F.; GOLDEN, B. L.; WASIL, E. A. A record-to-record travel algorithm for solving the heterogeneous fleet vehicle routing problem. Comput. Oper. Res. v.34, n.9, p.2734-2742, 2007.

LIU, S-C.; LEE, W-T. A heuristic method for the inventory routing problem with time windows. Expert Systems Appl. v.38, n.10, p.13223-13231., 2011.

LOURENÇO, H. R.; MARTIN, O. C.; E STÜTZLE, T. Iterated local search. In Handbook of metaheuristics, p. 320-353. Springer, 2002.

$\begin{array}{lcc}\begin{array}{l}\text { MARAVELIAS } \\ \text { Inventory }\end{array} & \text { Routing. } & \text { OF WISCONSIN-MADISON. } \\ \text { <https://maravelias.che.wisc.edu/?page_id=266>. Acesso em: } 11 \text { jun. } 2017 . & \text { em: }\end{array}$


MICHEL, S., VANDERBECK, F. A column-generation based tactical planning method for inventory routing. Operations Research. v.60, n.2, p.382-397, 2012.

MINKOFF, A. S. A Markov decision model and decomposition heuristic for dynamic vehicle dispatching. Oper. Res. v.41, n.1, p.77-90, 1993.

MISHRA, B. K.; RAGHUNATHAN, S. Retailer- vs. vendor-managed inventory and brand competition. Management Sci. v.50, n.4, p.445-457, 2004.

MJIRDA, A.; JARBOUI, B.; MACEDO, R.; HANAFI, S. A variable neighborhood search for the multi-product inventory routing problem. Electronic Notes in Discrete Math. v.39, n.1, p.91-98, 2012.

MLADENOVIC, N.; HANSEN, P. Variable Neighbourhood Search. Computers \& Operations Research, 24(11):1097-1100, 1997.

MOIN, N. H.; SALHI, S.; AZIZ, N. A. B. An efficient hybrid genetic algorithm for the multi-product multi-period inventory routing problem. Internat. J. Production Econom. v.133, n.1, p.334-343, 2011.

NOLZ, P. C.; ABSI, N.; FEILLET, D. A Bi-Objective Inventory Routing Problem for Sustainable Waste Management Under Uncertainty. Journal of Multi-Criteria Decision Analysis. v.21, n.5, p.299-314, 2014.

NOLZ, P. C.; ABSI, N.; FEILLET, D. A stochastic inventory routing problem for infectious medical waste collection. Networks v.63, n.1, p.82-95, 2014.

NOVAES, A. G. Logística e gerenciamento da cadeia de distribuição: estratégia, operação e avaliação. 3a. ed. Rio de Janeiro: Elsevier, 2007.

OHLMANN, J. W.; FRY, M. J.; THOMAS, B. W. Route design for lean production systems. Transportation Sci. v.42, n.3, p.352-370, 2008.

PERES, I. T.; REPOLHO, H. M.; MARTINELLI, R.; MONTEIRO, N. J. Optimization in inventory-routing problem with planned transshipment: A case study in the retail industry. International Journal of Production Economics. v.19 p.748-756, 2017.

PERSSON, J. A.; GÖTHE-LUNDGREN, M. Shipment planning at oil refineries using column generation and valid inequalities. Eur. J. Oper. Res. v.163, n.3, p.631-652, 2005.

PIRES, S. Gestão da Cadeia de Suprimentos (Supply Chain Management): Conceitos Estratégias, Práticas e Casos. 2a ed. São Paulo: Atlas, 2011.

POPOVI'C, D.; VIDOVI'C, M.; RADIVOJEVI'C, G. Variable neighborhood search heuristic for the inventory routing problem in fuel delivery. Expert Systems Appl. v.39, n.18, p.13390-13398, 2012.

QIU, Y.; QIAO, J.; PARDALOS, P. M. A branch-and-price algorithm for production routing problems with carbon cap-and-trade. Omega (United Kingdom). v.68, p.49-61, 2017. 
QU, W. W.; BOOKBINDER, J. H.; IYOGUN, P. An integrated inventorytransportation system with modified periodic policy for multiple products. Eur. J. Oper. Res. v.115, n.2, p.254-269, 1999.

RAHIMI, M.; BABOLI, A.; REKIK, Y. Multi-objective inventory routing problem: A stochastic model to consider profit, service level and green criteria. Transportation Research Part E: Logistics and Transportation Review. v.101, p. 59-83, 2017.

ROLDÁN, R. F.; BASAGOITI, R.; COELHO, L.C. Robustness of inventory replenishment and customer selection policies for the dynamic and stochastic inventory-routing problem. Computers and Operations Research. v.74, p.14-20, 2016.

RAMKUMAR, N.; SUBRAMANIAN, P.; NARENDRAN, T.; GANESH, K. Mixed integer linear programming model for multi-commodity multidepot inventory routing problem. OPSEARCH, v.49, n.4, p.413-429, 2012.

RONEN, D. Marine inventory routing: Shipments planning. J. Oper. Res. Soc. v.53, n.1, p.108-114, 2002.

ROUNDY, R. 98\%-effective integer-ratio lot-sizing for onewarehouse multiretailer systems. Management Sci. V.31, n.11, p.1416-1430, 1985.

RUOKOKOSKI, M.; SOLYALI, O.; CORDEAU, J-F.; JANS, R.; SÜRAL, H. Efficient formulations and a branch-and-cut algorithm for a production-routing problem. GERAD Technical Report G-2010-66, HEC Montréal, Canada; 2010.

SAlGadO, T. T. Logística Prática, Técnicas e Processos De Melhorias. Rio de Janeiro: Senac Nacional, 2013.

SANDERS, N. R. Supply chain management: a global perspective. New York: Wiley, 2012.

SHEN, Q.; CHU, F.; CHEN, H. A Lagrangian relaxation approach for a multi-mode inventory routing problem with transshipment in crude oil transportation. Computers and Chemical Engineerin, v. 35, p.2113-2123, 2011.

SANTOS, E. G. Uma Heurística Híbrida baseada em Iterated Local Search para o Problema de Estoque e Roteamento de Veículos. Niterói: UFF/CUFF, 2014.

SILVA, E. L.; MENEZES, E. M. Metodologia da Pesquisa e Elaboração de Dissertação. 3a rev. atual. Florianópolis: UFSC/PPGEP/LED, 2005.

SILVA JÚNIOR, O.; SOARES. Algoritmos para os Problemas de Roteirização Estática e Dinâmica de Veículos com Janelas de Tempo. 2013. Pontifícia Universidade Católica do Rio de Janeiro, 2013.

SIMCHI-LEVI, D.; KAMINSKY, P.; SIMCHI-LEVI, E. Cadeia de suprimentos: projetos e gestão. 3a ed. Porto Alegre: Bookman, 2010.

SINDHUCHAO, S.; ROMEIJN, H. E.; AKÇALI, E.; BOONDISKULCHOK, R. An integrated inventory-routing system for multi-item joint replenishment with limited vehicle capacity. J. Global Optim. v.32, n.1, p.93-118, 2005. 
SOYSAL, M. Closed-loop Inventory Routing Problem for returnable transport items. Transportation Research Part D: Transport and Environment. v.48, p. 31-45, 2016.

SOYSAL, M.; BLOEMHOF-RUWAARD, J. M.; HAIJEMA, R.; VAN DER VORST, J. G. A. J. Modeling a green inventory routing problem for perishable products with horizontal collaboration. Computers and Operations Research. 2016, Prelo.

SLACK, N.; CHAMBERS, S.; JOHNSTON, R.; BETTS, A. Gerenciamento de Operações e de Processos Princípios e Práticas de Impacto Estratégico. $3^{\mathrm{a}}$ ed. Porto Alegre: Bookman, 2013.

SOLYALI O.; CORDEAU J-F.; LAPORTE, G. Robust inventory routing under demand uncertainty. Transportation Sci. v.46, n.3, p.327-340, 2012.

SOLYALI, O.; SÜRAL, H. A. Branch-and-cut algorithm using a strong formulation and an a priori tour-based heuristic for na inventory-routing problem. Transportation Sci. v.45, n.3, p.335-345, 2011.

SOLYALI, O.; SÜRAL H. A. Relaxation based solution approach for the inventory control and vehicle routing problem in vendor managed systems. Modeling, computation and Optimization. Singapore: World Scientific. p.171-89, 2009.

SOLYALI, O.; SÜRAL, H. A. Single supplier-single retailer system with an orderup-to level inventory policy. Operational Research Lett. v.36, n.5 p.543-546, 2008.

SPERANZA, M. G.; UKOVICH, W. An algorithm for optimal shipments with given frequencies. Naval Res. Logist. v.43, n.5, p.655-671, 1996.

SPERANZA, M. G.; UKOVICH, W. Minimizing transportation and inventory costs for several products on a single link. Oper. Res. v.42, n.5, p.879-894, 1994.

SUBRAMANIAN, A. Heuristic, Exact and Hybrid Approaches for Vehicle Routing Problem. 2012. Universidade Federal Fluminense, Niterói, 2012.

TANG, C. Perspectives in supply chain risk management. International Journal of Production Economics. v.103, p.451-488, 2006.

TRUDEAU, P.; DROR, M. Stochastic inventory routing: Route design with stockouts and route failures. Transportation Sci. v.26, n.3, p.171-184, 1992.

VONOLFEN, S.; AFFENZELLER, M.; BEHAM, A.; LENGAUER, E.; WAGNER, S. Simulation-based evolution of resupply and routing policies in rich vendor-managed inventory scenarios. Central European Journal of Operations Research. v.21, n.2, p.379-400, 2013.

WORLD BANK. Connecting to compete: trade logistics in the global economy 2016.http://lpi.worldbank.org/international/scorecard/radar/254/C/BRA/2016/C/U SA/2007/C/CHN/2007/C/CAN/2007, 2017. 
XIAO, N.; RAO, Y. L. Multi-product multi-period inventory routing optimization with time window constrains. International Journal of Simulation Modelling. v.15, n.2, p. 352-364, 2016.

VIDOVIĆ M., POPOVIĆ D., RATKOVIĆ B. Mixed integer and heuristics model for the inventory routing problem in fuel delivery. International Journal of Production Economics. v.147 p.593-604, 2014.

VISWANATHAN, S.; MATHUR, K. Integrating routing and inventory decisions in one-warehouse multiretailer multiproduct distribution systems. Management Sci. v.43, n.3, p.294-312, 1997.

ZHANG, Q.; SUNDARAMOORTHY, A.; GROSSMANN, I. E.; PINTO, J. M. Multiscale production routing in multicommodity supply chains with complex production facilities. Computers and Operations Research v.79, p.207-222, 2017.

ZHANG, Y.; QI, M.; MIAO L.; LIU E. Hybrid metaheuristic solutions to inventory location routing problem. Transportation Research Part E v.70, p.305-323, 2014.

ZHAO Q-H.; WANG, S-Y.; LAI, K. K. A partition approach to thecinventory/routing problem. Eur. J. Oper. Res. v.177, n.2, p.786-802, 2007.

ZHONG, H.; HALL, R. W.; Dessouky, M. Territory planning and vehicle dispatching with driver learning. Transportation Sci. v.41, n.1, p.74-89, 2007.

ZHU Z., ZHANG Y., GAO D. A Study of VMI Model With Stochastic Demand. Journal of Wuhan University of Technology (Transportation Science \& Engineering). v.3 p.608-628, 2009. 


\section{ANEXO A}

Tabela 25 - Resultados do AP x Literatura K = 2 e H=3. Fonte: Autor (2018).

\begin{tabular}{|c|c|c|c|c|c|c|}
\hline Instâncias & Vc. & Média & $\mathrm{AP}$ & Tempo & Literatura & Gap \\
\hline h3-lowcost-2-abs 1 n10 & 2 & 2356.37 & 2263.19 & 5.65 & 2263.19 & $0.00 \%$ \\
\hline h3-lowcost-2-abs1n15 & 2 & 2431.67 & 2297.02 & 8.16 & 2297.02 & $0.00 \%$ \\
\hline h3-lowcost-2-abs1n20 & 2 & 3075.85 & 2982.32 & 14.53 & 2917.30 & $2.23 \%$ \\
\hline h3-lowcost-2-abs1n25 & 2 & 3409.49 & 3133.28 & 22.37 & 3133.28 & $0.00 \%$ \\
\hline h3-lowcost-2-abs1n30 & 2 & 4036.11 & 3965.78 & 36.25 & 3803.78 & $4.26 \%$ \\
\hline h3-lowcost-2-abs 1 n35 & 2 & 3920.53 & 3634.12 & 59.64 & 3597.90 & $1.01 \%$ \\
\hline h3-lowcost-2-abs1n40 & 2 & 4488.34 & 4127.80 & 87.82 & 3992.46 & $3.39 \%$ \\
\hline h3-lowcost-2-abs 1 n45 & 2 & 4689.53 & 4401.52 & 127.54 & 4077.86 & $7.94 \%$ \\
\hline h3-lowcost-2-abs1n5 & 2 & 1396.33 & 1396.33 & 3.47 & 1396.33 & $0.00 \%$ \\
\hline h3-lowcost-2-abs 1 n50 & 2 & 5113.72 & 4902.10 & 199.63 & 4567.16 & $7.33 \%$ \\
\hline h3-lowcost-2-abs 2 n10 & 2 & 2852.39 & 2809.86 & 4.99 & 2809.86 & $0.00 \%$ \\
\hline h3-lowcost-2-abs2n15 & 2 & 2651.02 & 2554.10 & 8.37 & 2554.10 & $0.00 \%$ \\
\hline h3-lowcost-2-abs2n20 & 2 & 2812.14 & 2664.98 & 13.28 & 2664.98 & $0.00 \%$ \\
\hline h3-lowcost-2-abs2n25 & 2 & 3764.35 & 3634.92 & 26.50 & 3501.14 & $3.82 \%$ \\
\hline h3-lowcost-2-abs2n30 & 2 & 4065.49 & 3841.02 & 39.46 & 3645.20 & $5.37 \%$ \\
\hline h3-lowcost-2-abs2n35 & 2 & 4394.85 & 4131.52 & 74.22 & 3854.60 & $7.18 \%$ \\
\hline h3-lowcost-2-abs2n40 & 2 & 4886.21 & 4476.33 & 106.10 & 4180.07 & $7.09 \%$ \\
\hline h3-lowcost-2-abs2n45 & 2 & 4668.72 & 4392.06 & 126.23 & 4183.68 & $4.98 \%$ \\
\hline h3-lowcost-2-abs2n5 & 2 & 1177.49 & 1177.49 & 3.42 & 1177.49 & $0.00 \%$ \\
\hline h3-lowcost-2-abs2n50 & 2 & 5559.04 & 5403.46 & 191.00 & 4842.92 & $11.57 \%$ \\
\hline h3-lowcost-2-abs3n10 & 2 & 2231.62 & 2220.46 & 5.28 & 2220.46 & $0.00 \%$ \\
\hline h3-lowcost-2-abs3n15 & 2 & 2960.10 & 2800.00 & 8.96 & 2800.00 & $0.00 \%$ \\
\hline h3-lowcost-2-abs3n20 & 2 & 3006.54 & 2865.62 & 12.51 & 2818.62 & $1.67 \%$ \\
\hline h3-lowcost-2-abs3n25 & 2 & 3704.53 & 3471.82 & 22.68 & 3471.82 & $0.00 \%$ \\
\hline h3-lowcost-2-abs3n30 & 2 & 4050.79 & 3666.16 & 38.47 & 3616.18 & $1.38 \%$ \\
\hline h3-lowcost-2-abs3n35 & 2 & 4596.13 & 4435.46 & 59.11 & 4184.06 & $6.01 \%$ \\
\hline h3-lowcost-2-abs3n40 & 2 & 4422.83 & 4284.58 & 81.70 & 4105.58 & $4.36 \%$ \\
\hline h3-lowcost-2-abs3n45 & 2 & 4709.63 & 4456.60 & 106.12 & 4121.72 & $8.12 \%$ \\
\hline h3-lowcost-2-abs3n5 & 2 & 2438.02 & 2438.02 & 3.32 & 2438.02 & $0.00 \%$ \\
\hline h3-lowcost-2-abs3n50 & 2 & 5350.76 & 4953.90 & 210.22 & 4705.74 & $5.27 \%$ \\
\hline h3-lowcost-2-abs4n10 & 2 & 2506.07 & 2482.06 & 4.88 & 2482.06 & $0.00 \%$ \\
\hline h3-lowcost-2-abs4n15 & 2 & 2718.56 & 2513.69 & 9.01 & 2513.69 & $0.00 \%$ \\
\hline h3-lowcost-2-abs4n20 & 2 & 3883.59 & 3790.32 & 18.00 & 3560.62 & $6.45 \%$ \\
\hline h3-lowcost-2-abs4n25 & 2 & 3707.98 & 3335.78 & 26.06 & 3247.61 & $2.71 \%$ \\
\hline h3-lowcost-2-abs4n30 & 2 & 4114.28 & 3829.99 & 49.74 & 3598.08 & $6.45 \%$ \\
\hline h3-lowcost-2-abs4n35 & 2 & 3864.42 & 3748.26 & 54.27 & 3441.32 & $8.92 \%$ \\
\hline h3-lowcost-2-abs4n40 & 2 & 4361.62 & 4151.00 & 80.03 & 3736.78 & $11.08 \%$ \\
\hline h3-lowcost-2-abs4n45 & 2 & 5117.21 & 4866.52 & 136.82 & 4457.26 & $9.18 \%$ \\
\hline
\end{tabular}




\begin{tabular}{|c|c|c|c|c|c|c|}
\hline 13-lowcost-2-abs4n5 & 2 & 1717.36 & 1717.29 & 3.54 & 1717.29 & $0.00 \%$ \\
\hline h3-lowcost-2-abs4n50 & 2 & 5225.32 & 4871.88 & 171.05 & 4662.84 & $4.48 \%$ \\
\hline h3-lowcost-2-abs5n10 & 2 & 2184.62 & 2159.18 & 4.93 & 2159.18 & $0.00 \%$ \\
\hline h3-lowcost-2-abs5n15 & 2 & 2892.43 & 2610.59 & 9.15 & 2610.59 & $0.00 \%$ \\
\hline h3-lowcost-2-abs5n20 & & 3656.79 & 3514.64 & 14.86 & 3417.18 & $.85 \%$ \\
\hline h3-lowcost-2-abs5n25 & & 3734.25 & 3506.70 & 25.01 & 3506.70 & $0.00 \%$ \\
\hline 3-lowcost-2-abs5n30 & & 3529.34 & 3357.60 & 36.74 & 3215.86 & $4.41 \%$ \\
\hline h3-lowcost-2-abs5n35 & & 3940.99 & 3761.78 & 56.46 & 3593.64 & $4.68 \%$ \\
\hline h3-lowcost-2-abs5n40 & 2 & 4457.94 & 4150.56 & 90.82 & 3895.46 & $6.55 \%$ \\
\hline h3-lowcost-2-abs5n45 & 2 & 4521.90 & 4373.96 & 132.86 & 3911.98 & $81 \%$ \\
\hline h3-lowcost-2-abs5n5 & 2 & 1220.21 & 1220.21 & 3.36 & 1220.21 & $0.00 \%$ \\
\hline h3-lowcost-2-abs5n50 & 2 & 5359.15 & 5131.39 & 203.05 & 4567.43 & 12. \\
\hline h3-highcost-2-abs1n10 & 2 & 5124.19 & 5032.05 & 5.57 & 5032.05 & $0.00 \%$ \\
\hline h3-highcost-2-abs1n15 & 2 & 5911.76 & 5755.54 & 8.77 & 5755.54 & $0.00 \%$ \\
\hline h3-highcost-2-abs1n20 & 2 & 7606.02 & 7537.38 & 15.12 & 7508.76 & $0.38 \%$ \\
\hline h3-highcost-2-abs1n25 & 2 & 8874.99 & 8654.62 & 27.53 & 8521.52 & $1.56 \%$ \\
\hline h3-highcost-2-abs1n30 & 2 & 12761.04 & 12581.66 & 45.53 & 12449.90 & $1.06 \%$ \\
\hline h3-highcost-2-abs1n35 & 2 & 12226.59 & 12149.22 & 64.77 & 11922.30 & $90 \%$ \\
\hline h3-highcost-2-abs1n40 & 2 & 14168.39 & 13865.36 & 98.78 & 13660.40 & $1.50 \%$ \\
\hline h3-highcost-2-abs1n45 & 2 & 15016.99 & 14695.10 & 143.63 & 14307.30 & $1 \%$ \\
\hline h3-highcost-2-abs1n5 & 2 & 2265.21 & 2265.21 & 3.59 & 2265.21 & $0.00 \%$ \\
\hline h3-highcost-2-abs1n50 & 2 & 15640.25 & 15442.62 & 213.19 & 15097.10 & $2.29 \%$ \\
\hline h3-highcost-2-abs2n10 & 2 & 5101.35 & 5080.54 & 5.81 & 5080.54 & $0.00 \%$ \\
\hline h3-highcost-2-abs2n15 & 2 & 5931.00 & 5857.63 & 8.68 & 5853.37 & $0.07 \%$ \\
\hline h3-highcost-2-abs2n20 & 2 & 7448.99 & 7254.98 & 17.81 & 7254.98 & $0.00 \%$ \\
\hline h3-highcost-2-abs2n25 & 2 & 9525.44 & 9442.00 & 29.89 & 9258.10 & $1.99 \%$ \\
\hline h3-highcost-2-abs2n30 & 2 & 11678.19 & 11618.89 & 44.21 & 11258.10 & $20 \%$ \\
\hline h3-highcost-2-abs2n35 & 2 & 11206.63 & 11090.83 & 77.42 & 10765.60 & $3.02 \%$ \\
\hline h3-highcost-2-abs 2 n40 & 2 & 12291.17 & 12150.25 & 114.17 & 11665.70 & $4.15 \%$ \\
\hline h3-highcost-2-abs2n45 & 2 & 14119.95 & 13779.24 & 149.46 & 13640.90 & $01 \%$ \\
\hline h3-highcost-2-abs2n5 & 2 & 1969.31 & 1969.31 & 4.05 & 1969.31 & $0.00 \%$ \\
\hline h3-highcost-2-abs2n50 & 2 & 15998.16 & 15874.34 & 212.41 & 15342.90 & $3.46 \%$ \\
\hline h3-highcost-2-abs3n10 & 2 & 4376.97 & 4371.94 & 5.97 & 4371.94 & $0.00 \%$ \\
\hline h3-highcost-2-abs3n15 & 2 & 6833.94 & 6646.62 & 10.46 & 6646.62 & $0.00 \%$ \\
\hline h3-highcost-2-abs3n20 & 2 & 7775.39 & 7592.14 & 14.07 & 7592.14 & $0.00 \%$ \\
\hline h3-highcost-2-abs3n25 & 2 & 9924.08 & 9804.92 & 24.17 & 9804.92 & $0.00 \%$ \\
\hline h3-highcost-2-abs3n30 & 2 & 12567.87 & 12424.42 & 44.20 & 12277.06 & $1.20 \%$ \\
\hline h3-highcost-2-abs3n35 & 2 & 14498.48 & 14422.46 & 63.34 & 14147.48 & $1.94 \%$ \\
\hline h3-highcost-2-abs3n40 & 2 & 14160.85 & 13834.76 & 96.71 & 13830.10 & $0.03 \%$ \\
\hline h3-highcost-2-abs3n45 & 2 & 15505.49 & 15401.52 & 114.97 & 15008.20 & $2.62 \%$ \\
\hline h3-highcost-2-abs3n5 & 2 & 3653.00 & 3653.00 & 3.67 & 3653.00 & $0.00 \%$ \\
\hline h3-highcost-2-abs3n50 & 2 & 16138.34 & 15808.71 & 216.71 & 15520.90 & $1.85 \%$ \\
\hline h3-highcost-2-abs4n10 & 2 & 4661.22 & 4643.24 & 5.02 & 4643.24 & $0.00 \%$ \\
\hline h3-highcost-2-abs4n15 & 2 & 5482.47 & 5397.72 & 9.86 & 5338.36 & $1.11 \%$ \\
\hline h3-highcost-2-abs4n20 & 2 & 7603.47 & 7392.24 & 18.37 & 7380.59 & $0.16 \%$ \\
\hline h3-highcost-2-abs4n25 & 2 & 8990.65 & 8774.87 & 28.84 & 8631.33 & $1.66 \%$ \\
\hline
\end{tabular}




\begin{tabular}{lcccccc} 
h3-highcost-2-abs4n30 & 2 & 10400.30 & 10062.80 & 53.34 & 9963.98 & $0.99 \%$ \\
h3-highcost-2-abs4n35 & 2 & 10961.31 & 10714.28 & 61.31 & 10522.10 & $1.83 \%$ \\
h3-highcost-2-abs4n40 & 2 & 12122.37 & 11801.32 & 93.57 & 11590.40 & $1.82 \%$ \\
h3-highcost-2-abs4n45 & 2 & 14639.65 & 14402.04 & 157.58 & 14033.50 & $2.63 \%$ \\
h3-highcost-2-abs4n5 & 2 & 2301.04 & 2301.04 & 3.81 & 2301.04 & $0.00 \%$ \\
h3-highcost-2-abs4n50 & 2 & 17226.53 & 16968.04 & 190.40 & 16775.10 & $1.15 \%$ \\
h3-highcost-2-abs5n10 & 2 & 4961.78 & 4930.79 & 4.86 & 4930.79 & $0.00 \%$ \\
h3-highcost-2-abs5n15 & 2 & 5581.69 & 5317.53 & 9.77 & 5317.53 & $0.00 \%$ \\
h3-highcost-2-abs5n20 & 2 & 8629.26 & 8467.74 & 17.82 & 8441.54 & $0.31 \%$ \\
h3-highcost-2-abs5n25 & 2 & 10770.26 & 10641.68 & 26.63 & 10633.06 & $0.08 \%$ \\
h3-highcost-2-abs5n30 & 2 & 10408.11 & 10209.50 & 38.95 & 10063.46 & $1.45 \%$ \\
h3-highcost-2-abs5n35 & 2 & 11474.45 & 11333.22 & 63.63 & 11127.00 & $1.85 \%$ \\
h3-highcost-2-abs5n40 & 2 & 13929.99 & 13791.40 & 101.14 & 13390.40 & $2.99 \%$ \\
h3-highcost-2-abs5n45 & 2 & 14257.97 & 14002.70 & 138.77 & 13792.40 & $1.52 \%$ \\
h3-highcost-2-abs5n5 & 2 & 2372.36 & 2372.36 & 3.61 & 2372.36 & $0.00 \%$ \\
h3-highcost-2-abs5n50 & 2 & 16790.47 & 16562.67 & 235.16 & 16027.70 & $3.34 \%$ \\
\hline
\end{tabular}

Tabela 26 - Resultados do AP x Literatura K = 2 e H = 6. Fonte: Autor (2018).

\begin{tabular}{lcccccc}
\hline Instâncias & Vc. & Média & AP & Tempo & Literatura & Gap \\
\hline h6-lowcost-2-abs1n10 & 2 & 5867.95 & 5740.61 & 23.49 & 5667.41 & $1.29 \%$ \\
h6-lowcost-2-abs1n15 & 2 & 6259.28 & 6016.53 & 58.53 & 5987.40 & $0.49 \%$ \\
h6-lowcost-2-abs1n20 & 2 & 7957.93 & 7697.25 & 128.96 & 7388.80 & $4.17 \%$ \\
h6-lowcost-2-abs1n25 & 2 & 8103.53 & 7717.72 & 225.98 & 7461.55 & $3.43 \%$ \\
h6-lowcost-2-abs1n30 & 2 & 9789.32 & 9337.78 & 437.22 & 9056.82 & $3.10 \%$ \\
h6-lowcost-2-abs1n5 & 2 & 3776.12 & 3775.68 & 6.19 & 3775.68 & $0.00 \%$ \\
h6-lowcost-2-abs2n10 & 2 & 6701.08 & 6546.32 & 21.00 & 6512.43 & $0.52 \%$ \\
h6-lowcost-2-abs2n15 & 2 & 6535.84 & 6336.04 & 57.29 & 6152.89 & $2.98 \%$ \\
h6-lowcost-2-abs2n20 & 2 & 6682.49 & 6586.36 & 126.87 & 6358.66 & $3.58 \%$ \\
h6-lowcost-2-abs2n25 & 2 & 9127.24 & 8962.73 & 219.12 & 8309.70 & $7.86 \%$ \\
h6-lowcost-2-abs2n30 & 2 & 9234.42 & 8955.44 & 384.85 & 8449.94 & $5.98 \%$ \\
h6-lowcost-2-abs2n5 & 2 & 3186.47 & 3185.19 & 6.19 & 3185.19 & $0.00 \%$ \\
h6-lowcost-2-abs3n10 & 2 & 5360.67 & 5317.93 & 21.63 & 5260.44 & $1.09 \%$ \\
h6-lowcost-2-abs3n15 & 2 & 7211.00 & 7106.19 & 58.95 & 7011.20 & $1.35 \%$ \\
h6-lowcost-2-abs3n20 & 2 & 7862.06 & 7649.30 & 114.14 & 7473.61 & $2.35 \%$ \\
h6-lowcost-2-abs3n25 & 2 & 9315.74 & 8917.81 & 232.38 & 8690.21 & $2.62 \%$ \\
h6-lowcost-2-abs3n30 & 2 & 9184.25 & 8649.87 & 401.76 & 8442.43 & $2.46 \%$ \\
h6-lowcost-2-abs3n5 & 2 & 5998.06 & 5964.08 & 6.95 & 5962.76 & $0.02 \%$ \\
h6-lowcost-2-abs4n10 & 2 & 6391.98 & 6200.39 & 22.67 & 6198.49 & $0.03 \%$ \\
h6-lowcost-2-abs4n15 & 2 & 6514.58 & 6252.37 & 60.10 & 6126.71 & $2.05 \%$ \\
h6-lowcost-2-abs4n20 & 2 & 8723.41 & 8418.54 & 141.43 & 8310.80 & $1.30 \%$ \\
h6-lowcost-2-abs4n25 & 2 & 8723.05 & 8328.27 & 235.27 & 7884.33 & $5.63 \%$ \\
h6-lowcost-2-abs4n30 & 2 & 9151.71 & 8792.69 & 396.12 & 8225.35 & $6.90 \%$ \\
h6-lowcost-2-abs4n5 & 2 & 3813.14 & 3805.98 & 6.82 & 3805.98 & $0.00 \%$ \\
h6-lowcost-2-abs5n10 & 2 & 5239.90 & 5137.95 & 21.54 & 5137.52 & $0.01 \%$ \\
h6-lowcost-2-abs5n15 & 2 & 6755.64 & 6505.67 & 57.93 & 6364.99 & $2.21 \%$ \\
h6-lowcost-2-abs5n20 & 2 & 8929.31 & 8778.03 & 123.43 & 8509.86 & $3.15 \%$
\end{tabular}




\begin{tabular}{|c|c|c|c|c|c|c|}
\hline h6-lowcost-2-abs5n25 & 2 & 8959.64 & 8747.57 & 241.47 & 8501.64 & $2.89 \%$ \\
\hline h6-lowcost-2-abs5n30 & 2 & 8717.74 & 8402.32 & 425.13 & 8045.41 & $4.44 \%$ \\
\hline h6-lowcost-2-abs5n5 & 2 & 2891.85 & 2891.85 & 5.92 & 2891.85 & $0.00 \%$ \\
\hline h6-highcost-2-abs1n10 & 2 & 10159.17 & 10075.26 & 23.32 & 9996.96 & $0.78 \%$ \\
\hline h6-highcost-2-abs1n15 & 2 & 12867.96 & 12732.80 & 59.47 & 12624.68 & $0.86 \%$ \\
\hline h6-highcost-2-abs1n20 & 2 & 16133.55 & 15871.97 & 137.28 & 15540.35 & $2.13 \%$ \\
\hline h6-highcost-2-abs1n25 & 2 & 16735.67 & 16547.48 & 239.67 & 15954.80 & $3.71 \%$ \\
\hline h6-highcost-2-abs1n30 & 2 & 24416.29 & 24179.22 & 453.96 & 23859.40 & $1.34 \%$ \\
\hline h6-highcost-2-abs1n5 & 2 & 6379.87 & 6379.56 & 7.16 & 6379.56 & $0.00 \%$ \\
\hline h6-highcost-2-abs2n10 & 2 & 9990.53 & 9814.04 & 20.79 & 9814.04 & $0.00 \%$ \\
\hline h6-highcost-2-abs2n15 & 2 & 12868.95 & 12614.80 & 60.73 & 12568.37 & $0.37 \%$ \\
\hline h6-highcost-2-abs2n20 & 2 & 15268.80 & 15088.10 & 130.23 & 14940.28 & $0.99 \%$ \\
\hline h6-highcost-2-abs2n25 & 2 & 18210.84 & 18008.17 & 264.25 & 17577.36 & $2.45 \%$ \\
\hline h6-highcost-2-abs2n30 & 2 & 21493.38 & 21136.10 & 376.24 & 20675.90 & $2.23 \%$ \\
\hline h6-highcost-2-abs2n5 & 2 & 5511.88 & 5498.64 & 7.03 & 5498.64 & $0.00 \%$ \\
\hline h6-highcost-2-abs3n10 & 2 & 9167.64 & 9107.27 & 20.97 & 9071.05 & $0.40 \%$ \\
\hline h6-highcost-2-abs3n15 & 2 & 14589.65 & 14485.21 & 58.57 & 14450.07 & $0.24 \%$ \\
\hline h6-highcost-2-abs3n20 & 2 & 15393.33 & 15219.72 & 128.72 & 14986.80 & $1.55 \%$ \\
\hline h6-highcost-2-abs3n25 & 2 & 19593.35 & 19314.91 & 253.64 & 19024.30 & $1.53 \%$ \\
\hline h6-highcost-2-abs3n30 & 2 & 24084.47 & 23907.53 & 424.11 & 23416.80 & $2.10 \%$ \\
\hline h6-highcost-2-abs3n5 & 2 & 8143.26 & 8134.33 & 5.88 & 8108.03 & $0.32 \%$ \\
\hline h6-highcost-2-abs4n10 & 2 & 10073.78 & 9978.47 & 22.62 & 9864.35 & $1.16 \%$ \\
\hline h6-highcost-2-abs4n15 & 2 & 11541.75 & 11281.99 & 62.26 & 11267.69 & $0.13 \%$ \\
\hline h6-highcost-2-abs4n20 & 2 & 15827.75 & 15496.25 & 143.19 & 15423.00 & $0.47 \%$ \\
\hline h6-highcost-2-abs4n25 & 2 & 17413.69 & 16928.06 & 259.48 & 16663.10 & $1.59 \%$ \\
\hline h6-highcost-2-abs4n30 & 2 & 18989.32 & 18673.53 & 420.25 & 18275.20 & $2.18 \%$ \\
\hline h6-highcost-2-abs4n5 & 2 & 5726.59 & 5718.02 & 6.94 & 5718.02 & $0.00 \%$ \\
\hline h6-highcost-2-abs5n10 & 2 & 10089.28 & 10021.66 & 20.34 & 10018.40 & $0.03 \%$ \\
\hline h6-highcost-2-abs5n15 & 2 & 11749.28 & 11519.76 & 60.81 & 11374.38 & $1.28 \%$ \\
\hline h6-highcost-2-abs5n20 & 2 & 17413.12 & 17288.90 & 134.16 & 17096.50 & $1.13 \%$ \\
\hline h6-highcost-2-abs5n25 & 2 & 20584.41 & 20188.45 & 241.26 & 20003.28 & $0.93 \%$ \\
\hline h6-highcost-2-abs5n30 & 2 & 20017.91 & 19898.24 & 402.00 & 19576.90 & $1.64 \%$ \\
\hline h6-highcost-2-abs5n5 & 2 & 5000.15 & 4999.24 & 6.13 & 4999.24 & $0.00 \%$ \\
\hline
\end{tabular}

Tabela 27 - Resultados do AP x Literatura K = 3 e H = 3. Fonte: Autor (2018).

\begin{tabular}{lcccccc}
\hline Instâncias & Vc. & Média & AP & Tempo & Literatura & Gap \\
\hline h3-lowcost-3-abs1n10 & 3 & 2824.40 & 2732.61 & 6.56 & 2732.61 & $0.00 \%$ \\
h3-lowcost-3-abs1n15 & 3 & 2927.18 & 2815.36 & 10.56 & 2783.77 & $1.13 \%$ \\
h3-lowcost-3-abs1n20 & 3 & 3793.33 & 3655.04 & 18.56 & 3605.72 & $1.37 \%$ \\
h3-lowcost-3-abs1n25 & 3 & 4107.57 & 3643.90 & 31.53 & 3503.38 & $4.01 \%$ \\
h3-lowcost-3-abs1n30 & 3 & 4820.44 & 4278.58 & 45.99 & 4251.64 & $0.63 \%$ \\
h3-lowcost-3-abs1n35 & 3 & 4514.45 & 4353.00 & 68.82 & 4080.60 & $6.68 \%$ \\
h3-lowcost-3-abs1n40 & 3 & 5320.45 & 4892.16 & 123.18 & 4532.84 & $7.93 \%$ \\
h3-lowcost-3-abs1n45 & 3 & 5498.33 & 5022.86 & 155.63 & 4537.30 & $10.70 \%$ \\
h3-lowcost-3-abs1n5 & 3 & 1430.51 & 1430.51 & 4.19 & 1430.51 & $0.00 \%$ \\
h3-lowcost-3-abs1n50 & 3 & 6245.10 & 5924.96 & 240.82 & 5202.18 & $13.89 \%$
\end{tabular}




\begin{tabular}{|c|c|c|c|c|c|c|}
\hline h3-lowcost-3-abs2n10 & 3 & 3605.64 & 3470.15 & 6.70 & 3470.15 & $0.00 \%$ \\
\hline h3-lowcost-3-abs2n15 & 3 & 3048.79 & 2851.90 & 11.20 & 2757.82 & $3.41 \%$ \\
\hline h3-lowcost-3-abs2n20 & 3 & 3088.60 & 3020.18 & 22.56 & 2908.48 & $3.84 \%$ \\
\hline h3-lowcost-3-abs2n25 & 3 & 4461.64 & 4233.00 & 34.34 & 3952.08 & $7.11 \%$ \\
\hline h3-lowcost-3-abs2n30 & 3 & 4645.07 & 4307.59 & 50.03 & 4102.37 & $5.00 \%$ \\
\hline h3-lowcost-3-abs2n35 & 3 & 5178.62 & 4950.33 & 83.97 & 4221.73 & $17.26 \%$ \\
\hline h3-lowcost-3-abs 2 n40 & 3 & 5721.08 & 5561.95 & 122.13 & 4544.37 & $22.39 \%$ \\
\hline h3-lowcost-3-abs2n45 & 3 & 5638.99 & 5376.30 & 147.20 & 4744.96 & $13.31 \%$ \\
\hline h3-lowcost-3-abs2n5 & 3 & 1582.69 & 1582.69 & 4.02 & 1582.69 & $0.00 \%$ \\
\hline h3-lowcost-3-abs2n50 & 3 & 6496.12 & 6207.40 & 219.56 & 5695.96 & $8.98 \%$ \\
\hline h3-lowcost-3-abs3n10 & 3 & 2654.53 & 2649.26 & 6.74 & 2649.26 & $0.00 \%$ \\
\hline h3-lowcost-3-abs3n15 & 3 & 3277.78 & 3072.84 & 12.21 & 3072.84 & $0.00 \%$ \\
\hline h3-lowcost-3-abs3n20 & 3 & 3348.05 & 3064.78 & 17.62 & 3064.78 & $0.00 \%$ \\
\hline h3-lowcost-3-abs3n25 & 3 & 4475.31 & 4275.66 & 31.98 & 4068.66 & $5.09 \%$ \\
\hline h3-lowcost-3-abs3n30 & 3 & 4346.47 & 4220.68 & 50.11 & 3820.66 & $10.47 \%$ \\
\hline h3-lowcost-3-abs3n35 & 3 & 5243.21 & 4899.86 & 69.53 & 4725.86 & $3.68 \%$ \\
\hline h3-lowcost-3-abs3n40 & 3 & 5007.61 & 4703.94 & 109.69 & 4310.24 & $9.13 \%$ \\
\hline h3-lowcost-3-abs3n45 & 3 & 5042.24 & 4703.06 & 123.51 & 4267.42 & $10.21 \%$ \\
\hline h3-lowcost-3-abs3n5 & 3 & 2997.44 & 2997.44 & 4.17 & 2997.44 & $0.00 \%$ \\
\hline h3-lowcost-3-abs3n50 & 3 & 6146.77 & 5772.68 & 243.28 & 5180.15 & $11.44 \%$ \\
\hline h3-lowcost-3-abs4n10 & 3 & 3314.73 & 3234.95 & 6.24 & 3183.36 & $1.62 \%$ \\
\hline h3-lowcost-3-abs4n15 & 3 & 3032.73 & 2929.32 & 11.57 & 2886.32 & $1.49 \%$ \\
\hline h3-lowcost-3-abs4n20 & 3 & 4551.95 & 4293.46 & 20.49 & 4088.88 & $5.00 \%$ \\
\hline h3-lowcost-3-abs4n25 & 3 & 4240.55 & 3956.62 & 32.33 & 3659.14 & $8.13 \%$ \\
\hline h3-lowcost-3-abs4n30 & 3 & 4807.72 & 4659.04 & 54.19 & 3958.58 & $17.69 \%$ \\
\hline h3-lowcost-3-abs4n35 & 3 & 4572.76 & 4368.54 & 62.92 & 4011.04 & $8.91 \%$ \\
\hline h3-lowcost-3-abs4n40 & 3 & 5026.28 & 4721.56 & 90.32 & 3994.38 & $18.21 \%$ \\
\hline h3-lowcost-3-abs4n45 & 3 & 5791.85 & 5515.44 & 165.71 & 4921.16 & $12.08 \%$ \\
\hline h3-lowcost-3-abs4n5 & 3 & 2291.17 & 2291.17 & 3.74 & 2291.17 & $0.00 \%$ \\
\hline h3-lowcost-3-abs4n50 & 3 & 6198.99 & 6039.86 & 188.92 & 5309.86 & $13.75 \%$ \\
\hline h3-lowcost-3-abs5n10 & 3 & 2475.45 & 2461.11 & 6.71 & 2461.11 & $0.00 \%$ \\
\hline h3-lowcost-3-abs5n15 & 3 & 3394.53 & 3260.59 & 11.73 & 3260.59 & $0.00 \%$ \\
\hline h3-lowcost-3-abs5n20 & 3 & 4548.97 & 4205.50 & 20.01 & 4124.24 & $1.97 \%$ \\
\hline h3-lowcost-3-abs5n25 & 3 & 4378.30 & 4279.71 & 39.55 & 4120.26 & $3.87 \%$ \\
\hline h3-lowcost-3-abs5n30 & 3 & 4135.65 & 4012.22 & 42.17 & 3588.64 & $11.80 \%$ \\
\hline h3-lowcost-3-abs5n35 & 3 & 4608.27 & 4427.78 & 63.33 & 4034.70 & $9.74 \%$ \\
\hline h3-lowcost-3-abs5n40 & 3 & 5242.62 & 4930.06 & 103.69 & 4339.54 & $13.61 \%$ \\
\hline h3-lowcost-3-abs5n45 & 3 & 5117.38 & 4675.54 & 152.72 & 4140.74 & $12.92 \%$ \\
\hline h3-lowcost-3-abs5n5 & 3 & 1513.84 & 1513.76 & 4.06 & 1513.76 & $0.00 \%$ \\
\hline h3-lowcost-3-abs5n50 & 3 & 6192.97 & 5731.89 & 213.16 & 5237.65 & $9.44 \%$ \\
\hline h3-highcost-3-abs1n10 & 3 & 5597.05 & 5506.09 & 6.84 & 5506.09 & $0.00 \%$ \\
\hline h3-highcost-3-abs1n15 & 3 & 6369.78 & 6252.54 & 11.70 & 6242.90 & $0.15 \%$ \\
\hline h3-highcost-3-abs1n20 & 3 & 8437.05 & 8294.76 & 19.31 & 8165.42 & $1.58 \%$ \\
\hline h3-highcost-3-abs1n25 & 3 & 9353.84 & 9135.85 & 36.46 & 8893.82 & $2.72 \%$ \\
\hline h3-highcost-3-abs1n30 & 3 & 13358.78 & 13096.74 & 59.47 & 12908.90 & $1.46 \%$ \\
\hline h3-highcost-3-abs1n35 & 3 & 12805.70 & 12560.06 & 79.34 & 12395.96 & $1.32 \%$ \\
\hline
\end{tabular}




\begin{tabular}{|c|c|c|c|c|c|c|}
\hline h3-highcost-3-abs1n40 & 3 & 14889.87 & 14617.60 & 153.98 & 14224.10 & $2.77 \%$ \\
\hline h3-highcost-3-abs 1 n45 & 3 & 15595.01 & 15326.96 & 193.23 & 14770.98 & $3.76 \%$ \\
\hline h3-highcost-3-abs1n5 & 3 & 2298.73 & 2298.73 & 4.28 & 2298.73 & $0.00 \%$ \\
\hline h3-highcost-3-abs 1 n50 & 3 & 16742.03 & 16481.04 & 252.41 & 15732.60 & $4.76 \%$ \\
\hline h3-highcost-3-abs 2 n10 & 3 & 5828.63 & 5743.25 & 6.61 & 5743.25 & $0.00 \%$ \\
\hline h3-highcost-3-abs2n15 & 3 & 6398.98 & 6165.90 & 11.50 & 6071.26 & $1.56 \%$ \\
\hline h3-highcost-3-abs2n20 & 3 & 7649.73 & 7585.19 & 25.52 & 7499.50 & $1.14 \%$ \\
\hline h3-highcost-3-abs2n25 & 3 & 10186.99 & 9864.20 & 36.89 & 9708.34 & $1.61 \%$ \\
\hline h3-highcost-3-abs2n30 & 3 & 12241.54 & 11995.83 & 53.84 & 11686.46 & $2.65 \%$ \\
\hline h3-highcost-3-abs2n35 & 3 & 12035.71 & 11742.70 & 90.15 & 11125.27 & $5.55 \%$ \\
\hline h3-highcost-3-abs2n40 & 3 & 12949.57 & 12614.22 & 137.62 & 12015.60 & $4.98 \%$ \\
\hline h3-highcost-3-abs2n45 & 3 & 14944.37 & 14510.46 & 183.29 & 14211.00 & $2.11 \%$ \\
\hline h3-highcost-3-abs2n5 & 3 & 2369.93 & 2369.93 & 3.70 & 2369.93 & $0.00 \%$ \\
\hline h3-highcost-3-abs2n50 & 3 & 16826.83 & 16289.66 & 239.53 & 16041.88 & $1.54 \%$ \\
\hline h3-highcost-3-abs 3 n 10 & 3 & 4808.06 & 4808.06 & 6.88 & 4808.06 & $0.00 \%$ \\
\hline h3-highcost-3-abs $3 \mathrm{n} 15$ & 3 & 7185.40 & 7116.10 & 13.31 & 6926.18 & $2.74 \%$ \\
\hline h3-highcost-3-abs3n20 & 3 & 8020.48 & 7840.54 & 17.66 & 7840.54 & $0.00 \%$ \\
\hline h3-highcost-3-abs3n25 & 3 & 10755.06 & 10443.60 & 32.87 & 10404.88 & $0.37 \%$ \\
\hline h3-highcost-3-abs3n30 & 3 & 12962.58 & 12735.75 & 62.50 & 12487.96 & $1.98 \%$ \\
\hline h3-highcost-3-abs3n35 & 3 & 15256.21 & 14988.30 & 100.35 & 14694.46 & $2.00 \%$ \\
\hline h3-highcost-3-abs 3 n40 & 3 & 14664.62 & 14276.40 & 114.29 & 14040.36 & $1.68 \%$ \\
\hline h3-highcost-3-abs3n45 & 3 & 16088.22 & 15727.94 & 151.97 & 15169.96 & $3.68 \%$ \\
\hline h3-highcost-3-abs3n5 & 3 & 4191.26 & 4191.26 & 3.86 & 4191.26 & $0.00 \%$ \\
\hline h3-highcost-3-abs 3 n50 & 3 & 16853.20 & 16413.42 & 250.52 & 15979.29 & $2.72 \%$ \\
\hline h3-highcost-3-abs4n10 & 3 & 5446.85 & 5336.85 & 6.24 & 5335.29 & $0.03 \%$ \\
\hline h3-highcost-3-abs4n15 & 3 & 5802.64 & 5707.54 & 13.37 & 5705.16 & $0.04 \%$ \\
\hline h3-highcost-3-abs4n20 & 3 & 8294.40 & 8122.47 & 21.24 & 7919.09 & $2.57 \%$ \\
\hline h3-highcost-3-abs4n25 & 3 & 9443.27 & 9163.34 & 34.40 & 9049.07 & $1.26 \%$ \\
\hline h3-highcost-3-abs4n30 & 3 & 11030.35 & 10641.39 & 65.52 & 10287.09 & $3.44 \%$ \\
\hline h3-highcost-3-abs4n35 & 3 & 11642.21 & 11267.68 & 87.57 & 11092.88 & $1.58 \%$ \\
\hline h3-highcost-3-abs4n40 & 3 & 12835.71 & 12685.79 & 109.11 & 11848.98 & $7.06 \%$ \\
\hline h3-highcost-3-abs4n45 & 3 & 15445.99 & 15252.44 & 186.36 & 14476.74 & $5.36 \%$ \\
\hline h3-highcost-3-abs4n5 & 3 & 2874.10 & 2874.10 & 3.93 & 2874.10 & $0.00 \%$ \\
\hline h3-highcost-3-abs4n50 & 3 & 18189.18 & 17953.54 & 221.22 & 17417.38 & $3.08 \%$ \\
\hline h3-highcost-3-abs5n10 & 3 & 5242.97 & 5224.45 & 6.62 & 5224.45 & $0.00 \%$ \\
\hline h3-highcost-3-abs5n15 & 3 & 6135.66 & 6008.67 & 12.80 & 5967.25 & $0.69 \%$ \\
\hline h3-highcost-3-abs5n20 & 3 & 9538.20 & 9397.42 & 23.88 & 9149.16 & $2.71 \%$ \\
\hline h3-highcost-3-abs5n25 & 3 & 11522.63 & 11382.92 & 39.68 & 11250.90 & $1.17 \%$ \\
\hline h3-highcost-3-abs5n30 & 3 & 10826.18 & 10631.76 & 49.86 & 10450.40 & $1.74 \%$ \\
\hline h3-highcost-3-abs5n35 & 3 & 12040.26 & 11784.36 & 77.54 & 11568.30 & $1.87 \%$ \\
\hline h3-highcost-3-abs5n40 & 3 & 14579.95 & 14392.66 & 116.13 & 13835.10 & $4.03 \%$ \\
\hline h3-highcost-3-abs5n45 & 3 & 14864.54 & 14409.58 & 166.92 & 14012.20 & $2.84 \%$ \\
\hline h3-highcost-3-abs5n5 & 3 & 2663.66 & 2663.66 & 3.97 & 2663.66 & $0.00 \%$ \\
\hline h3-highcost-3-abs5n50 & 3 & 17474.53 & 17231.19 & 268.22 & 16629.62 & $3.62 \%$ \\
\hline
\end{tabular}


Tabela 28 - Resultados do AP x Literatura $\mathrm{K}=3$ e H = 6. Fonte: Autor (2018).

\begin{tabular}{|c|c|c|c|c|c|c|}
\hline Instâncias & Vc. & Média & $\mathrm{AP}$ & Tempo & Literatura & Gap \\
\hline h6-lowcost-3-abs 1 n10 & 3 & 7402.83 & 7275.28 & 32.50 & 7119.24 & $2.19 \%$ \\
\hline h6-lowcost-3-abs1n15 & 3 & 7312.41 & 7157.04 & & 6861.07 & $4.31 \%$ \\
\hline ost-3-abs1n20 & 3 & 9644.32 & 9094.36 & 187.17 & 8804 & $3.29 \%$ \\
\hline h6-lowcost-3-abs 1 n25 & 3 & 9270.87 & 8841.77 & 329.77 & & $4.76 \%$ \\
\hline h6-lowcost-3-abs 1 n30 & 3 & 11487.31 & 11322.11 & 643.42 & 10883.80 & $4.03 \%$ \\
\hline h6-lowcost-3-abs1n5 & 3 & 4675.27 & 4657.15 & & 4657.15 & $0.00 \%$ \\
\hline h6-lowcost-3-abs2n10 & 3 & 8388.36 & 8282.71 & 30.88 & 8275.94 & $0.08 \%$ \\
\hline h6-lowcost-3-abs2n15 & 3 & 7604.69 & 7256.79 & 80.97 & 7107.77 & $2.10 \%$ \\
\hline h6-lowcost-3-abs2n20 & 3 & 7468.30 & 7206.03 & 171.16 & 6928.07 & $4.01 \%$ \\
\hline h6-low & 3 & 10793.40 & 10458.56 & & & $6.94 \%$ \\
\hline h6-lowcost-3- & 3 & 10522.76 & 1011 & 530.35 & 9445.46 & $7.08 \%$ \\
\hline h6-low & 3 & 4227.96 & 4221 & 9.02 & 422 & $0.01 \%$ \\
\hline h6-lowcost-3-abs3n10 & 3 & 6382.28 & 6187.09 & 31.99 & 6185.29 & $0.03 \%$ \\
\hline h6-lowcost-3-abs3n15 & 3 & 8554.74 & 8363.70 & & 8158.42 & $2.52 \%$ \\
\hline h6-lowcost-3-abs3n20 & 3 & 8946.42 & 8739.13 & 165.01 & 8410.66 & $3.91 \%$ \\
\hline h6-lowcost-3-abs3n25 & 3 & 11233.51 & 10877.90 & 355.12 & 10588.91 & $2.73 \%$ \\
\hline h6-lov & 3 & 10170.73 & 9766.15 & 568.69 & & $2.89 \%$ \\
\hline h6-low & 3 & 7818.69 & 7728.23 & 7.65 & 7703.53 & $0.32 \%$ \\
\hline h6-lo & 3 & 778 & & & & $1.57 \%$ \\
\hline h6-lowcost-3-a & 3 & 7648.56 & 7519.74 & 82.59 & 7157.60 & $5.06 \%$ \\
\hline & 3 & & & & & $2.57 \%$ \\
\hline h6-lowcost-3-a & 3 & 9743.95 & 9412 & & & $6.83 \%$ \\
\hline h6-lowcost-3-a & 3 & 10571.19 & 10194 & 499.12 & 9444.94 & $7.94 \%$ \\
\hline h6-lowcost-3-abs4n5 & 3 & 4578.69 & 4495.31 & & 4495.31 & $0.00 \%$ \\
\hline h6-lowcost-3-abs5n10 & 3 & 6022.54 & 5891.18 & 29.24 & 5824.09 & $1.15 \%$ \\
\hline h6-low & 3 & 8207.32 & & & & $4.54 \%$ \\
\hline h6-lov & 3 & 11251.80 & 1106 & 169.39 & 1059 & $4.40 \%$ \\
\hline h6-lov & 3 & 11020.26 & 1069 & & 1040 & $2.73 \%$ \\
\hline h6-low & 3 & 10058.84 & 9701 & 594.86 & 9348.98 & $3.77 \%$ \\
\hline h6-lowcost-3-al & 3 & 879.09 & & & & $0 \%$ \\
\hline h6-highcost-3-abs1n10 & 3 & 11702.98 & & & & $0.81 \%$ \\
\hline h6-highcost-3-abs1n15 & 3 & 13946.84 & 13777.76 & 87.55 & 13517.60 & $1.92 \%$ \\
\hline h6-highcost-3-abs 1 n20 & 3 & 17596.49 & 17326. & & 16932.69 & $2.33 \%$ \\
\hline h6-highcost-3-abs1n25 & 3 & 17818.99 & 17338.09 & 331.64 & 16893.51 & $2.63 \%$ \\
\hline h6-highcost-3-abs1n30 & 3 & 25948.88 & 25609.57 & 660.08 & 25657.30 & $-0.19 \%$ \\
\hline h6-highcost-3-abs1n5 & 3 & 7263.96 & 7259.05 & & 7259.05 & $0.00 \%$ \\
\hline h6-highcost-3-abs2n10 & 3 & 11710.54 & 11629.42 & & 11584.36 & $0.39 \%$ \\
\hline h6-highcost-3-abs2n15 & 3 & 13930.46 & 13606.91 & 85.87 & 13512.67 & $0.70 \%$ \\
\hline h6-highcost-3-abs2n20 & 3 & & & & & $1.26 \%$ \\
\hline h6-highcost-3-abs2n25 & 3 & 19861.80 & 19489.59 & 329.95 & 19244.98 & $1.27 \%$ \\
\hline h6-highcost-3-abs2n30 & 3 & 22766.83 & 22350.32 & 526.30 & 20111.17 & $11.13 \%$ \\
\hline & 3 & 6539.73 & 6532.00 & & 6530.35 & $0.03 \%$ \\
\hline h6-highcost-3-abs3n10 & 3 & 10184.71 & 9982.68 & 31.69 & 9982.68 & $0.00 \%$ \\
\hline h6-highcost-3-abs3n15 & 3 & 15974.85 & 15725.46 & 86.80 & 15611.73 & $0.73 \%$ \\
\hline
\end{tabular}




\begin{tabular}{lcccccc} 
h6-highcost-3-abs3n20 & 3 & 16385.20 & 16127.10 & 173.22 & 15940.40 & $1.17 \%$ \\
h6-highcost-3-abs3n25 & 3 & 21427.23 & 21033.15 & 351.79 & 20786.60 & $1.19 \%$ \\
h6-highcost-3-abs3n30 & 3 & 25209.27 & 24819.29 & 582.83 & 24390.20 & $1.76 \%$ \\
h6-highcost-3-abs3n5 & 3 & 9951.62 & 9862.89 & 8.28 & 9862.89 & $0.00 \%$ \\
h6-highcost-3-abs4n10 & 3 & 11448.27 & 11308.16 & 32.84 & 11168.50 & $1.25 \%$ \\
h6-highcost-3-abs4n15 & 3 & 12776.06 & 12498.29 & 98.86 & 12295.96 & $1.65 \%$ \\
h6-highcost-3-abs4n20 & 3 & 17721.69 & 17535.58 & 193.33 & 17132.33 & $2.35 \%$ \\
h6-highcost-3-abs4n25 & 3 & 18445.81 & 18159.05 & 316.84 & 17593.30 & $3.22 \%$ \\
h6-highcost-3-abs4n30 & 3 & 20646.63 & 20051.41 & 578.89 & 19460.40 & $3.04 \%$ \\
h6-highcost-3-abs4n5 & 3 & 6489.97 & 6405.74 & 8.25 & 6405.74 & $0.00 \%$ \\
h6-highcost-3-abs5n10 & 3 & 10896.53 & 10709.63 & 30.56 & 10702.08 & $0.07 \%$ \\
h6-highcost-3-abs5n15 & 3 & 13079.27 & 12826.62 & 83.25 & 12610.70 & $1.71 \%$ \\
h6-highcost-3-abs5n20 & 3 & 19713.15 & 19478.75 & 181.47 & 19047.50 & $2.26 \%$ \\
h6-highcost-3-abs5n25 & 3 & 22573.37 & 22024.57 & 337.16 & 21936.90 & $0.40 \%$ \\
h6-highcost-3-abs5n30 & 3 & 21243.91 & 20989.67 & 608.75 & 21036.60 & $-0.22 \%$ \\
h6-highcost-3-abs5n5 & 3 & 5972.78 & 5972.78 & 8.20 & 5972.78 & $0.00 \%$ \\
\hline
\end{tabular}

Tabela 29 - Resultados do AP x Literatura K = 4 e H = 3. Fonte: Autor (2018).

\begin{tabular}{|c|c|c|c|c|c|c|}
\hline Instâncias & Vc. & Média & AP & Tempo & Literatura & Gap \\
\hline h3-lowcost-4-abs1n10 & 4 & 3267.27 & 3261.94 & 8.43 & 3261.94 & $0.00 \%$ \\
\hline h3-lowcost-4-abs1n15 & 4 & 3343.14 & 3212.96 & 15.48 & 3166.44 & $1.47 \%$ \\
\hline h3-lowcost-4-abs1n20 & 4 & 4446.27 & 4274.01 & 24.63 & 4148.00 & $3.04 \%$ \\
\hline h3-lowcost-4-abs1n25 & 4 & 4325.38 & 4112.78 & 40.92 & 3949.73 & $4.13 \%$ \\
\hline h3-lowcost-4-abs1n30 & 4 & 5254.34 & 4891.08 & 68.48 & 4720.58 & $3.61 \%$ \\
\hline h3-lowcost-4-abs1n35 & 4 & 5071.71 & 4583.20 & 95.60 & 4368.96 & $4.90 \%$ \\
\hline h3-lowcost-4-abs $1 \mathrm{n} 40$ & 4 & 5970.72 & 5625.72 & 138.16 & 5033.58 & $11.76 \%$ \\
\hline h3-lowcost-4-abs $1 \mathrm{n} 45$ & 4 & 5819.22 & 5332.28 & 216.68 & 4989.48 & $6.87 \%$ \\
\hline h3-lowcost-4-abs1n5 & 4 & 1601.57 & 1601.57 & 4.44 & 1601.57 & $0.00 \%$ \\
\hline h3-lowcost-4-abs 1 n50 & 4 & 7093.22 & 6865.56 & 270.02 & 6406.50 & $7.17 \%$ \\
\hline h3-lowcost-4-abs2n10 & 4 & 4295.52 & 4272.01 & 8.12 & 4271.02 & $0.02 \%$ \\
\hline h3-lowcost-4-abs2n15 & 4 & 3474.52 & 3396.66 & 14.99 & 3396.66 & $0.00 \%$ \\
\hline h3-lowcost-4-abs2n20 & 4 & 3294.20 & 3132.51 & 28.72 & 3128.05 & $0.14 \%$ \\
\hline h3-lowcost-4-abs2n25 & 4 & 4983.39 & 4688.26 & 43.40 & 4501.34 & $4.15 \%$ \\
\hline h3-lowcost-4-abs2n30 & 4 & 5108.80 & 4663.85 & 68.47 & 4429.49 & $5.29 \%$ \\
\hline h3-lowcost-4-abs2n35 & 4 & 5806.67 & 5410.05 & 102.61 & 4624.20 & $16.99 \%$ \\
\hline h3-lowcost-4-abs2n40 & 4 & 6320.99 & 5966.76 & 150.78 & 5136.10 & $16.17 \%$ \\
\hline h3-lowcost-4-abs2n45 & 4 & 6516.28 & 6221.78 & 192.35 & 5321.38 & $16.92 \%$ \\
\hline h3-lowcost-4-abs2n5 & 4 & 1812.65 & 1812.65 & 4.03 & 1812.65 & $0.00 \%$ \\
\hline h3-lowcost-4-abs2n50 & 4 & 7324.02 & 6826.46 & 241.84 & 6488.43 & $5.21 \%$ \\
\hline h3-lowcost-4-abs3n10 & 4 & 2998.10 & 2968.74 & 8.85 & 2968.74 & $0.00 \%$ \\
\hline h3-lowcost-4-abs3n15 & 4 & 3840.16 & 3783.43 & 16.61 & 3757.36 & $0.69 \%$ \\
\hline h3-lowcost-4-abs3n20 & 4 & 3830.92 & 3734.48 & 24.57 & 3645.48 & $2.44 \%$ \\
\hline h3-lowcost-4-abs3n25 & 4 & 5139.56 & 4781.84 & 41.10 & 4687.62 & $2.01 \%$ \\
\hline h3-lowcost-4-abs3n30 & 4 & 4629.52 & 4416.64 & 77.99 & 4142.12 & $6.63 \%$ \\
\hline h3-lowcost-4-abs3n35 & 4 & 5986.43 & 5641.15 & 105.18 & 5281.94 & $6.80 \%$ \\
\hline h3-lowcost-4-abs3n40 & 4 & 5502.78 & 5035.60 & 137.09 & 4642.30 & $8.47 \%$ \\
\hline h3-lowcost-4-abs3n45 & 4 & 5455.45 & 5223.70 & 139.69 & 4514.50 & $15.71 \%$ \\
\hline h3-lowcost-4-abs3n5 & 4 & 3621.02 & 3603.74 & 4.01 & 3603.74 & $0.00 \%$ \\
\hline h3-lowcost-4-abs3n50 & 4 & 6573.86 & 6221.44 & 294.70 & 5589.17 & $11.31 \%$ \\
\hline h3-lowcost-4-abs4n10 & 4 & 3839.79 & 3772.96 & 7.55 & 3683.17 & $2.44 \%$ \\
\hline
\end{tabular}




\begin{tabular}{|c|c|c|c|c|c|c|}
\hline t & & & & & & \\
\hline h3-lowcost-4-abs4n20 & & 139.66 & 4974.74 & 26.03 & 4773.73 & $4.21 \%$ \\
\hline 3-lowcost-4-abs4n25 & & 619.41 & 4285.64 & 8.15 & 044.84 & $5.95 \%$ \\
\hline 3-lowcost-4-abs4n30 & & 410.99 & & 8.40 & & $17.94 \%$ \\
\hline 3-lowcost-4-abs4n35 & & 107.56 & & 81.65 & & $3.46 \%$ \\
\hline -lowcost-4-abs4n40 & & & & & & $15.48 \%$ \\
\hline 3-lowcost-4-abs4n45 & & & & 199.18 & & $11.20 \%$ \\
\hline 3-lowcost-4-abs4n5 & & 631.58 & & 4.01 & & $0.00 \%$ \\
\hline lowcost-4-abs 4 n50 & & 950.48 & & 231.60 & & $33 \%$ \\
\hline & & & & 7.97 & & $0.00 \%$ \\
\hline & & & & & & $38 \%$ \\
\hline & & & & 25.62 & & \\
\hline 3-lowcost-4-abs5n25 & & & & 48.41 & 82 & $3 \%$ \\
\hline & & & & & & \\
\hline & & & & 80.09 & & \\
\hline & & & & 122.27 & & $16.00 \%$ \\
\hline st-4-abs5n45 & & 99 & & 176.61 & .22 & $13.36 \%$ \\
\hline & & & & 4.21 & & \\
\hline & & & & 250.66 & .77 & \\
\hline & & & & & & \\
\hline $\ln 15$ & & & & 16.28 & & $0.00 \%$ \\
\hline$n 20$ & & & & 25.05 & .83 & $4 \%$ \\
\hline & & & & & 90 & $3 \%$ \\
\hline & & & & & & \\
\hline n35 & & .43 & & 138.15 & 8.30 & $3.00 \%$ \\
\hline 140 & & & 68 & .47 & .72 & $4.61 \%$ \\
\hline 145 & & & & 270.20 & .60 & $1 \%$ \\
\hline & & & & & & \\
\hline h3-hig & & .52 & .18 & 301.59 & 8.64 & $5.19 \%$ \\
\hline h3-h & & & & 8.42 & & $0.00 \%$ \\
\hline & & & & 15.74 & .87 & $0 \%$ \\
\hline & & & & & & \\
\hline h3-h & & & & 50.50 & & $2.63 \%$ \\
\hline & & .96 & & 75.58 & 7.89 & $2.36 \%$ \\
\hline h3-1 & & & & 118.15 & .40 & $5.81 \%$ \\
\hline & & & & & & \\
\hline h3-h & & & & & & $4.62 \%$ \\
\hline & & & & 4.07 & & $0.00 \%$ \\
\hline h3-1 & & 178 & 17 & 269.40 & 3.89 & $3.83 \%$ \\
\hline & & & & & & \\
\hline & & & & & & \\
\hline & & & & & & $0.02 \%$ \\
\hline h3-h & & 0.30 & 1.08 & 48.64 & 11026.80 & $2.40 \%$ \\
\hline & & & & & & \\
\hline & & & & & & \\
\hline & & & & & & \\
\hline$t-4-a b s 3 n 45$ & & 16382.40 & 16024.12 & 167.42 & 15451.66 & $3.70 \%$ \\
\hline & & & & 4.60 & & \\
\hline & & & & 307.79 & 16412.80 & \\
\hline & & & & & & \\
\hline & & & & 17.86 & 6017.46 & $1.05 \%$ \\
\hline & & & & & & $1.06 \%$ \\
\hline & & & & 41.16 & & $2.47 \%$ \\
\hline h3-highcost-4-abs4n30 & 4 & 11551.23 & 11234.88 & 75.42 & 10776.26 & $4.26 \%$ \\
\hline
\end{tabular}




\begin{tabular}{lcccccc} 
h3-highcost-4-abs4n35 & 4 & 12286.82 & 11934.38 & 108.62 & 11582.02 & $3.04 \%$ \\
h3-highcost-4-abs4n40 & 4 & 13271.83 & 13056.09 & 141.69 & 12329.30 & $5.89 \%$ \\
h3-highcost-4-abs4n45 & 4 & 16272.91 & 16034.13 & 215.99 & 15201.30 & $5.48 \%$ \\
h3-highcost-4-abs4n5 & 4 & 3210.24 & 3210.24 & 4.60 & 3210.24 & $0.00 \%$ \\
h3-highcost-4-abs4n50 & 4 & 19042.74 & 18776.86 & 276.81 & 18552.12 & $1.21 \%$ \\
h3-highcost-4-abs5n10 & 4 & 5678.79 & 5644.39 & 8.13 & 5644.39 & $0.00 \%$ \\
h3-highcost-4-abs5n15 & 4 & 6541.50 & 6375.39 & 16.80 & 6375.39 & $0.00 \%$ \\
h3-highcost-4-abs5n20 & 4 & 10215.37 & 10018.12 & 32.11 & 9782.55 & $2.41 \%$ \\
h3-highcost-4-abs5n25 & 4 & 12124.85 & 11996.90 & 54.58 & 11805.98 & $1.62 \%$ \\
h3-highcost-4-abs5n30 & 4 & 11366.46 & 11169.11 & 73.45 & 10857.66 & $2.87 \%$ \\
h3-highcost-4-abs5n35 & 4 & 12720.54 & 12438.88 & 88.57 & 11970.14 & $3.92 \%$ \\
h3-highcost-4-abs5n40 & 4 & 15220.23 & 14789.14 & 138.67 & 14239.57 & $3.86 \%$ \\
h3-highcost-4-abs5n45 & 4 & 15286.98 & 14935.17 & 194.71 & 14305.00 & $4.41 \%$ \\
h3-highcost-4-abs5n5 & 4 & 2824.50 & 2824.50 & 3.96 & 2824.50 & $0.00 \%$ \\
h3-highcost-4-abs5n50 & 4 & 18245.55 & 17727.10 & 303.76 & 17512.14 & $1.23 \%$ \\
\hline
\end{tabular}

Tabela 30 - Resultados do AP x Literatura $K=4$ e H = 6. Fonte: Autor (2018).

\begin{tabular}{|c|c|c|c|c|c|c|}
\hline Instâncias & Vc. & Média & AP & Tempo & Literatu & Gap \\
\hline h6-lowcost-4-abs1n10 & 4 & 8770.44 & 8643.56 & & & $2.62 \%$ \\
\hline & 4 & 32247 & & & & $4.72 \%$ \\
\hline & & & & & & \\
\hline h6-lowcost-4-abs1n25 & 4 & 10369.74 & 9961.83 & 460.19 & & $5.66 \%$ \\
\hline h6-lowcost-4-abs1n30 & 4 & 13259.22 & 12759.70 & & & $-4.52 \%$ \\
\hline h6-lowcost-4-abs1n5 & 4 & 5506 & 5506 & 10 & & $0.00 \%$ \\
\hline & 4 & 10147 & 10044 & & & $1.71 \%$ \\
\hline & 4 & 8721. & 8291.16 & & & $2.69 \%$ \\
\hline & 4 & 8269 & 7958 & & & $3.95 \%$ \\
\hline h6-1 & 4 & 12245 & 1173 & 433 & & $-1.47 \%$ \\
\hline & 4 & & & & & $5.39 \%$ \\
\hline & 4 & 5129 & & & & $0.00 \%$ \\
\hline & 4 & & & & & $0.04 \%$ \\
\hline h6-1 & 4 & 9731 & & & & $2.31 \%$ \\
\hline & 4 & 100 & & & & $2.72 \%$ \\
\hline h6- & 4 & 132 & & & & $2.18 \%$ \\
\hline & 4 & & & & & \\
\hline & 4 & & & & & $0.01 \%$ \\
\hline & 4 & & & & & $1.65 \%$ \\
\hline & 4 & & & & & $3.16 \%$ \\
\hline & 4 & & & & & \\
\hline & 4 & & & & & $5.55 \%$ \\
\hline & 4 & & & .06 & & $2.03 \%$ \\
\hline & 4 & 5096 & & 9.92 & & $0.00 \%$ \\
\hline & 4 & & & & & $1.22 \%$ \\
\hline & 4 & & & & & $1.25 \%$ \\
\hline & 4 & & & & & $3.95 \%$ \\
\hline h6- & 4 & 13143. & 12951.15 & 444.75 & & $3.31 \%$ \\
\hline & 4 & & & 763.66 & & $-4.71 \%$ \\
\hline & 4 & & & & & $0.00 \%$ \\
\hline & 4 & & & & & $1.48 \%$ \\
\hline h6-highcost-4-abs1n15 & 4 & 14945.88 & 14780.26 & 125.68 & 14438.80 & $2.36 \%$ \\
\hline & 4 & & & & & $1.89 \%$ \\
\hline h6-highcost-4-abs 1 n25 & 4 & 18802.89 & & 494.50 & & $3.07 \%$ \\
\hline h6-highcost-4-abs 1 n30 & 4 & 27700.83 & 27283.44 & 992.03 & 28602.54 & $-4.61 \%$ \\
\hline
\end{tabular}




\begin{tabular}{lcccccc} 
h6-highcost-4-abs1n5 & 4 & 8111.69 & 8111.31 & 11.38 & 8111.31 & $0.00 \%$ \\
h6-highcost-4-abs2n10 & 4 & 13417.69 & 13298.78 & 44.01 & 13190.40 & $0.82 \%$ \\
h6-highcost-4-abs2n15 & 4 & 14964.69 & 14858.57 & 129.00 & 14514.70 & $2.37 \%$ \\
h6-highcost-4-abs2n20 & 4 & 16736.30 & 16530.36 & 247.50 & 16256.30 & $1.69 \%$ \\
& & & & & & - \\
\hline h6-highcost-4-abs2n25 & 4 & 21408.64 & 21118.99 & 458.09 & 27684.54 & $23.72 \%$ \\
h6-highcost-4-abs2n30 & 4 & 23999.23 & 23674.67 & 761.75 & 23175.20 & $2.16 \%$ \\
h6-highcost-4-abs2n5 & 4 & 7419.12 & 7411.33 & 11.44 & 7411.33 & $0.00 \%$ \\
h6-highcost-4-abs3n10 & 4 & 11204.68 & 11114.56 & 46.65 & 11067.90 & $0.42 \%$ \\
h6-highcost-4-abs3n15 & 4 & 17206.03 & 16957.33 & 119.29 & 16747.90 & $1.25 \%$ \\
h6-highcost-4-abs3n20 & 4 & 17571.57 & 17176.86 & 256.04 & 17089.40 & $0.51 \%$ \\
\hline h6-highcost-4-abs3n25 & 4 & 23325.29 & 22829.73 & 533.17 & 28205.36 & $19.06 \%$ \\
h6-highcost-4-abs3n30 & 4 & 26268.54 & 25803.99 & 786.34 & 25690.10 & $0.44 \%$ \\
h6-highcost-4-abs3n5 & 4 & 11525.47 & 11475.27 & 9.73 & 11475.27 & $0.00 \%$ \\
h6-highcost-4-abs4n10 & 4 & 12712.48 & 12553.59 & 46.39 & 12323.90 & $1.86 \%$ \\
h6-highcost-4-abs4n15 & 4 & 13960.06 & 13747.78 & 136.57 & 13464.90 & $2.10 \%$ \\
h6-highcost-4-abs4n20 & 4 & 19703.28 & 19248.50 & 276.91 & 19196.00 & $0.27 \%$ \\
h6-highcost-4-abs4n25 & 4 & 19720.10 & 19438.54 & 465.92 & 18649.40 & $4.23 \%$ \\
h6-highcost-4-abs4n30 & 4 & 21953.58 & 21695.45 & 763.17 & 21487.60 & $0.97 \%$ \\
h6-highcost-4-abs4n5 & 4 & 6992.53 & 6989.17 & 10.10 & 6985.40 & $0.05 \%$ \\
h6-highcost-4-abs5n10 & 4 & 11622.63 & 11547.96 & 42.60 & 11471.48 & $0.67 \%$ \\
h6-highcost-4-abs5n15 & 4 & 14416.43 & 13990.07 & 121.17 & 13996.10 & $-0.04 \%$ \\
h6-highcost-4-abs5n20 & 4 & 21817.06 & 21602.10 & 259.40 & 21180.50 & $1.99 \%$ \\
h6-highcost-4-abs5n25 & 4 & 24513.78 & 24084.22 & 462.38 & 24248.60 & $-0.68 \%$ \\
h6-highcost-4-abs5n30 & 4 & 22646.32 & 22410.01 & 848.51 & 22829.25 & $-1.84 \%$ \\
h6-highcost-4-abs5n5 & 4 & 6999.94 & 6996.36 & 9.31 & 6996.36 & $0.00 \%$ \\
\hline & & & & & & \\
\hline
\end{tabular}

Tabela 31 - Resultados do AP x Literatura K= 5 e H=3. Fonte: Autor (2018).

\begin{tabular}{lcccccc}
\hline Instâncias & Vc. & Média & AP & Tempo & Literatura & Gap \\
\hline h3-lowcost-5-abs1n10 & 5 & 3784.03 & 3728.96 & 9.73 & 3728.78 & $0.00 \%$ \\
h3-lowcost-5-abs1n15 & 5 & 3704.56 & 3605.01 & 19.28 & 3580.81 & $0.68 \%$ \\
h3-lowcost-5-abs1n20 & 5 & 4808.74 & 4602.44 & 31.13 & 4404.77 & $4.49 \%$ \\
h3-lowcost-5-abs1n25 & 5 & 4761.37 & 4372.69 & 56.23 & 4095.20 & $6.78 \%$ \\
h3-lowcost-5-abs1n30 & 5 & 5831.11 & 5648.10 & 107.90 & 5314.74 & $6.27 \%$ \\
h3-lowcost-5-abs1n35 & 5 & 5663.46 & 5293.70 & 137.45 & 4764.98 & $11.10 \%$ \\
h3-lowcost-5-abs1n40 & 5 & 6667.51 & 6273.18 & 207.14 & 5565.14 & $12.72 \%$ \\
h3-lowcost-5-abs1n45 & 5 & 6626.63 & 6127.64 & 265.56 & 5470.10 & $12.02 \%$ \\
h3-lowcost-5-abs1n5 & 5 & 1710.34 & 1710.34 & 4.46 & 1710.34 & $0.00 \%$ \\
h3-lowcost-5-abs1n50 & 5 & 8038.63 & 7781.96 & 377.96 & 7167.86 & $8.57 \%$ \\
h3-lowcost-5-abs2n10 & 5 & 4726.16 & 4681.34 & 9.81 & 4681.34 & $0.00 \%$ \\
h3-lowcost-5-abs2n15 & 5 & 4012.89 & 3889.43 & 18.96 & 3889.43 & $0.00 \%$ \\
h3-lowcost-5-abs2n20 & 5 & 3560.55 & 3456.57 & 36.59 & 3344.11 & $3.36 \%$ \\
h3-lowcost-5-abs2n25 & 5 & 5593.66 & 5151.04 & 58.16 & 5009.76 & $2.82 \%$ \\
h3-lowcost-5-abs2n30 & 5 & 5405.64 & 5041.48 & 98.03 & 4879.36 & $3.32 \%$ \\
h3-lowcost-5-abs2n35 & 5 & 6345.83 & 6112.65 & 128.17 & 5013.75 & $21.92 \%$ \\
h3-lowcost-5-abs2n40 & 5 & 6715.40 & 6321.51 & 184.62 & 5864.94 & $7.78 \%$ \\
h3-lowcost-5-abs2n45 & 5 & 7197.77 & 6902.76 & 254.46 & 5971.94 & $15.59 \%$ \\
h3-lowcost-5-abs2n5 & 5 & 2019.58 & 2019.58 & 4.50 & 2019.58 & $0.00 \%$ \\
h3-lowcost-5-abs2n50 & 5 & 8376.30 & 7850.11 & 297.11 & 8284.56 & $-5.24 \%$ \\
h3-lowcost-5-abs3n10 & 5 & 3463.35 & 3459.12 & 9.12 & 3401.18 & $1.70 \%$
\end{tabular}




\begin{tabular}{|c|c|c|c|c|c|c|}
\hline & ) & & & 19.81 & & \\
\hline & & & & 33.46 & & $95 \%$ \\
\hline ost-5-abs3n25 & & 68.01 & 642.25 & & & $00 \%$ \\
\hline & & & & & & $28 \%$ \\
\hline & & 28 & 14 & 9.27 & & $20 \%$ \\
\hline & & & & & & \\
\hline & & & & & & $93 \%$ \\
\hline & & & & & & \\
\hline & & & & & & $28 \%$ \\
\hline & & & & & & \\
\hline & & & & & & \\
\hline 20 & & 664.65 & 356.22 & & & $69 \%$ \\
\hline & & & & & & \\
\hline & & & & & & $.71 \%$ \\
\hline & & & & & & \\
\hline & & & & & & \\
\hline & & & & & & $8.53 \%$ \\
\hline & & & & & & \\
\hline & & & & & & \\
\hline & & & & & & $0.00 \%$ \\
\hline n15 & & 1 & & & & $17 \%$ \\
\hline & & & & & & $8 \%$ \\
\hline & & & & & & \\
\hline & & & & & & \\
\hline & & & & & & \\
\hline & & & & & & \\
\hline & & & & & & \\
\hline & & & & & & \\
\hline & & & 92.35 & 320.02 & .77 & $15.38 \%$ \\
\hline & & & & & & \\
\hline & & & & & & $0.04 \%$ \\
\hline & & & & & & $4 \%$ \\
\hline & & & & & & \\
\hline & 5 & & & & & $0 \%$ \\
\hline & & & & & & \\
\hline Shiobost-5-5 & 5 & 292.81 & & & 5257.24 & $5.27 \%$ \\
\hline & & & & & & $11 \%$ \\
\hline 3-highcost-5-abs 1n5 & & 2577.54 & 2577.54 & & 25775 & $0.00 \%$ \\
\hline & & 18272.90 & & 386.00 & & $0.87 \%$ \\
\hline & & & & & & \\
\hline -abs2n15 & 5 & 1 & 90.42 & & .30 & $.34 \%$ \\
\hline & & & & & & $0.01 \%$ \\
\hline & 5 & & & & & $2.72 \%$ \\
\hline 3-highcost-5-abs2n30 & 5 & & & & & $1.62 \%$ \\
\hline 3-highcost-5-abs2n35 & & 13205.88 & & 138.15 & & $8.06 \%$ \\
\hline & & 14035.22 & 13580.20 & 200.8 & 13068.00 & $3.92 \%$ \\
\hline
\end{tabular}




\begin{tabular}{|c|c|c|c|c|c|c|}
\hline & & & & & & \\
\hline & & & & & & \\
\hline & & & 8355.86 & 353.01 & & $67 \%$ \\
\hline & & & & & & \\
\hline & & & & & & $8 \%$ \\
\hline & & & & & & \\
\hline & & & & & & $72 \%$ \\
\hline & & & & & & \\
\hline & & & & & & \\
\hline & & & & 237. & & $17 \%$ \\
\hline & & & & & & \\
\hline & & & & & & $3 \%$ \\
\hline & & & & 477.36 & & \\
\hline & & & & & & $1 \%$ \\
\hline & & & & & & $5 \%$ \\
\hline & & & & & & $27 \%$ \\
\hline & & & & 1.21 & & $0 \%$ \\
\hline & & & & 102.25 & & $.57 \%$ \\
\hline & & & & & & \\
\hline & & & & & & $57 \%$ \\
\hline & & 1685 & .29 & 289.28 & & $.05 \%$ \\
\hline & & & & & & \\
\hline n50 & & 200 & & 408.83 & & $-3.21 \%$ \\
\hline & & & & & & \\
\hline & & 7090.26 & .94 & 21.58 & .56 & $0.88 \%$ \\
\hline & & & & & & \\
\hline & & 12859.92 & 12659.54 & 67.54 & 12451 & \\
\hline & & .99 & & 94.18 & & $1.97 \%$ \\
\hline & & & & & & $4.85 \%$ \\
\hline & 5 & & 15182.00 & 185.55 & & \\
\hline & & & 15435.54 & 242.98 & 14486.40 & $6.55 \%$ \\
\hline & 5 & & & & & \\
\hline 3-highcost-5-abs5n50 & 5 & 19036.26 & 18793.37 & 364.96 & 17695.79 & $6.20 \%$ \\
\hline
\end{tabular}

